\title{
THESIS
}

\section{THE MECHANICS OF PLASTIC-ALUMINUM COMPOSITE I-BEAMS}

\author{
Submitted by \\ Kirsten LaRhea Peterson \\ Department of Civil and Environmental Engineering
}

In partial fulfillment of the requirements

For the Degree of Master of Science

Colorado State University

Fort Collins, Colorado

Spring 2014

Master's Committee:

Advisor: Paul Heyliger

Rebecca Atadero

Robert Leisure 
Copyright by Kirsten LaRhea Peterson 2014

All Rights Reserved 


\section{ABSTRACT}

\section{THE MECHANICS OF PLASTIC-ALUMINUM COMPOSITE I-BEAMS}

This thesis presents an initial investigation of the mechanics of I-beams developed with plasticaluminum composite technology. Plastic-aluminum composites in structural beam/frame/truss elements are a relatively new concept that has seen little, if any, application in modern construction. This technology has considerable potential to add innovative choices to the array of materials currently available in the construction industry. Several new tests were designed and performed on different portions of the beams, including Push-Through and Knit-Line Pull tests, and tensile tests per ASTM D638-10. The results of these tests showed increased strength with an increase of talc filler content and also showed that the addition of a metal deactivator additive to the plastic results in a slight increase in strength. Duration of Load tests were performed per ASTM D7031-04 and none of the beams tested exhibit tertiary creep. The I-beams investigated here use an internal shear connector (deboss) which acts as a mechanical fastener between the aluminum and the flange plastic. A numerical finite element model was developed in ABAQUS to better understand the underlying physics of the deboss and was compared with a PushThrough test specimen. The results from the model closely match experimental results and the model can be used to predict within $10 \%$ the load per deboss region that can be resisted before the plastic begins to yield and extensively deform. This model can be used for differing deboss geometries and any plastic with known material properties. Overall, the results of this research support potential future research involving a more in-depth investigation of this innovative, new class of material technology for use as a structural material. 


\section{TABLE OF CONTENTS}

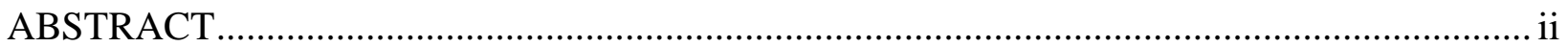

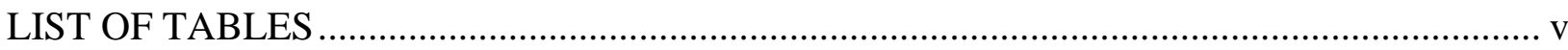

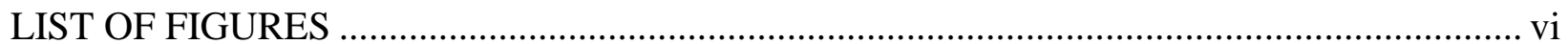

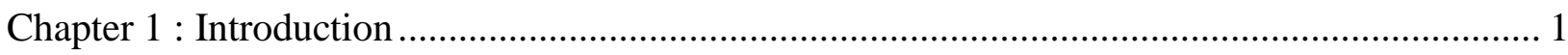

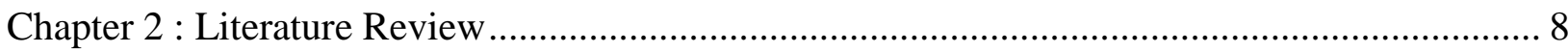

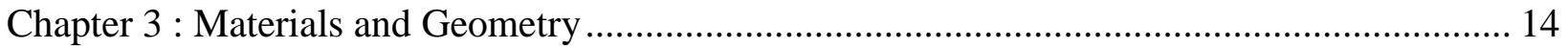

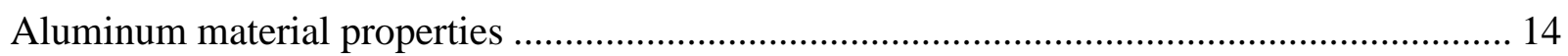

Flange plastic considerations ………………………….................................................. 14

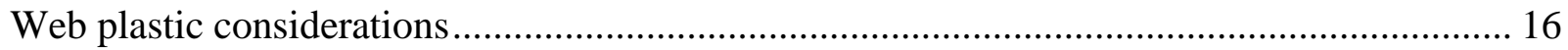

Effects of additives and filler materials on the plastic material properties .............................. 17

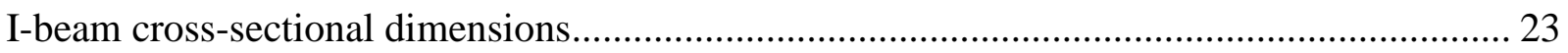

Aluminum profiles with differing deboss geometries............................................................. 23

Aluminum Profile 1 - Corner stamped deboss.................................................................. 24

Aluminum Profile 2 - Face stamped deboss with scarification ........................................... 25

Aluminum Profile 3 - Completely smooth aluminum ....................................................... 26

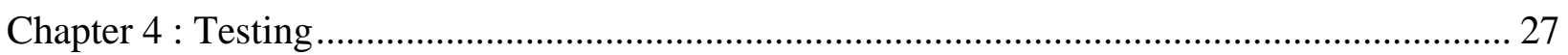

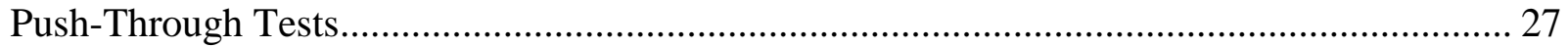

Push-Through Test - All Specimen Details .......................................................................... 37

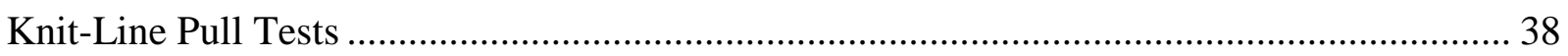

Knit-Line Pull Test - All Specimen Details ........................................................................ 43

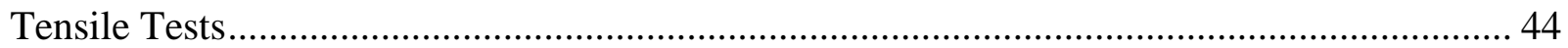

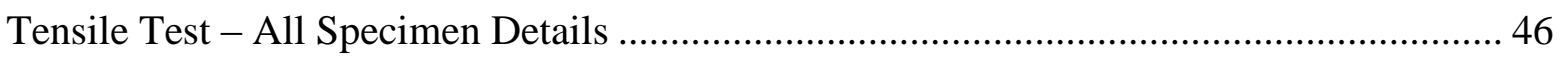

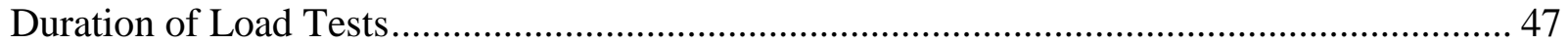

Duration of Load Test - All Specimen Details ................................................................ 53

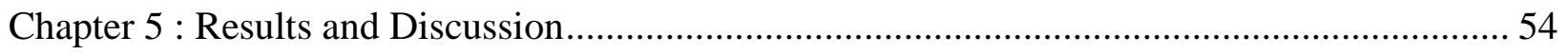

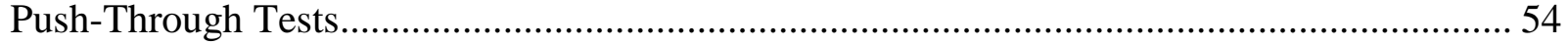

Linear relationship .................................................................................................. 54

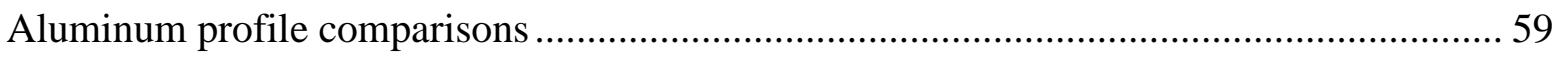

Comparisons between all 3 aluminum profiles …………………............................. 67 


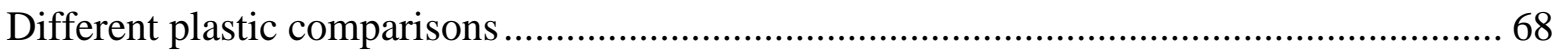

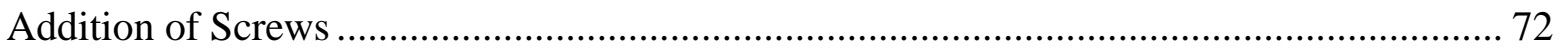

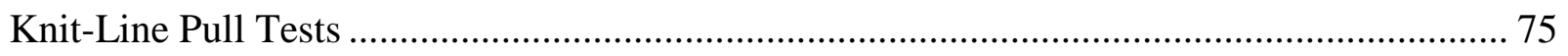

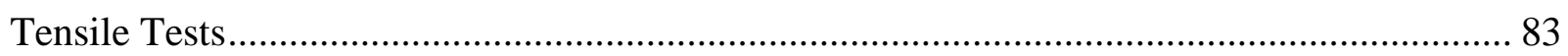

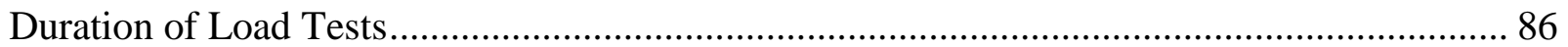

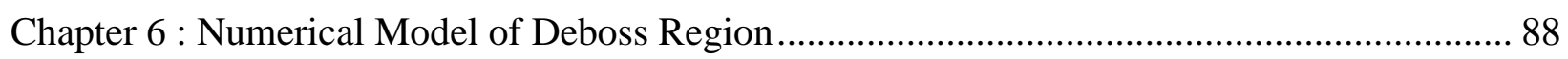

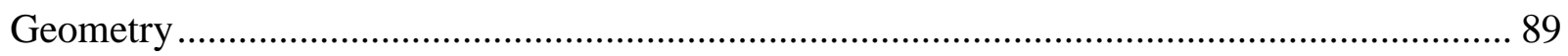

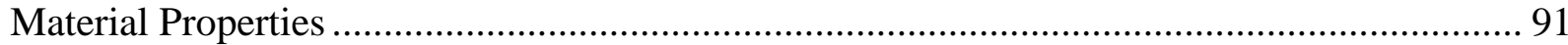

Interactions between the Aluminum and Plastic ……………................................................ 93

Boundary Conditions........................................................................................................ 94

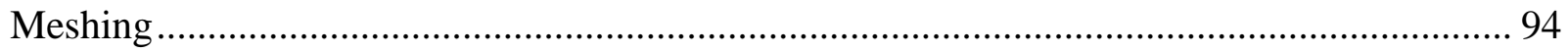

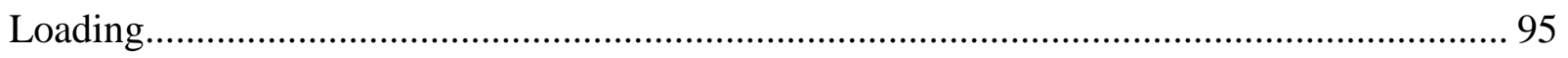

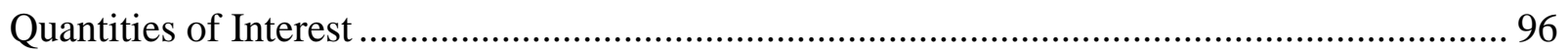

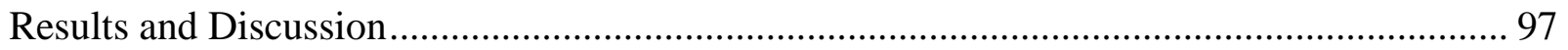

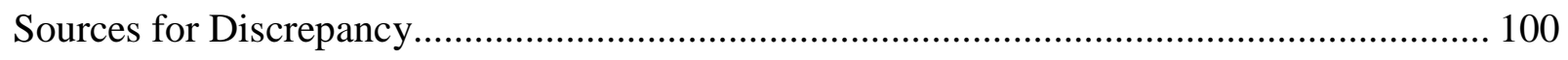

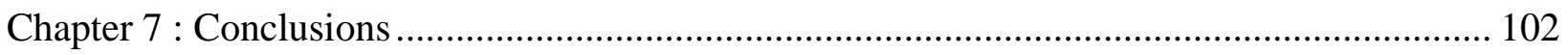

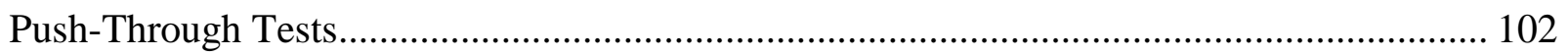

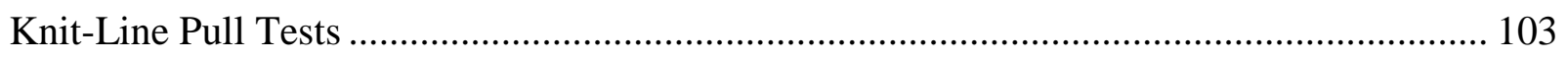

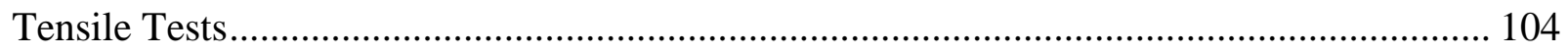

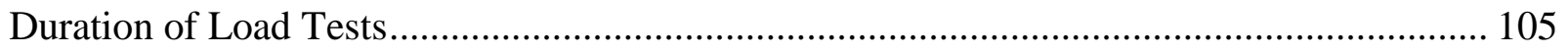

Numerical Model of Deboss Region ............................................................................... 106

Recommendations for Future Work ……………………............................................... 106

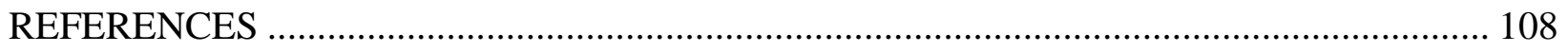




\section{LIST OF TABLES}

Table 2-1: Main mechanical properties of the adhesives used in study [8]............................. 8

Table 3-1: Aluminum material properties Values referenced from Aerospace Specification

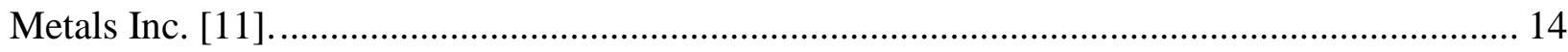

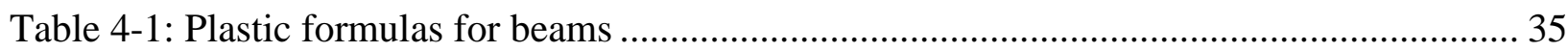

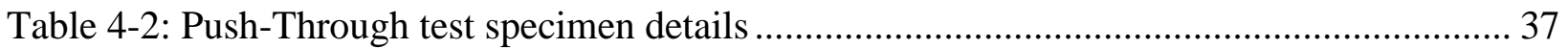

Table 4-3: First set of Knit-Line Pull test beam details ...................................................... 42

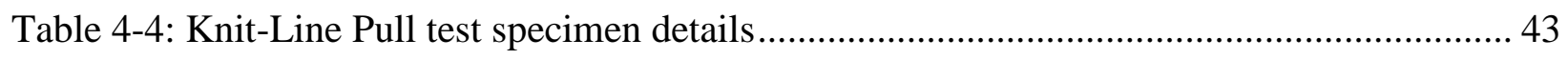

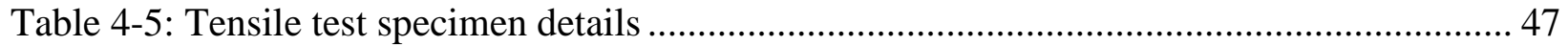

Table 4-6: Duration of Load test specimen details .......................................................... 53

Table 5-1: Push-Through test linear relationship results ....................................................... 54

Table 5-2: Push-Through test deboss geometry comparison results ......................................... 60

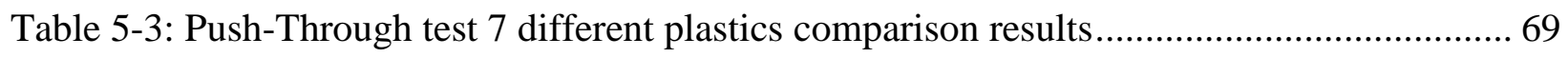

Table 5-4: Metal deactivator additive comparison ............................................................... 71

Table 5-5: Push-Through test screw comparison results .................................................. 73

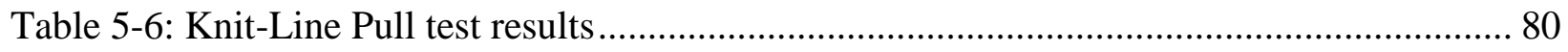

Table 5-7: Knit-Line Pull test summary of results............................................................... 81

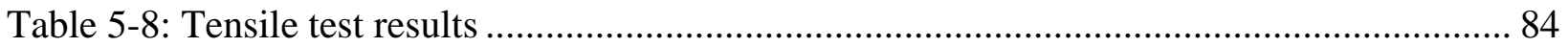

Table 4-6: Duration of Load test specimen details .......................................................... 86

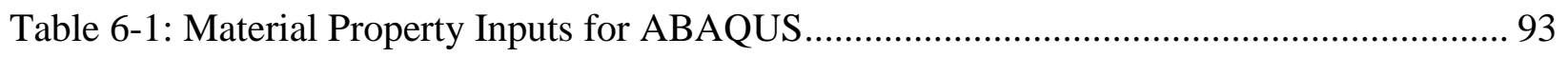

Table 6-2: Mesh properties for the ABAQUS model .......................................................... 94

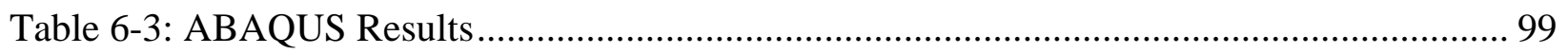




\section{LIST OF FIGURES}

Figure 1-1: Length profile of plastic-aluminum composite I-beams [1] .................................... 2

Figure 1-2: Smooth aluminum profile with no deboss present ................................................... 4

Figure 2-1: Force-Deflection results for static bending [8] ...................................................... 10

Figure 2-2: The nine test specimens used in the tubular study [9] ............................................ 11

Figure 2-3: Load-Displacement graphs obtained from bending tests [9] ................................... 12

Figure 3-1: Aspect ratios of fillers with different shapes [15] .................................................. 18

Figure 3-2: Effect of talc particle size and volume fraction on flexural modulus [15] ................ 19

Figure 3-3: Effect of talc content on tensile modulus [19] ......................................................... 20

Figure 3-4: Evolution of strain at break of high density polyethylene/talc composites as a

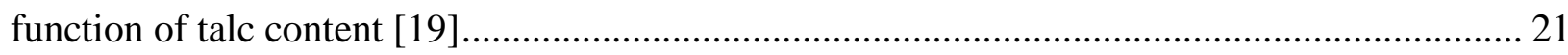

Figure 3-5: Aluminum-plastic composite I-beam cross-sectional dimensions .............................. 23

Figure 3-6: Aluminum Profile 1 photographs .............................................................................. 24

Figure 3-7: Aluminum Profile 1 dimensions ............................................................................... 24

Figure 3-8: Aluminum Profile 2 photographs Scarification on all outer surfaces....................... 25

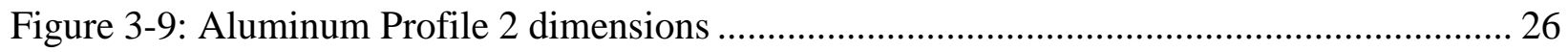

Figure 3-10: Aluminum Profile 3 photograph ......................................................................... 26

Figure 4-1: Example Push-Through test specimen ................................................................... 28

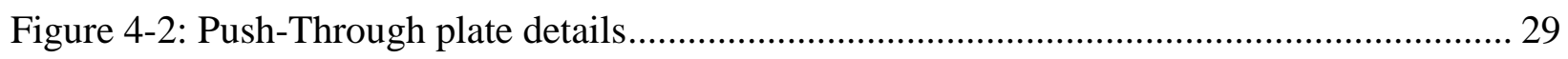

Figure 4-3: Specimens loaded on the Instron directly before testing .......................................... 31

Figure 4-4: 12 Beam specimens for Push-Through tests ......................................................... 32

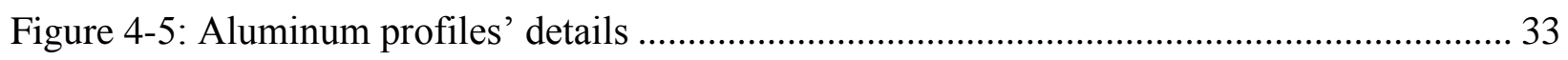

Figure 4-6: Beam specimen directly before testing ................................................................. 34

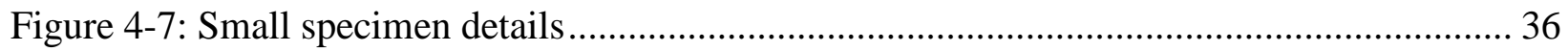

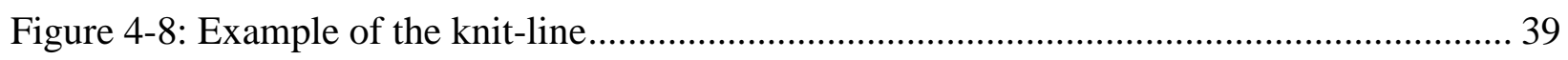

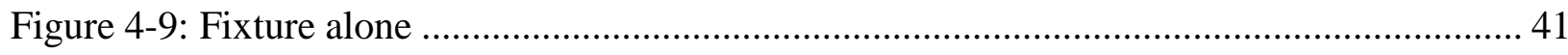

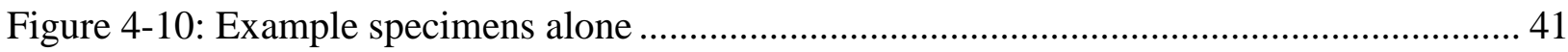

Figure 4-11: Specimens connected to fixture before testing ..................................................... 41

Figure 4-12: Specimens and fixture loaded to Instron before testing ........................................... 42

Figure 4-13: Example specimens during testing ...................................................................... 43 


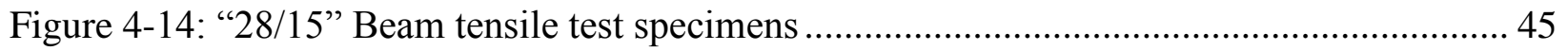

Figure 4-15: "28/15” Beam specimens in Instron machine ........................................................ 46

Figure 4-16: Duration of Load fixture with beam placed prior to loading. .................................. 49

Figure 4-17: Dial indicator located at center of beam ............................................................... 49

Figure 4-18: Duration of Load fixture details .................................................................. 50

Figure 4-19: Loading platform details prior to loading ......................................................... 50

Figure 4-20: First Duration of Load test beam ………………………………………………. 51

Figure 4-21: End bearing points raised with metal plates......................................................... 51

Figure 4-22: Extended support bar for loading platform ...................................................... 52

Figure 4-23: Loaded beam after modifications were made to fixture ………………………...... 52

Figure 5-1: Push-Through test results for the 6 in, 8 in, and 12 in specimens ............................ 55

Figure 5-2: Push-Through linear relationship test specimen after testing ................................... 55

Figure 5-3: 12in(a) Specimen (left) vs. 12in(b) Specimen (right) Showing deformed aluminum

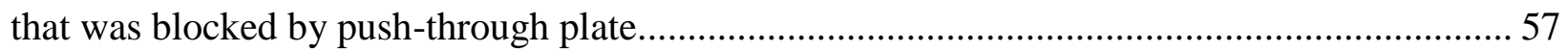

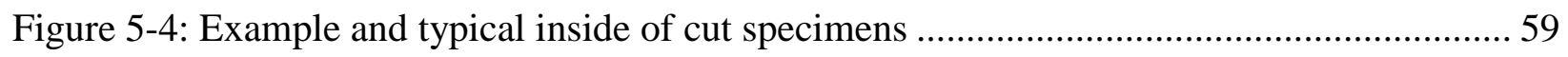

Figure 5-5: Aluminum Profile 1 specimens after testing ( $1 \& 2$ extended to $0.500 \mathrm{in}, 3$ to $1.000 \mathrm{in}$,

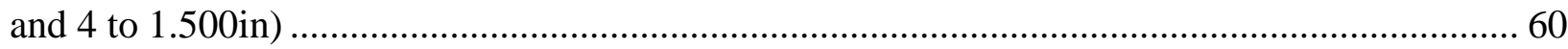

Figure 5-6: Push-Through test deboss comparison Aluminum Profile 1 results ............................. 61

Figure 5-7: Aluminum Profile 2 specimens after testing (5\&6 extended to $0.500 \mathrm{in}, 7$ to $1.136 \mathrm{in}$,

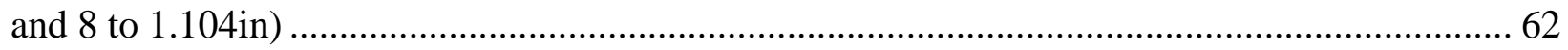

Figure 5-8: Push-Through test deboss comparison Aluminum Profile 2 results .......................... 63

Figure 5-9: Cracks formed in ends of specimens 5 (left) \& 6 (right) ………………………........ 64

Figure 5-10: Cracks formed in specimens 7 (right) \& 8 (left) ................................................... 64

Figure 5-11: End view of specimen 7 after testing Shiny region (indicated with arrow) is crushed

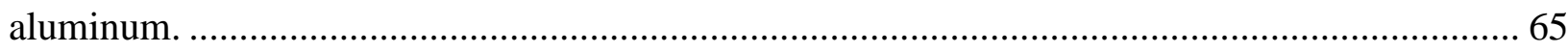

Figure 5-12: Aluminum Profile 3 specimens after testing (9\&10 extended to 0.500in, 11 to

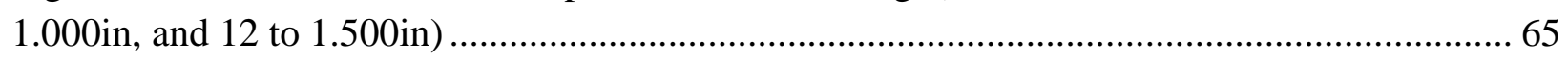

Figure 5-13: Push-Through test deboss comparison Aluminum Profile 3 results ......................... 66

Figure 5-14: Push-Through test Beam 3B results (for example of trends) .................................... 70

Figure 5-15: Push-Through test screw comparison results........................................................ 73

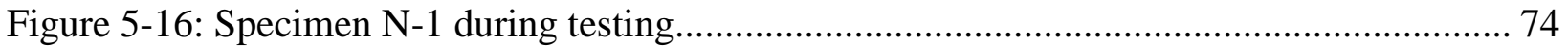

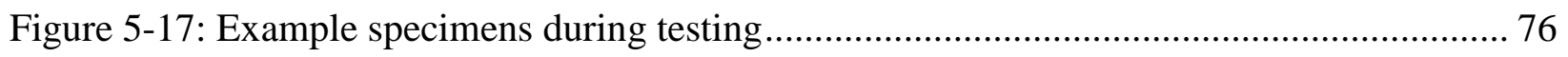


Figure 5-18: Example specimens with complete brittle failures ......................................... 77

Figure 5-19: Example specimens with partial brittle failures ............................................. 77

Figure 5-20: Example complete brittle failure surface after testing ....................................... 78

Figure 5-21: Example partial brittle failure outside surface after testing ................................ 78

Figure 5-22: Knit-Line Pull test failure comparison graph................................................ 79

Figure 5-23: Example tensile test specimens after testing ................................................ 83

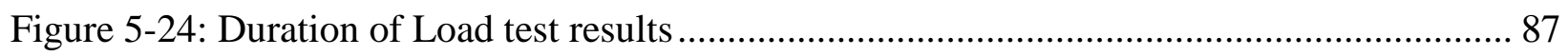

Figure 6-1: The aluminum and flange plastic deboss regions - one quarter of a single flange.... 88

Figure 6-2: Aluminum region of the deboss section, with 2 different views with faces A and B

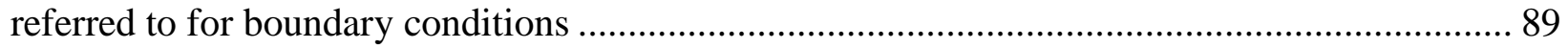

Figure 6-3: Flange plastic regions, 2 different views with faces C, D, and E labeled................ 90

Figure 6-4: Assembled model in ABAQUS ...................................................................... 90

Figure 6-5: Plastic material property input curve for ABAQUS - Flange Plastic 1................... 92

Figure 6-6: Plastic material property input curve for ABAQUS - Flange Plastic 2.................. 92

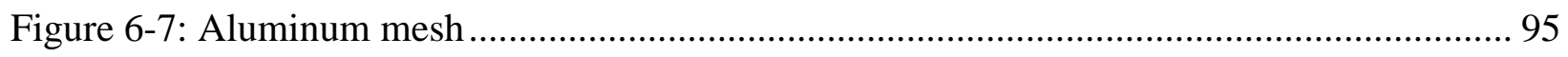

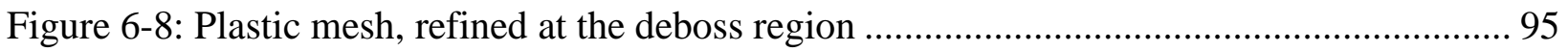

Figure 6-9: Small specimen Push-Through test experimental results .................................... 97

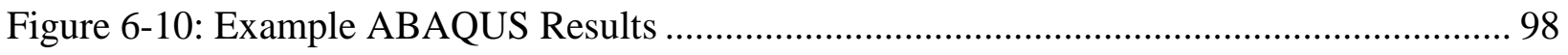




\section{Chapter 1 : Introduction}

The goal of composite materials is to optimize desired properties from different constituent materials. In doing so, a part or structural component is created that outperforms each of the constituents individually, and possibly even better than the simple addition of each constituent's properties. Conservation of materials is important to economic and sustainability considerations. Utilizing composite technology, one can develop a part or structural component out of composite materials with less material consumption, yet still providing the same strength as a noncomposite counterpart. When considering composites made from plastic and aluminum, the goal is to combine the low density and moldability of plastic with the high stiffness, high strength, and relative light weight of aluminum. Plastic-aluminum composite material technology has considerable potential to add innovative choices to the array of materials currently available in the construction industry. This thesis presents research that has been conducted to investigate the properties of I-beams constructed with this technology.

The plastic-aluminum composite I-beam technology studied here was developed by Tegracore, who were also collaborators with the testing work presented in this thesis. The initial motivation for these beams was for use in decking understructure and as a competitor to wood products currently available. These plastic-aluminum composite I-beams can be cut to any length and are shown below in Figure 1-1. 


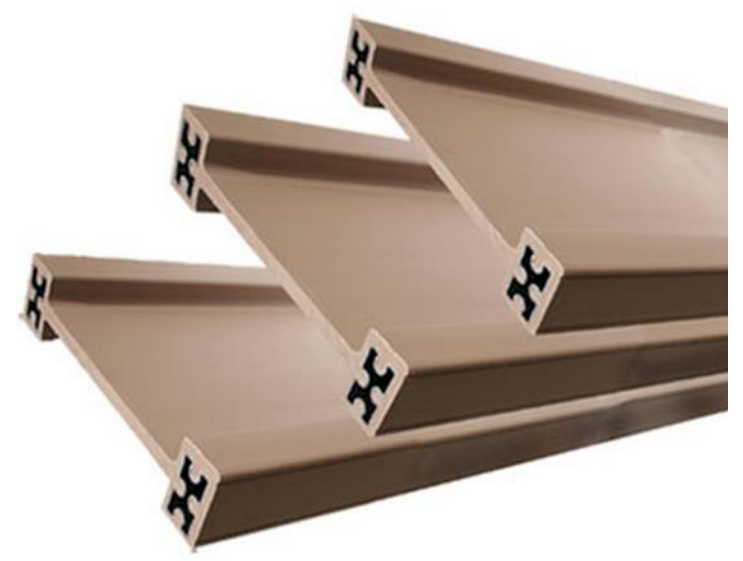

Figure 1-1: Length profile of plastic-aluminum composite I-beams [1]

Because these beams will be competitors for wood products, it is important to review and compare certain properties between the two products. Preliminary testing of the plasticaluminum composite I-beams has shown that a $10 \mathrm{ft}$ span beam fails in flexure when loaded to about 6400 lb. Tables provided by the American Wood Council [2] show that in order for a wood beam to have this same flexural strength at about the same depth as the I-beams, it would need a cross-sectional area of $40 \mathrm{in}^{2}$. Note that this rough estimate does not take into account the modulus of elasticity values specific to the species and grade of lumber used. It is assumed here, for comparisons sake, that a $10 \mathrm{ft}$ span beam of any type of wood with a cross-sectional area of $40 \mathrm{in}^{2}$ would have comparable flexural strength to the composite I-beams. The weight of wood varies greatly from species to species and is highly dependent on moisture content [3]. Multiplying weights per cubic foot provided by the American Wood Council [4] by 40 in $^{2}$ and converting units, results in a range of $5.9 \mathrm{lb} / \mathrm{ft}$ (lower end of softwood) to $13.3 \mathrm{lb} / \mathrm{ft}$ (higher end of hardwood) for wood beams of similar flexural capacity to the composite I-beams. The weight of the I-beams varies slightly depending on the plastic formula, but averages about $4.3 \mathrm{lb} / \mathrm{ft}$. Therefore, it can be seen that a wood beam with comparable properties to a composite I-beam of the same length would weigh on average (depending on the type of wood) over twice as much. 
Decking understructure (and many other structures) built from wood must be periodically treated with appropriate preservatives (especially in a marine environment) to prevent attacks from destructive organisms, such as fungi and marine borers, and moisture [5]. The preservatives themselves and the labor to apply them cost time and money. Because of the nature of the composite I-beams, they are innately resistant to these problems and do not require any treatment. Also, the properties of the plastics used in Tegracore beams provide excellent resistance to weathering, insects, rotting, warping, and splintering [1], all of which yield advantages over wood product counterparts.

The aluminum used in the flanges of the composite I-beams is a standard structural material with known material properties. Different plastics are used for the web and flanges in this study and many different combinations of web and flange plastics were tested. When combined with structural plastics, aluminum can be positioned so that its excellent mechanical properties can be optimized in a mechanics sense. Generally speaking, different plastics have a broad range of properties, and a specifically desired structural property of a beam made from aluminum and plastic can be acquired. For example, adding filler materials to a plastic not only decreases the cost, but also increases the stiffness, improving the resistance to deflection for an I-beam's web material.

The ability to modify specific properties of a structural component with this technology has the potential for new and innovative design. Not only can the web and flange plastic materials be modified to gain certain properties, but the method of bonding the aluminum and plastic can also be adjusted. Other composite material technologies have utilized adhesives. However, the Ibeams investigated here use an internal shear connector which acts as a mechanical fastener between the aluminum and the flange plastic. The geometry of the shear connectors can be 
modified to optimize certain desired properties. Following terminology used by the beam developers, these internal shear connectors will be referred to as deboss throughout this thesis. More specifically, the deboss are indentations in the aluminum. When the I-beams are extruded, the flange plastic forms into these indentations and the plastic and aluminum together in these regions acts as the mechanical fastener that resists shear forces when the beams are loaded.

For one specific test, three different aluminum profile geometries were tested. For an example here, one was a smooth aluminum profile for a baseline comparison with no shear connector, as shown in Figure 1-2.

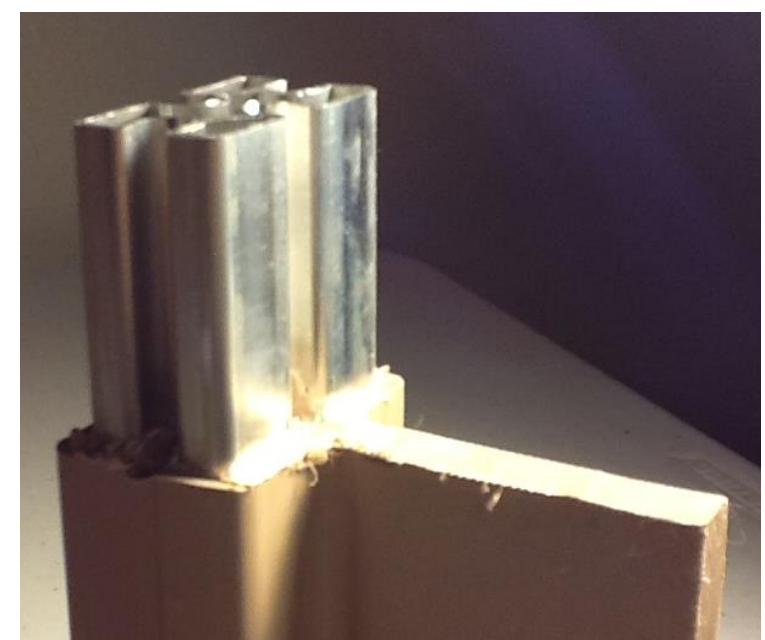

Figure 1-2: Smooth aluminum profile with no deboss present

Plastic-aluminum composites in structural beam/frame/truss elements are a relatively new concept that has seen little, if any, application in modern construction. Current American Society of Testing and Materials (ASTM) standards lack documents that address beam properties specific to this new technology. For example, the location of the bond (knit-line) between two different plastics in the I-beams does not have a testing standard, simply because that technology has yet to have an application in a structural sense. In order to test and quantify desired 
properties of the I-beams, the following physical tests were designed and performed on parts of the beams and will be described in greater detail in this thesis.

1. Push Through Test - no current ASTM applicable designed to quantify the strength of bond between the aluminum and the plastic of one flange of the I-beams

2. Knit Line Pull Test - no current ASTM applicable designed to quantify the strength at the knit line between the web and flange plastics of the I-beams

The following ASTM tests were also performed on parts of the I-beams:

1. Tensile Test - ASTM D638-10 [6] covered the determination of the tensile properties of multiple web and flange plastics used for the I-beams

2. Duration of Load Test - ASTM D7031-04 [7] quantified the effects on beams' deflection rates under a constant static load over a 90 day period *NOTE: this standard is actually in place for wood-plastic composite products Since the key difference between these composite beams and comparable beams made from other materials (e.g. wood) is the addition of the second material in the flanges, the relationship between the aluminum and the plastic is of primary importance. The fundamental mechanics of the shear connectors were explored both in terms of the physical tests described above and by a finite element model in ABAQUS. The results from the Push Through Tests were used as a basis to verify the results of the numerical model. In the future, this model could be used to explore 
different flange plastics and even different deboss aluminum profiles, which would allow for rapid assessment of the controlling parameters without having to construct a physical model.

Currently, talc is used as a filler material in the plastic. The effects that talc has on the plastic's material properties have also been investigated. Physical and chemical characteristics of the filler material, along with the bond strength between polymers and different filler compositions are important factors to consider.

Research towards furthering applications of recyclable materials in construction can have a huge impact and although not the focus of this thesis, it is important to note that these plasticaluminum composite I-beams have the potential to be completely recyclable. Both the plastic in this composite and the aluminum are easily recycled making these structural materials one of the few types of renewable composites. A machine has been developed to separate the flanges from the web and another machine is currently underway that will separate the flange plastic from the aluminum. The aluminum can be directly recycled and depending on the formula, the plastics have the potential to be melted down for recycling. In theory, thermoplastics are infinitely recyclable, as is aluminum. This demonstrates that plastic-aluminum composites are an economical and environmentally-sustainable alternative to wood and overall, the potential for applications of these plastic-aluminum composite I-beams is substantial.

The fundamental mechanical properties, such as flexural strength, of the plastic-aluminum composite I-beams have been studied before the work of this thesis, but presently much of this information is proprietary. Here, the properties specific to these beams and how these properties can be studied is the focus. The objectives of work completed for this thesis are to:

- Quantify the bond strength between the plastic and aluminum of the flanges

- Quantify the bond strength at the boundary between the flange and web plastics 
- Study and compare the properties of differing plastic formulas to understand the effects of multiple types of plastics and additives

- Quantify the effect of talc filler percentage on properties of the plastics and on the bond strengths

- Develop a numerical model used to accurately predict the load resisted by the deboss region before yielding and excessive deformation

In the remainder of this thesis, the pertinent literature is reviewed, the underlying mechanics of the composite beam are described, the physical tests and numerical model and their results are given, and a discussion of all results is presented. Finally, conclusions and recommendations for future work are discussed for this novel composite. 
Chapter 2 : Literature Review

Plastic-aluminum composite material technology has yet to have a significant role in large-scale structural applications; however, some research has been completed on potential applications of metal-plastic composites in the automotive industry. One of the most important factors to consider for plastic-metal composite materials is the connection and/or bonding between the two materials. Droste et al. [8] presented a comparison between three different adhesives and rivets in applications of this technology in the automotive industry. Droste et al. [8] argued that using adhesive across the entire connection surface allows creation of a continuous joint that will distribute the load uniformly between the two materials and eliminate complications due to stress concentrations. The three adhesives used and their properties are presented in Table 2-1.

Table 2-1: Main mechanical properties of the adhesives used in study [8]

\begin{tabular}{|c|c|c|c|}
\hline Adhesive & $\begin{array}{c}\text { Elastic Modulus } \\
(\mathbf{M p a})\end{array}$ & $\begin{array}{c}\text { Tensile Strength } \\
(\mathbf{M p a})\end{array}$ & $\begin{array}{c}\text { Elongation at Break } \\
(\boldsymbol{\%})\end{array}$ \\
\hline BETAMATE LESA 74020 & 2200 & 17.2 & 1.0 \\
\hline BETAMATE LESA 74030 & 1000 & 13.8 & 60 \\
\hline BETAMATE 2810 PU & 7 & 8 & 200 \\
\hline
\end{tabular}

The composite beams for this study [8] were made with a truss-like layout made from long-glass fiber reinforced polypropylene with a metal plate joined to the plastic beam along the two flanges. The beams were tested in static bending, torsion, and impact. The impact test was to determine the behavior under dynamic loading, which would give information necessary to analyze a part made from this composite material technology during an automobile crash.

The results shown in Figure 2-1 appear intuitively reasonable. The solid line with no markers is the basic plastic beam and the others have the metal plates connected to them by various 
methods. The maximum force for the basic plastic beam is the smallest, as expected. The rest are dependent on the individual properties of the different adhesives used. In this study, the beam cross-section was not optimized for bending (as is one of the goals of the aluminum-plastic Ibeams); therefore the differences between the composite beams' results and the basic plastic beam could be much greater. It is still interesting to see the upward trend in bending strength as better composite action is used. Overall, although Droste et al. [8] seems to favor the use of adhesives for bonding metals and plastics in these composite beams, it can be seen from Figure 2-1 that using a mechanical fastener (a rivet here) has a very comparable increase in the bending strength. When considering both techniques, there is additional labor required for both: pretreatment of the materials for adhesives and creating the shear connector for the mechanical fastener. A major difference between the two is that the adhesive technique adds a new material into consideration, while the mechanical fastener technique can use the materials already present (as with the aluminum-plastic composite I-beams investigated in this thesis). Therefore, an argument can be made for the latter technique being more economical, assuming the machinery needed for both are already in place. 


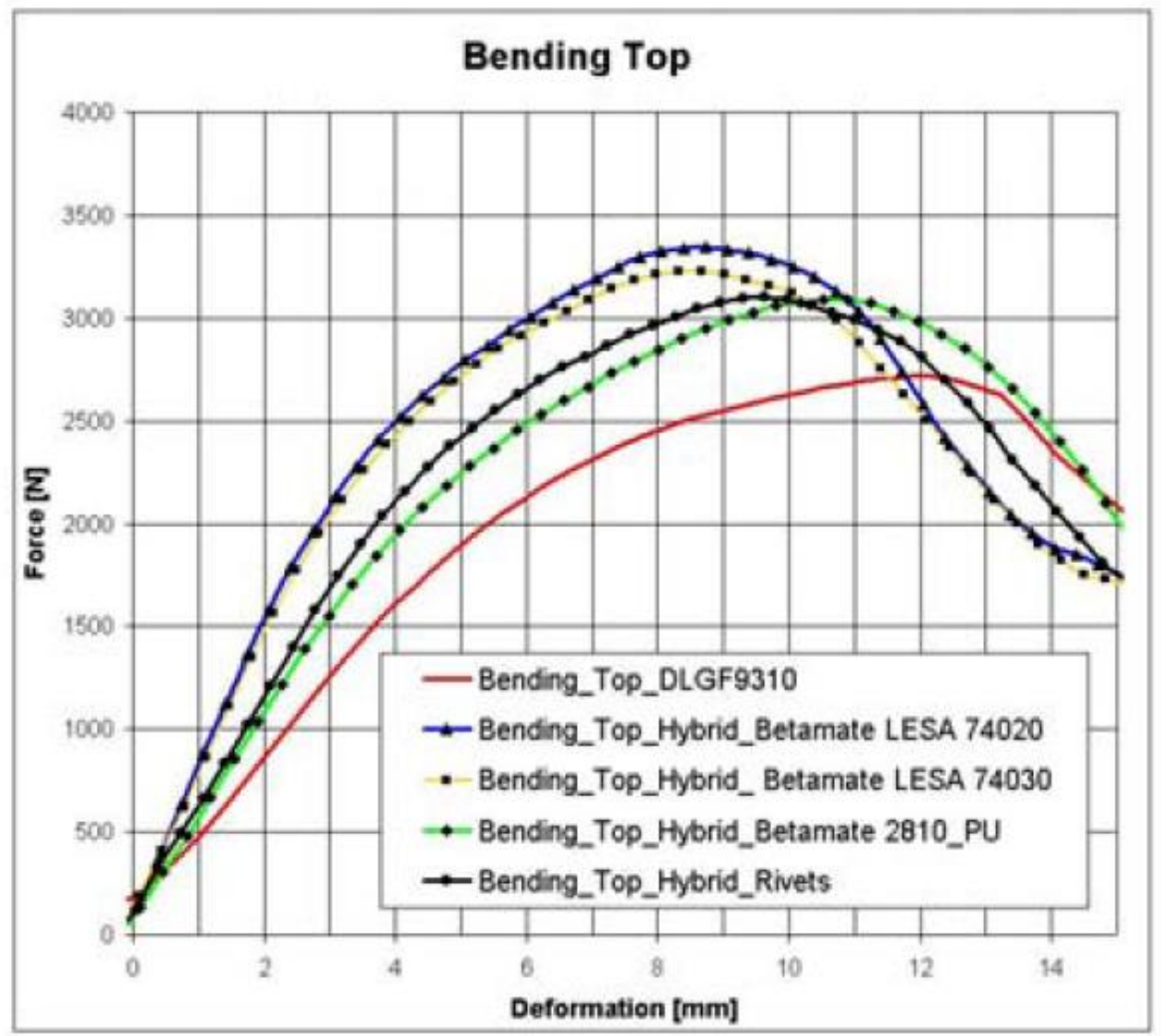

Figure 2-1: Force-Deflection results for static bending [8]

Most existing applications of plastic-metal composite materials, predominantly smaller scale parts in the automotive industry, use adhesives for the bonding between the two materials. This is a major difference between past work and the present.

Although the research conducted for this thesis is the first on an I-beam application of the plastic-aluminum composite material technology, another study has shown promising results for thin-walled aluminum tubular beams (ATBs) reinforced with internal polyamide 6 (PA6) and external fiber reinforcing layers. Eksi et al. [9] demonstrated many of the benefits of plasticmetal hybrid-composite structures, obtained by combining the low density and good moldability properties of plastic materials with the high strength and good stiffness properties of metallic materials in the same structure. Using ANSYS to run a finite element analysis, they showed that 
(for thin-walled ATBs) any type of inner reinforcement provides improvement in load-carrying capacity and that outer reinforcement contributes to resistance of global buckling. With these results from ANSYS, they then performed a systematic investigation on the contribution of internal PA6 and external fiber reinforcing layers specifically on the buckling and bending behaviors of the beams. The fiber reinforcements tested were a glass fiber reinforced polymer (GFRP) and a carbon fiber reinforced polymer (CFRP). For the experimental tests, nine different types of specimen were created to test each of the reinforcements independently and the interaction effects. Figure 2-2 shows the different types of test specimen.

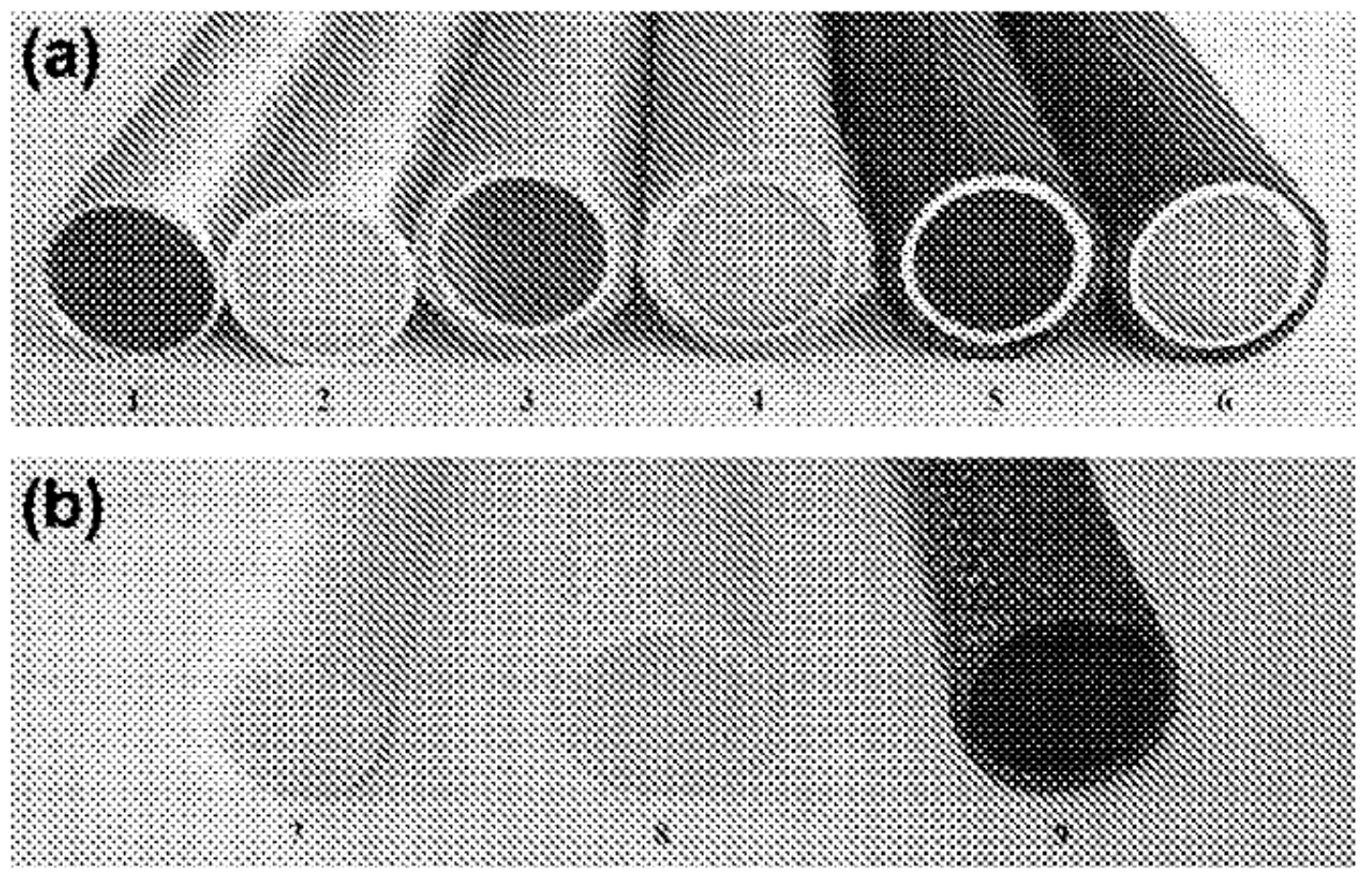

Figure 2-2: The nine test specimens used in the tubular study [9] 1: ATB, 2: ATB+PA6, 3: GFRP+ATB, 4: GFRP+ATB+PA6, 5: CFRP+ATB, 6: CFRP+ATB+PA6, 7: PA6, 8: GFRP, and 9: CFRP

The beams were tested in buckling and bending. Considering the comparison being made between the beams in the study and the plastic-aluminum composite I-beams of this thesis, only the bending test results from the research [9] will be presented and are shown in Figure 2-3. 


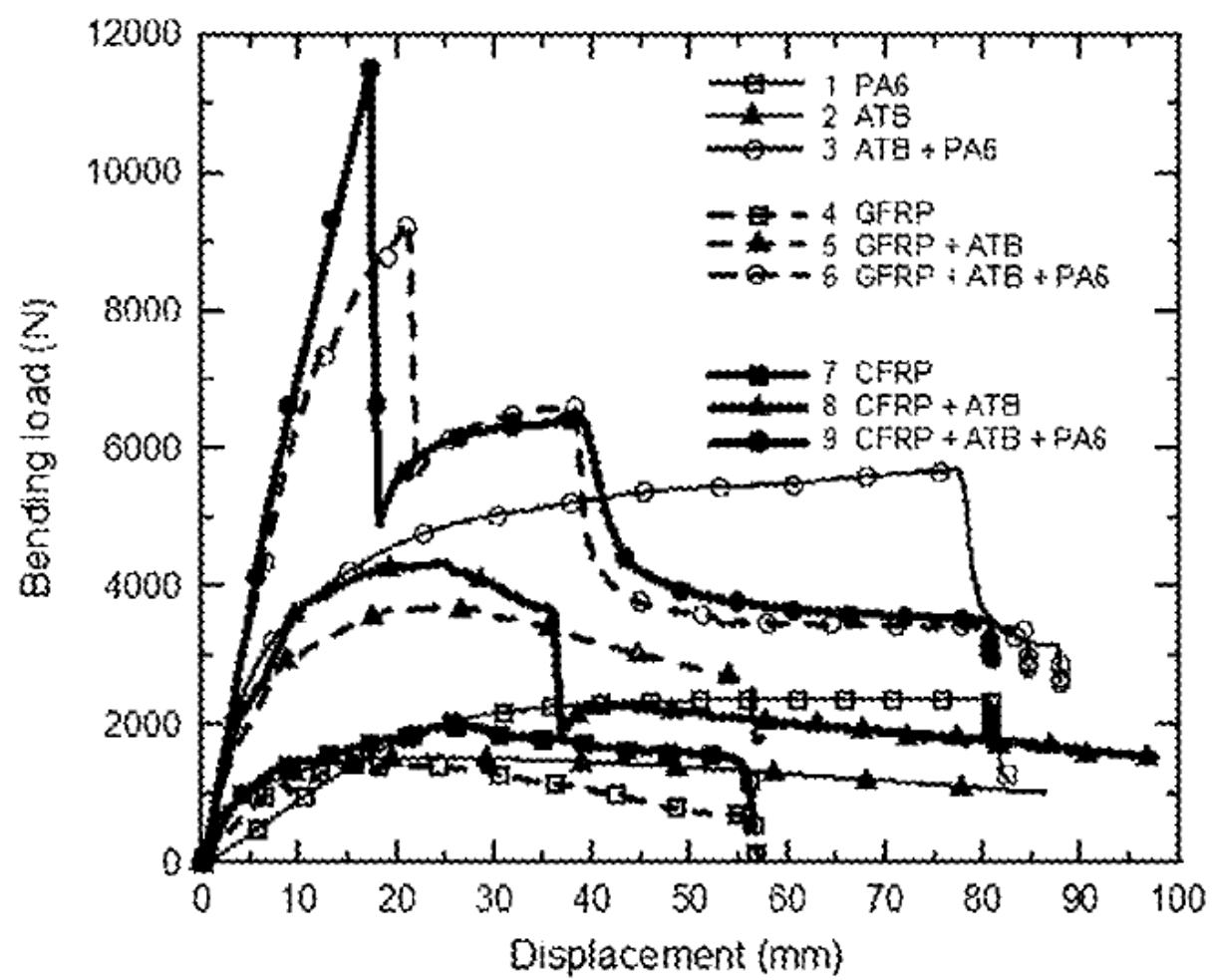

Figure 2-3: Load-Displacement graphs obtained from bending tests [9]

In Eksi et al.'s [9] study, reinforcing the aluminum tubular beams with both the carbon fiber reinforced polymer and the polyamide 6 resulted in a $661 \%$ increase in the bending load. The results show that combining the PA6 with fiber reinforcement increases the bending strength of the ATBs by the largest margin, with the carbon fiber reinforced beams showing a higher bending strength increase than the glass fiber reinforced beams, which would be expected. In general, it is known that increasing a beam's moment of inertia will increase its flexural strength. Therefore, without even considering the actual material properties of the fiber reinforcement, simply adding the material a certain distance away from the neutral axis of the cross-section increased the moment of inertia of these beams. This same strategy is noticed in the plasticaluminum composite I-beams of this thesis. The aluminum is held at a much larger distance from the neutral axis by the plastic than would be possible with the same amount of aluminum and no plastic. The density and modulus of elasticity of the aluminum are significantly larger than the 
values for the plastics. Therefore, its properties will have a much larger relative contribution when considering the composite properties of the beam as a whole. Eksi et al. [9] presented that the increase in flexural strength of the reinforced beams greatly exceeded the simple addition of each material's individual flexural strengths. This is due to the composite interaction between components and will be an important theme throughout this thesis. Overall, this study concluded that "the use of plastics and metal together as a reinforced structure yields better mechanical performance properties such as high resistance to buckling and bending loads, dimensional stability and high energy absorption capacity, including weight reduction."

The literature is limited in research specifically pertaining to the use of metal-plastic composite materials used in a structural sense. Composites in general, however, have been used for many years. One of the earliest uses of composite technology dates back to the 1500s B.C. when Egyptians mixed mud and straw [10] to build strong and durable buildings (considering the time period). Using straw for making bricks is even mentioned in the book of Exodus in the Bible. Composite technology for structures has huge potential in the field of engineering today, especially considering the research being conducted on new materials. Combining materials to optimize desired properties and take advantage of composite action is a big part of the future of structural mechanics and engineering. 


\section{Chapter 3 : Materials and Geometry}

The plastic-aluminum composite I-beams are composed of three different materials: aluminum, flange plastic, and web plastic. The plastic used for the flanges and web are typically different plastics, but could be the same. For the organization of this chapter, the following topics will be discussed in this order: aluminum material properties, flange plastic considerations, web plastic considerations, effects of additives and filler materials on the plastic material properties, I-beam cross-sectional dimensions, and aluminum profiles with differing deboss geometries.

\section{Aluminum material properties}

Aluminum is a standard structural material with well-known material properties. A 6005 extruded aluminum alloy was used for all beams tested and discussed in this thesis. The assumed material properties for the aluminum are summarized in Table 3-1.

Table 3-1: Aluminum material properties Values referenced from Aerospace Specification Metals Inc. [11].

\begin{tabular}{|l|r|}
\hline Poisson's Ratio & 0.33 \\
\hline Young's Modulus (psi) & $10,000,000$ \\
\hline Density (lb/in ${ }^{\mathbf{3}}$ ) & 0.0975 \\
\hline
\end{tabular}

\section{Flange plastic considerations}

The flanges and web have very different purposes, but must work together to exhibit the required performance of the structure. The geometry of the I-beam makes it the ideal geometry to resist bending and shear loads. The flanges resist bending while the web resists shear. Different material properties for the plastics were chosen based on the performance requirements of the flanges and web of an I-beam. For these composite I-beams, it will be assumed that the aluminum is solely responsible for the structural performance of the flanges and the flange 
plastic is there only to support the aluminum and complete the composite structure. The main considerations for the flange plastic are 1) bond with the aluminum, 2) reaction with the aluminum, 3) bond with the web plastic at the knit-line, and 4) economic considerations.

1) Bond with the aluminum: The first consideration is addressed by the mechanical shear connector (deboss region) described in great detail later in this thesis.

2) Reaction with the aluminum: The second consideration raises the concern that under an electrical charge (possibly from a lightning strike, etc.) the flange plastic may react with the aluminum. This could cause the plastic properties to change or be compromised and/or the surface of the aluminum to change, thereby changing the bond between the aluminum and the plastic. This is not desirable and the addition of a metal deactivator additive into the flange plastic can address this concern. Metal deactivators for polymers were originally developed for polypropylene insulation for copper wiring [12]. A metal deactivator does what its name implies and stops the elements in the plastic from reacting with the elements in the metal. Details of this reaction are not of importance to this research and will not be discussed here.

3) Bond with the web plastic at the knit-line: The third consideration is also a consideration for the web plastic and is addressed through testing discussed later in this thesis.

4) Economic considerations: The fourth consideration is addressed with the addition of talc, ethylene propylene diene monomer (EPDM), and/or a bonding elastomer as filler materials, which lower the price of the plastic. This thesis does not consider economic issues, but price is another element that must be considered when optimizing the filler strategy for the beams. Several factors that can affect price are the volume ordered and whether or not a relationship already exists between the manufacturers and the distributers. Again, this is beyond the scope 
of this thesis, but important to note here and the properties of these filler materials are described in the effects of additives and filler materials on the plastic material properties section.

\section{Web plastic considerations}

The moment of inertia generated from the I-beam's cross-sectional shape is the fundamental benefit over a rectangular cross-section made from the same amount of material. This is because the moment of inertia is in the denominator of the bending stress equation and as the moment of inertia increases the stress is reduced [13]. Also, displacement is inversely proportional to length [13]. Therefore, using an I-beam cross section, one can create a beam with high flexural properties which is lighter in weight than its rectangular counterpart. Consequently, not only must the web resist shear forces, it must also be stiff enough to support the flanges' increased distance from the neutral axis. To resist the shear forces, the web must have a high modulus, for stiffness considerations, while not being too stiff to prevent cracking (as with most structural materials) and catastrophic brittle failure. As the depth of the web increases, buckling considerations become important. The web must have a high enough modulus and moment of inertia to be safe from buckling, but should not be too bulky to take advantage of an I-beam's potential for being lightweight and economical. Shear stress will cause failure if the web section is too thin [13]. The moment of inertia is also in the denominator of the shear stress equation and therefore, again, as the moment of inertia increases the stress is reduced. [13]

Therefore, the web plastic considerations are 1) stiffness and modulus of elasticity, 2) bond adequately with the flange plastic at the knit-line, and 3) reduce costs of materials and manufacturing. The first and second considerations are by far the most important. The first will be discussed in detail in the next section of this chapter and the second is addressed through 
testing described later in this thesis. The third consideration has the same explanation as the economic considerations discussed for the flange plastic considerations.

\section{Effects of additives and filler materials on the plastic material properties}

For the plastic-aluminum composite I-beams, polyethylene has been used for both the flange and web plastics. Polypropylene was used in the flange plastic of the I-beams at one stage of research and development, but because polyethylene was chosen early on as the predominant material, only the effects of additives and fillers on polyethylene will be discussed for the purposes of this thesis. Many additives and filler materials can be used in polyethylene, but only those considered and tested specifically for these composite I-beams will be discussed.

Fillers have two main purposes: 1) lower the cost of the plastic and/or 2) improve certain desired properties of the plastic. When used, filler materials modify practically all properties of the plastic and therefore will influence the design [14]. Fillers can increase impact strength, flexural modulus, and/or provide dimensional stability to the composite. Also, fillers can change optical properties of the composite, such as transparency, and/or increase heat deflection temperature [15]. One goal when developing plastics for use in composites is optimizing the different contributions from different materials added. For example, high density polyethylene can be reinforced with short glass fibers and also filled with talc, but the behavior between all of the materials together must be investigated [16] and this goes for any plastic formula approach.

Polyethylene is innately flexible, durable, and tear-resistant. When filler materials are added to polyethylene, the properties are greatly affected by the filler characteristics, filler content, and interfacial adhesion. Talc $\left(\mathrm{Mg}_{3} \mathrm{Si}_{4} \mathrm{O}_{10}(\mathrm{OH})_{2}\right)$ was used as the filler material for the plasticaluminum composite I-beams studied here. Talc is made from a layer of brucite $\left(\mathrm{Mg}(\mathrm{OH})_{2}\right)$ sandwiched between two sheets of silica $\left(\mathrm{SiO}_{2}\right)$. It has a layered, platy shape with a hexagonal 
cross section and a high aspect ratio (typically 20:1) [15]. When used as a filler material in thermoplastics, talc increases the stiffness, thermal conductivity, creep resistance, and chemical resistance of the material [17]. In general, if a filler material has a higher aspect ratio (length/thickness), it will have a higher flexural modulus [15]. When plastic parts are extruded, the molecules can orient themselves and this is especially true for molecules with high aspect ratios. Therefore, the talc filler will have even more of an effect on the modulus of the plastics in the plastic-aluminum composite I-beams, due to the molecule orientation during extrusion. Raw material samples of the plastics before extrusion are not available and a comparison to quantify the effect of the talc orientation will not be made. A comparison of aspect ratios for common fillers is shown in Figure 3-1.

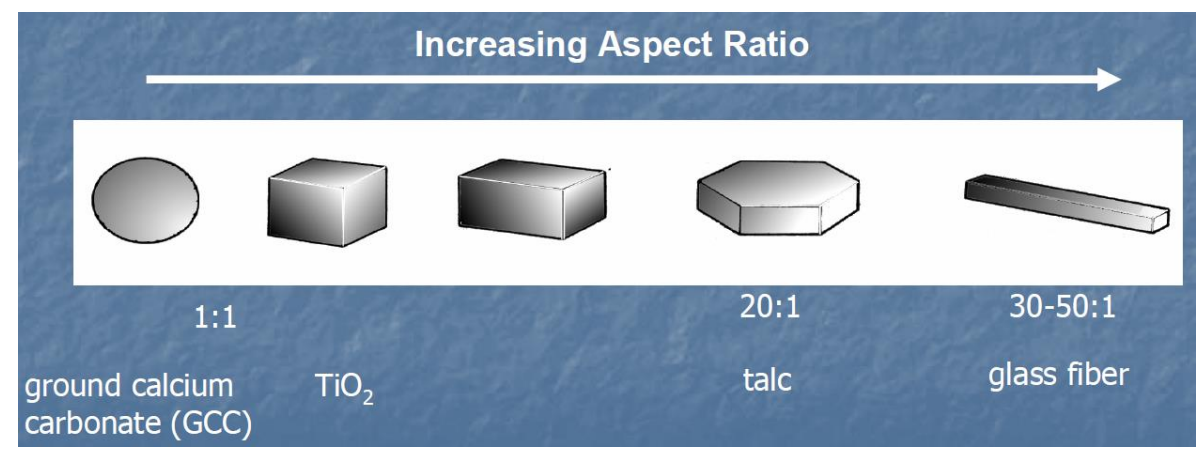

Figure 3-1: Aspect ratios of fillers with different shapes [15]

The type and volume fraction of filler additions affect the material properties of the plastic, but as mentioned above, interfacial adhesion also has a large effect on these properties. For fine particle filler materials, because of their small size, agglomeration is an issue that should be addressed. Agglomeration refers to the gathering and clumping of filler particles. This negative behavior can cause problems, but it specifically has a negative effect on tensile strength. The tensile strength of agglomerates was studied in detail by Schubert [18]. To avoid this adverse behavior, a surface treatment may be needed for the filler particles to increase interfacial adhesion. There are many different agents that can be used for surface treatments, and each will 
change the properties of the filler material in different ways. No surface treatments were needed for the talc added to the plastics discussed here, but it is important to at least note their existence.

When added to polyethylene, talc not only decreases the overall cost of the material, but also stiffens the thermoplastic. Because stiffness is a major concern for the web of an I-beam, there are obvious benefits of using talc to stiffen the web plastic, especially considering the innate flexibility of polyethylene on its own. Wernett [15] has shown the results of an evaluation of thermoplastic performance with fine and ultrafine talcs. Overall, both smaller talc particle size and higher talc concentrations correlate with greater stiffness in the composite. Figure 3-2 shows this behavior, with the volume fraction percent labeled next to each line. As expected with increased stiffness, impact strength decreases with higher talc concentration. However, smaller talc particle size still gives the higher values of impact strength. This should not be surprising, considering the relationship between modulus and aspect ratio discussed earlier (talc is on the high end of Figure 3-1).

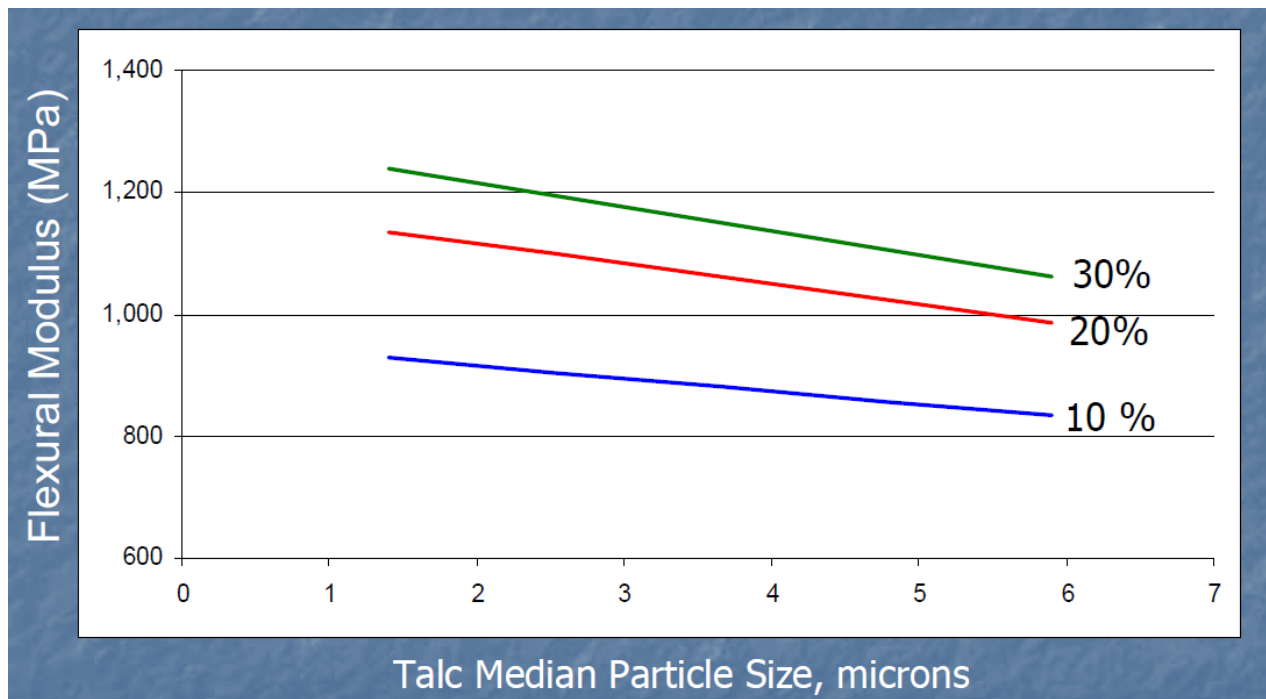

Figure 3-2: Effect of talc particle size and volume fraction on flexural modulus [15]

Karrad et al. [19] gave detailed results on the effect of talc content on the relative tensile modulus. It is called "relative" tensile modulus here, because it is the ratio of the polyethylene 
with talc filler modulus over the polyethylene on its own modulus. The ranges shown around the diamond points on Figure 3-3 are the experimental points and are of primary importance here. The other lines were comparisons made during the study [19] and are not germane to this discussion. The experimental results show that the tensile modulus increases with increased talc content.

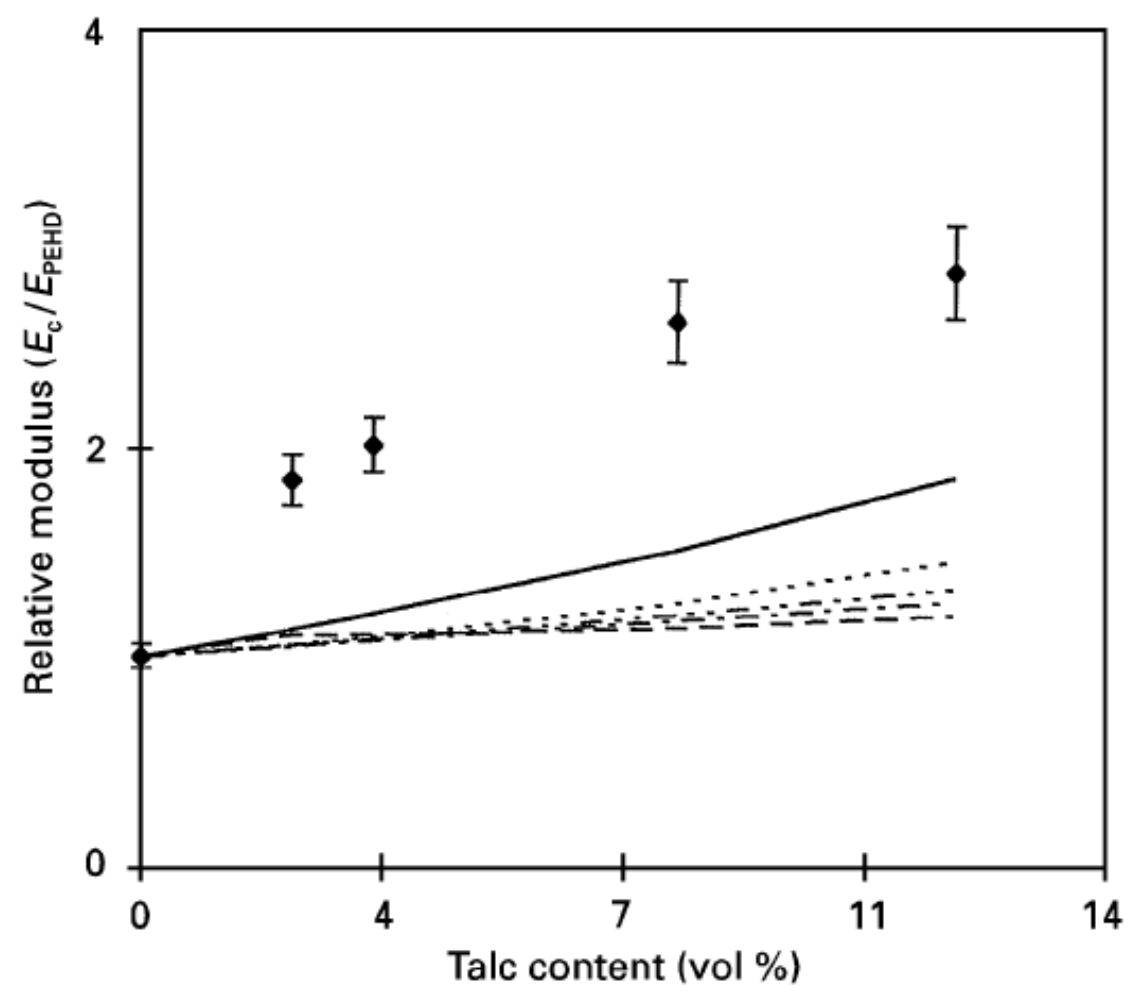

Figure 3-3: Effect of talc content on tensile modulus [19]

Kirrad et al. [19] also investigated the relationship between strain to failure, directly related to toughness, and talc content. An unexpected result found through this study is that there is actually an increase in the strain at failure, up to a talc content of about $4 \%$. As previously described, the addition of talc increases the stiffness of polyethylene, therefore decreases the strain to failure and toughness. However, Nicolais and Nicodema (as cited in [19]) hypothesized that because cavities around filler particles can be introduced with the addition of fillers, a method of blunting a crack tip is also introduced. If a crack encounters a poorly bonded interface 
between a filler particle and the polyethylene, then the interfacial debonding can blunt the crack tip and/or slow down further propagation. This would explain the increase in strain at break at lower talc contents shown in Figure 3-4 [19]. Note that the range of talc contents used for the plastics of the aluminum-plastic composite I-beams start at a minimum of $20 \%$. Therefore, this unexpected increase in strain at break at low talc contents is not a concern for the research of this thesis.

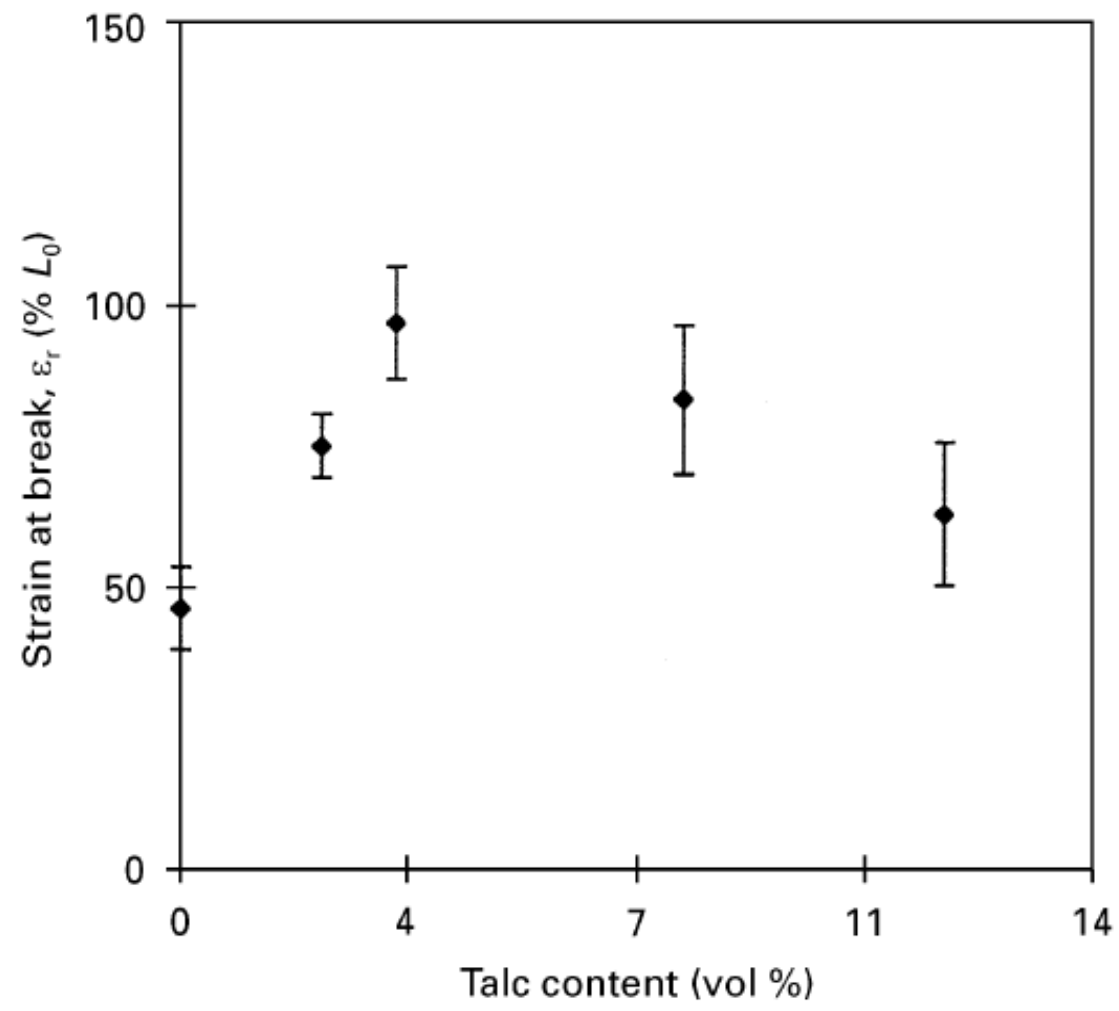

Figure 3-4: Evolution of strain at break of high density polyethylene/talc composites as a function of talc content [19]

Usually, adding a material with a high modulus to polyethylene will increase the material's modulus of elasticity, but it will also increase the brittleness. On the contrary, adding a rubbery material to a polyethylene matrix will increase the impact strength, but decrease the modulus of elasticity [20]. Conscientious addition of both could result in both increased modulus and impact strength [21]. For the flange plastics of the plastic-aluminum composite I-beams, this filler 
strategy was implemented with the addition of EPDM (the rubbery material) and talc (the high modulus material). One issue is that EPDM does not homogeneously bond with high density polyethylene (HDPE). Although, one study as cited by Vranjes et al. [22] has observed that EPDM can promote the interfacial bonding between polypropylene and HDPE used together in a plastic formula. For the composite I-beams studied here, early research and development concluded that there were cracking issues in the flanges of the beams when the beams were subjected to direct sunlight over long periods of time. It was thought that the non-homogenous bonding between the EPDM and the HDPE could be a factor in these results and finding a filler material that homogeneously bonds with HDPE to replace EPDM was a goal. In later testing, a high flow bonding elastomer (A55TPR 09-1020) was tried in place of the EPDM and for the rest of this thesis it will be referred to as the "bonding elastomer".

Two other additives used in the plastics are a UV stabilizer (UV) and color. The UV is added to protect the flange and web plastics from long-term deterioration due to sunlight. The color is added to give the web and flange plastics the same color simply for aesthetic considerations. Technically, any color can be chosen for this purpose.

Finally, the nomenclature used for the plastics in other chapters of this thesis will be described here. As described earlier, polypropylene thermoplastic elastomer (PPTPE) was at one point used for the beam's flange plastic. High density polyethylene (HDPE) was used for both the web and flange plastics throughout development. HDPE is known for its high strength to density ratio as compared to normal polyethylene. High molecular weight (HMW) HDPE has a higher crystallinity compared to normal HDPE. The crystallinity in polyethylene increases with increased length of polymer chains and decreased number of side branches. This allows the chains to be more tightly packed in a smaller volume, therefore increasing the weight per volume 
and also the strength to density ratio as compared to normal HDPE [23]. HDPE and HMW HDPE are compared during the testing.

\section{I-beam cross-sectional dimensions}

The beams have cross-sectional dimensions (all inches) shown in Figure 3-5 and can be cut to any length:
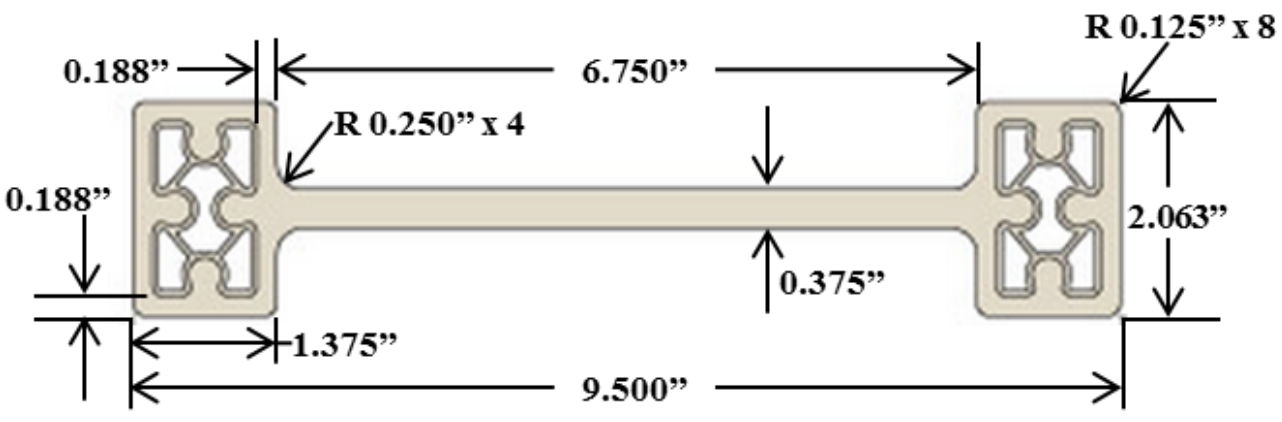

Figure 3-5: Aluminum-plastic composite I-beam cross-sectional dimensions

\section{Aluminum profiles with differing deboss geometries}

Three different types of aluminum profiles have been manufactured and tested. Figure 3-6 through Figure 3-10 are dimensioned drawings and photographs of these. 


\section{Aluminum Profile 1 - Corner stamped deboss}

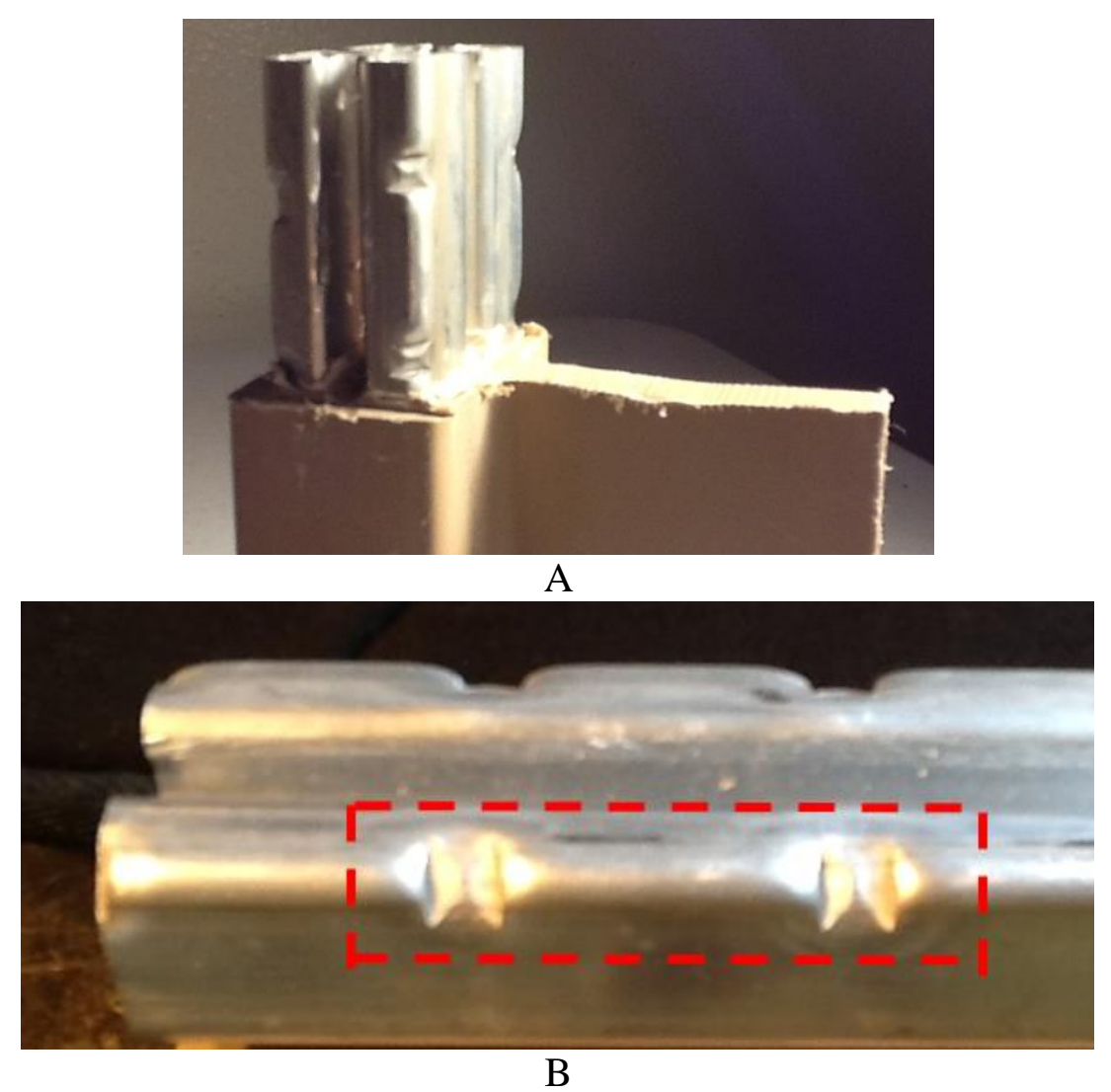

Figure 3-6: Aluminum Profile 1 photographs

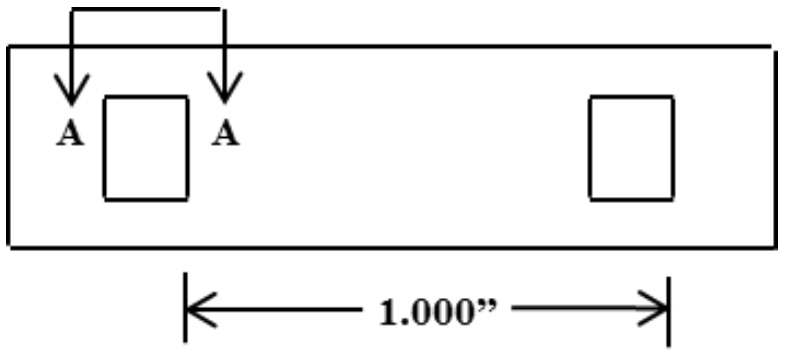

A) Dashed outline view from Figure 3-6 B

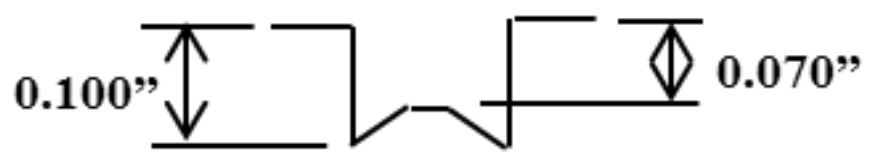

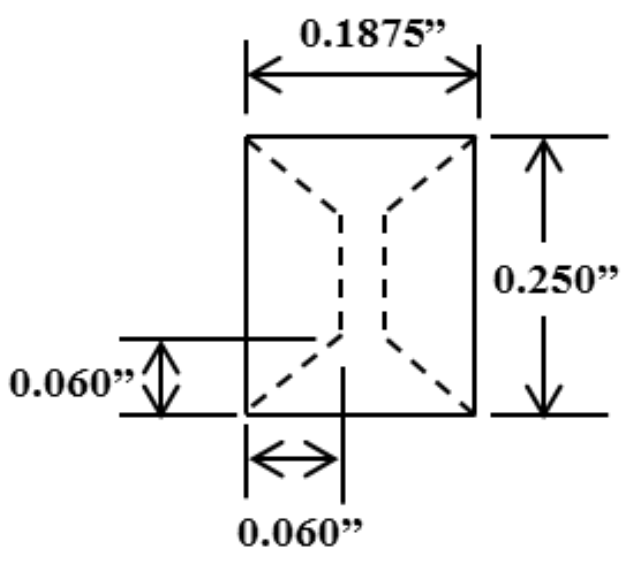

Doubly symmetric

B) A-A Section view

C) Single deboss dimensions

Figure 3-7: Aluminum Profile 1 dimensions 
Ideally, the deboss on each corner of the flange are aligned, but due to manufacturing limitations, this does not always happen. However, there are always 4 deboss regions around each flange within an inch of length.

\section{Aluminum Profile 2 - Face stamped deboss with scarification}

Scarification is a process that roughens the surface of the aluminum, allowing for a stronger mechanical bonding between the two materials. The scarification was applied before the deboss.

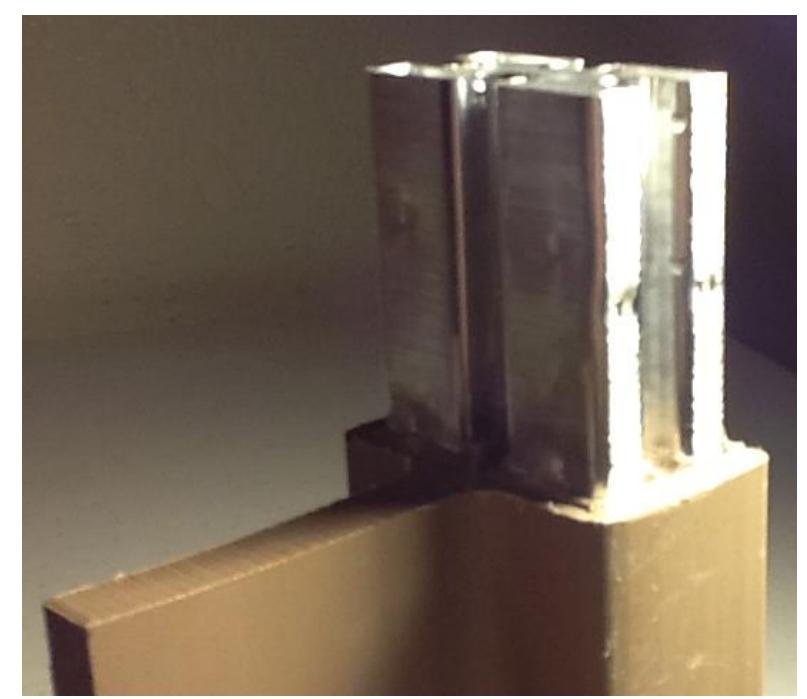

A

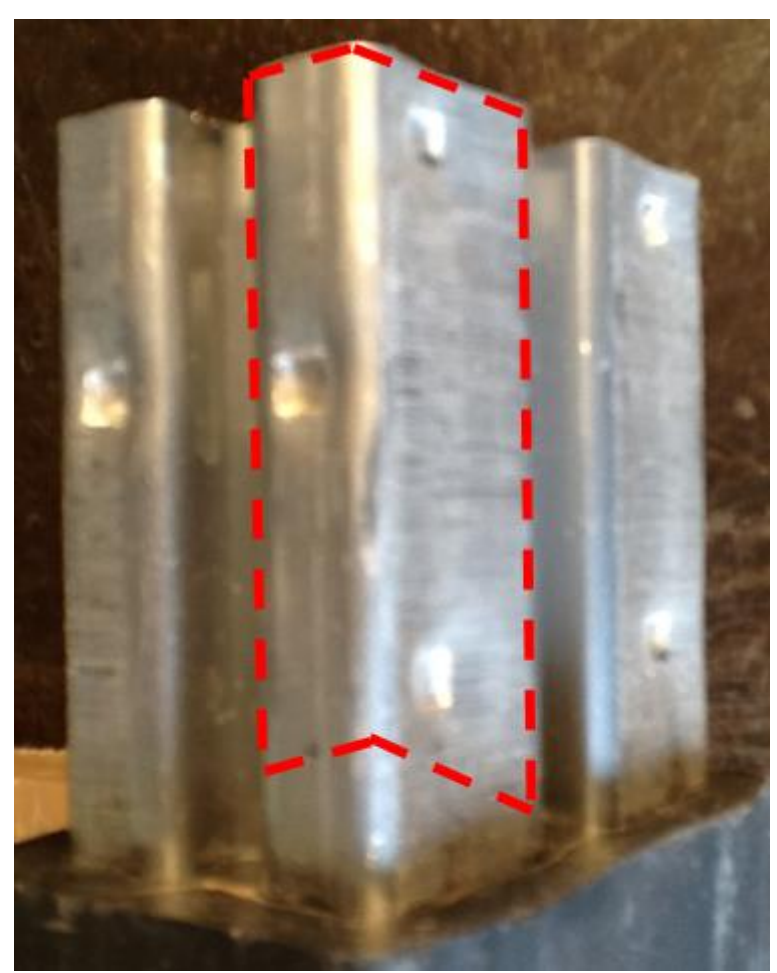

B

Figure 3-8: Aluminum Profile 2 photographs

Scarification on all outer surfaces. 


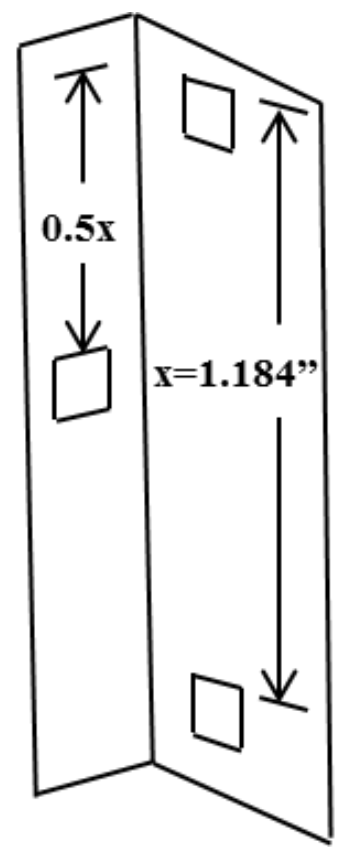

A) Dashed outline view from Figure 3-8 B

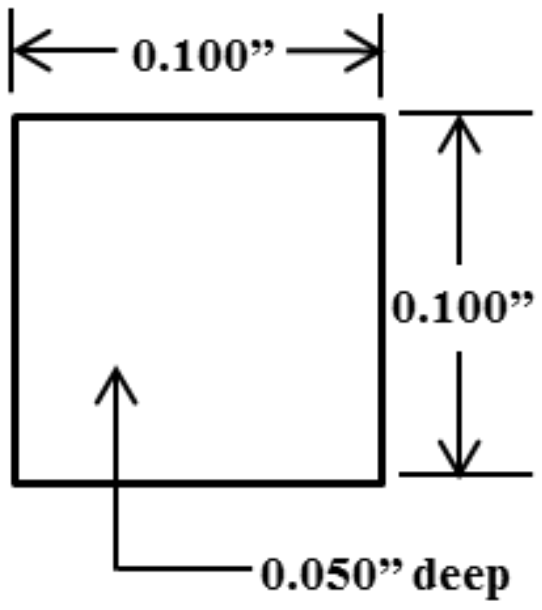

B) Single deboss dimensions

Figure 3-9: Aluminum Profile 2 dimensions

As can be seen in Figure 3-8, the wider face's deboss regions are more gradually sloped to the 0.050 inch depth, while the narrower face's deboss regions have a more defined "stamp" to the 0.050 inch depth. This is a result of the manufacturing and the varying rigidity of the aluminum faces oriented in different directions.

Aluminum Profile 3 - Completely smooth aluminum

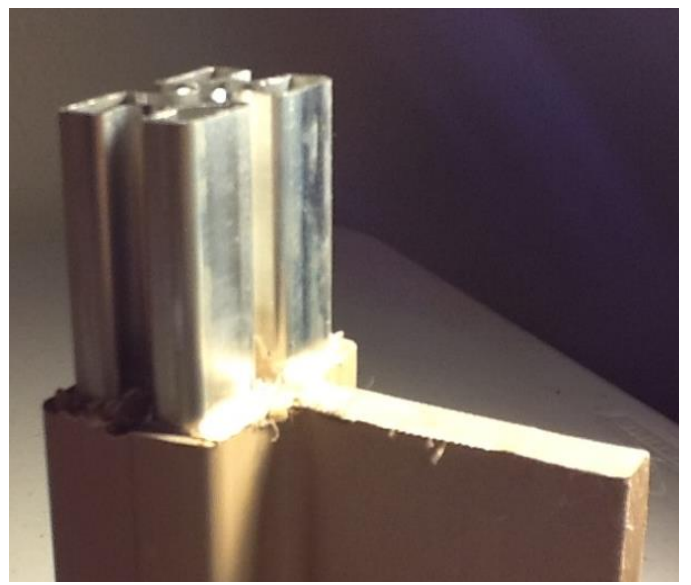

Figure 3-10: Aluminum Profile 3 photograph 


\section{Chapter 4 : Testing}

Tests were performed on the plastic-aluminum composite I-beams to quantify the properties of the deboss regions in the flanges, the knit-line between the web and flange plastics, and also the entire beam. For organizational purposes, each test will be described along with the specimen details of the multiple sets of that specific test.

\section{Push-Through Tests}

One of the most important properties of a composite material is the bonding and interaction between the different materials. This is required to maintain displacement and traction continuity. The strength between the plastic and aluminum of these composite I-beams is of particular interest and not only is the strength dependent on the surface between the two materials of the composite, but also the geometry and spacing of the physical deboss. The PushThrough Test was developed to quantify the strength of the bond between the aluminum and the plastic of the composite I-beams.

The composite I-beams were cut through the web and a total of 2 inches of plastic was removed from the end(s) of each specimen. The test was run using an Instron test machine, initially with a 20,000 lb load cell and then later a 5,000lb load cell. The 20,000 lb load cell was only used for the first set of testing, because the strength between the plastic and the aluminum was generally unknown. Data gathered during the first set of testing showed the 5,000 lb load cell was adequate for the remaining testing and higher resolution data could be gathered. An example specimen is shown in Figure 4-1. 


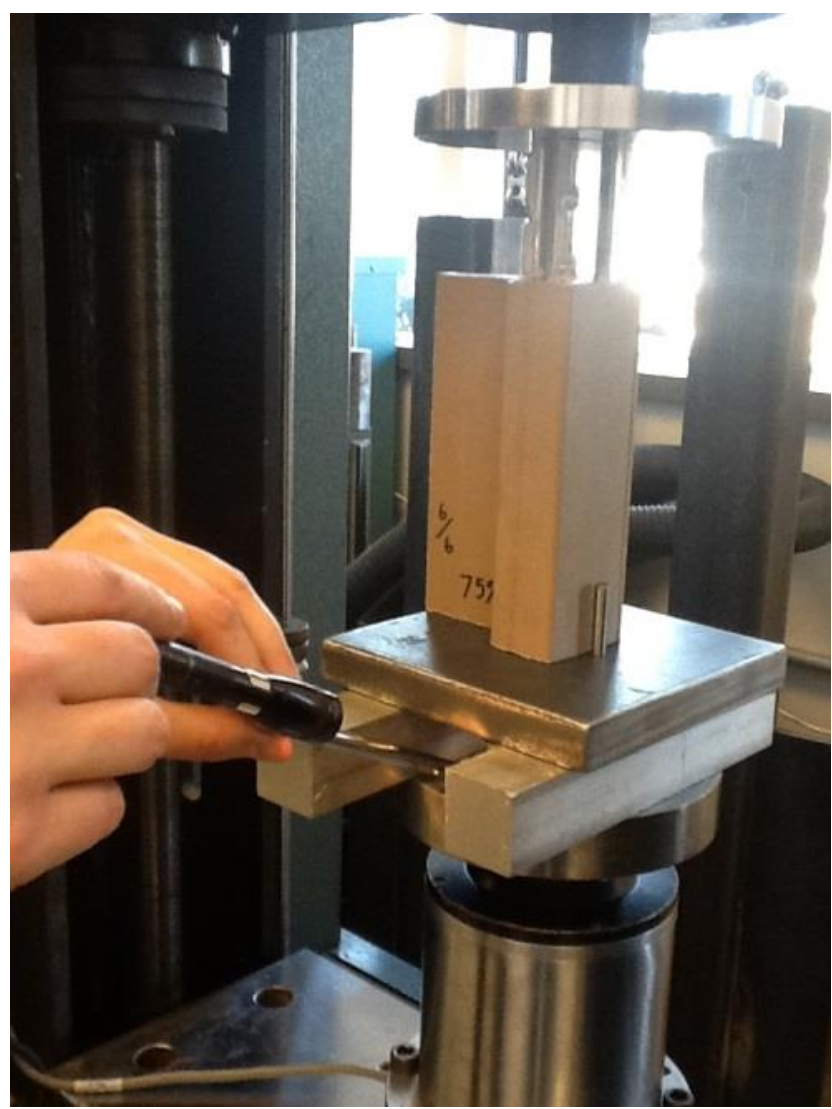

Figure 4-1: Example Push-Through test specimen

To allow the aluminum to be pushed through the plastic, a support plate, referred to as pushthrough plate from here on, was fabricated that allows the aluminum to penetrate up to $3 / 4 \mathrm{in}$. The push-through plate can also be lifted and supported with metal bars to allow for further penetration. The profile of the aluminum was cut into the push-through plate and then three dowel pins were positioned to help align the specimens. Figure 4-2 shows the push-through plate in detail and it can also be seen at the bottom of the specimen in Figure 4-1 above. After the first set of Push-Through tests, a mirror and flashlight were used to ensure alignment. In early testing, some data was compromised because of misalignment with the push-through plate (causing the aluminum to bear up against the plate); therefore, in later testing, $1 / 4$ in of the aluminum was exposed at the bottom of the specimens so they could be placed directly into the aluminum 
profile cutout on the push-through plate and guarantee alignment. The amount of plastic cut away for these tests was always 2 in, but further specimen details are described separately.

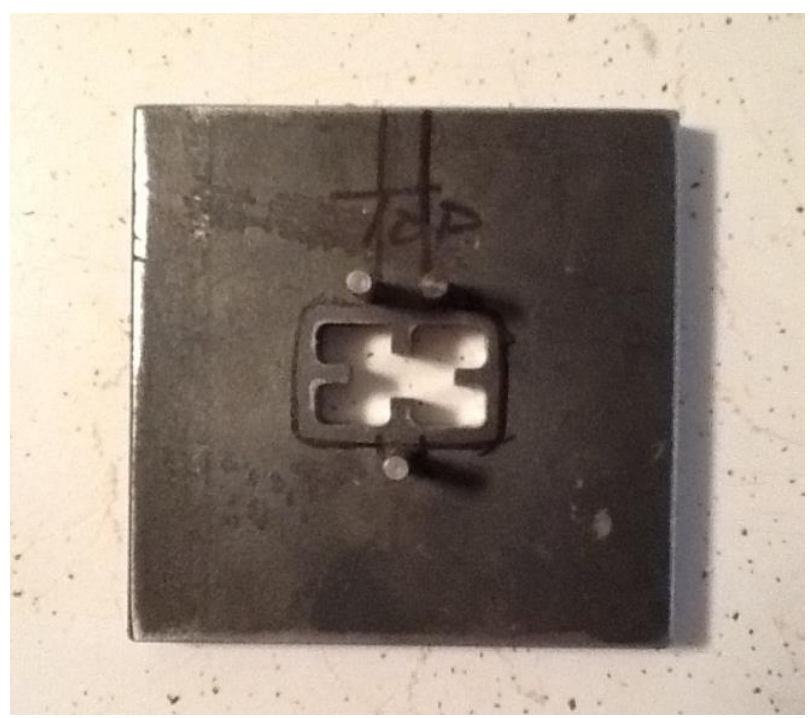

A) Push-Through plate top view

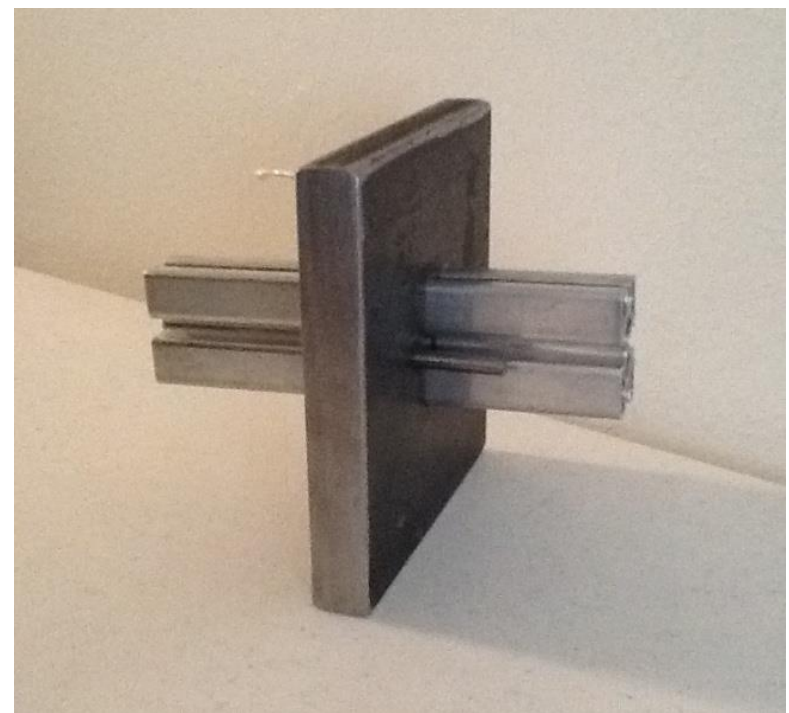

B) Push-Through plate showing aluminum profile fit

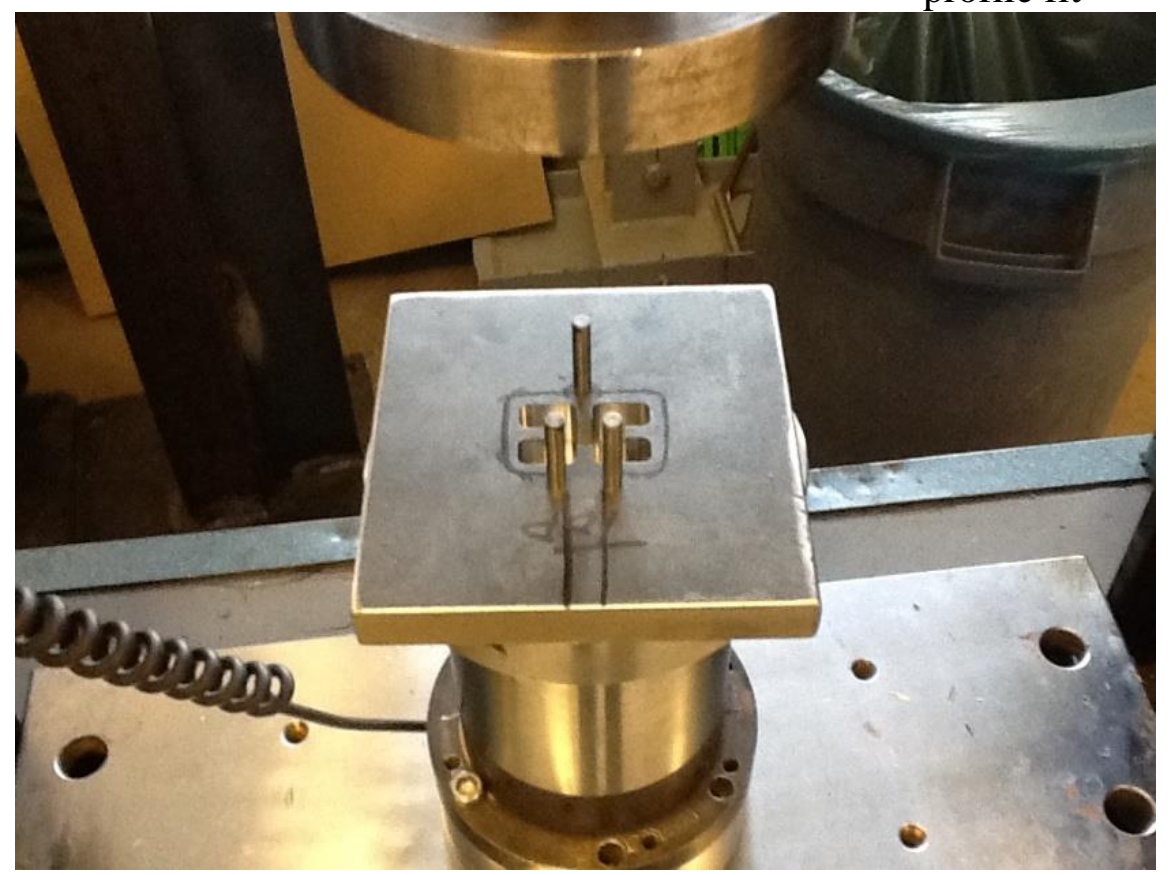

C) Push-Through plate on Instron test machine Figure 4-2: Push-Through plate details 
The data rate was set to record $5 \mathrm{pts} / \mathrm{sec}$. The shutoff points of each test (either maximum extension or minimum load after peak) varied from test to test and are described below. The two quantities measured were the applied load and the corresponding axial extension.

The first set of Push-Through tests was performed on specimens of multiple lengths to determine if the strength of the bond between the two materials has a linear relationship with the length of embedded aluminum. The specimen's names correlate with the length of aluminum bound by plastic; therefore the actual length of the specimens is their name plus 2 inches. Four specimens were made with three different lengths of plastic and their individual details are shown in Table 4-2. All specimens had " $28 / 15$ " flange plastic, a polyethylene with $28 \%$ talc filler and $15 \%$ ethylene propylene diene monomer (EPDM). A 20,000 lb load cell was used. At first, the test machine was pre-set to shut off at the lower of either 0.5 in displacement or a decreasing load of $1000 \mathrm{lb}$. This was to ensure that the specimen did not go all the way through the $3 / 4$ in pushthrough plate. After testing the 6 in specimen, the decreasing load shutoff point was changed to $500 \mathrm{lb}$ in order to get more data for the remaining specimen. Figure 4-3 shows the different lengths of specimen loaded on the Instron directly before testing. Notice that for these tests, the push-through plate was not lifted up on blocks. Observations during this set of tests are described in the Results and Discussion chapter and brought about the push-through plate being lifted onto blocks. 


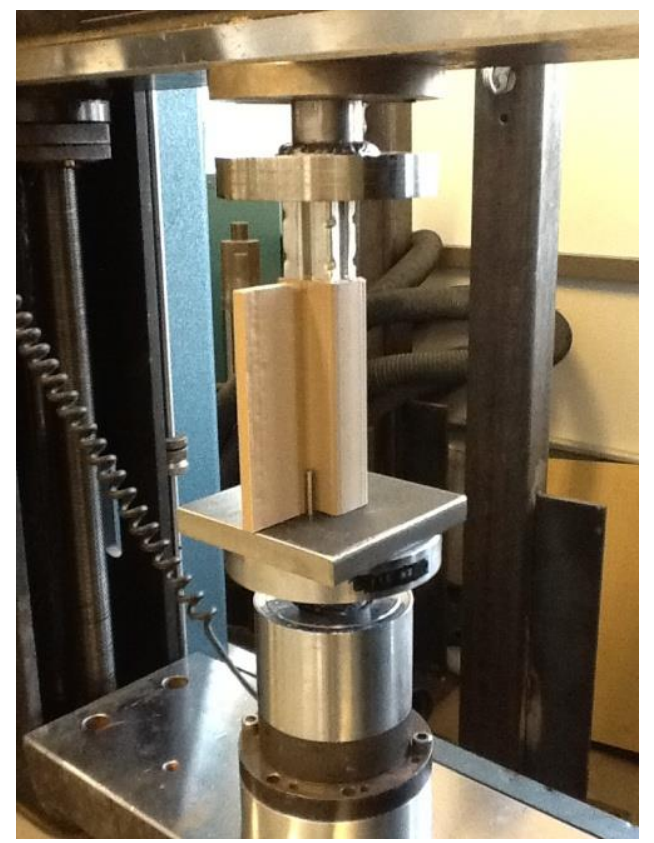

A) 6 in Specimen

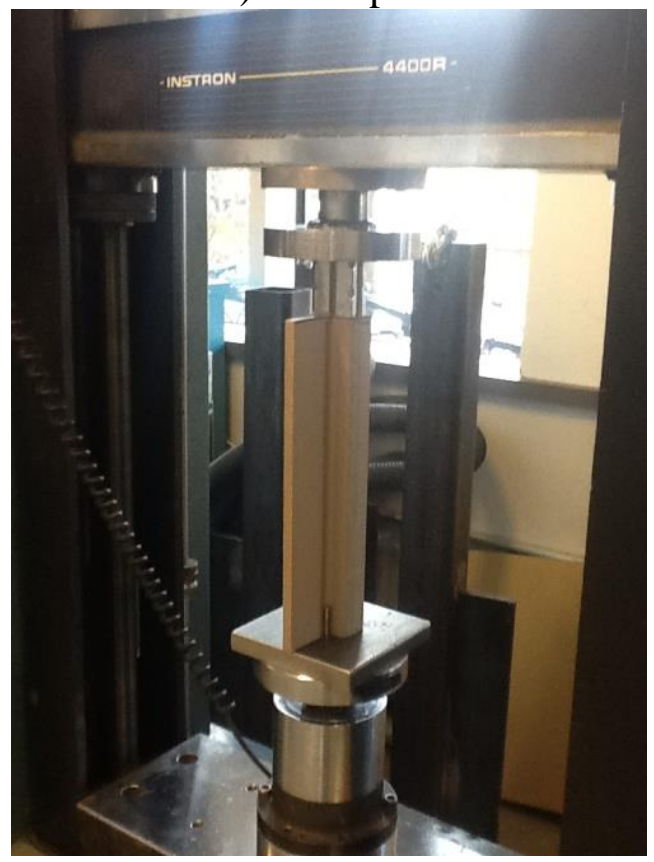

C) 12 in(a) Specimen

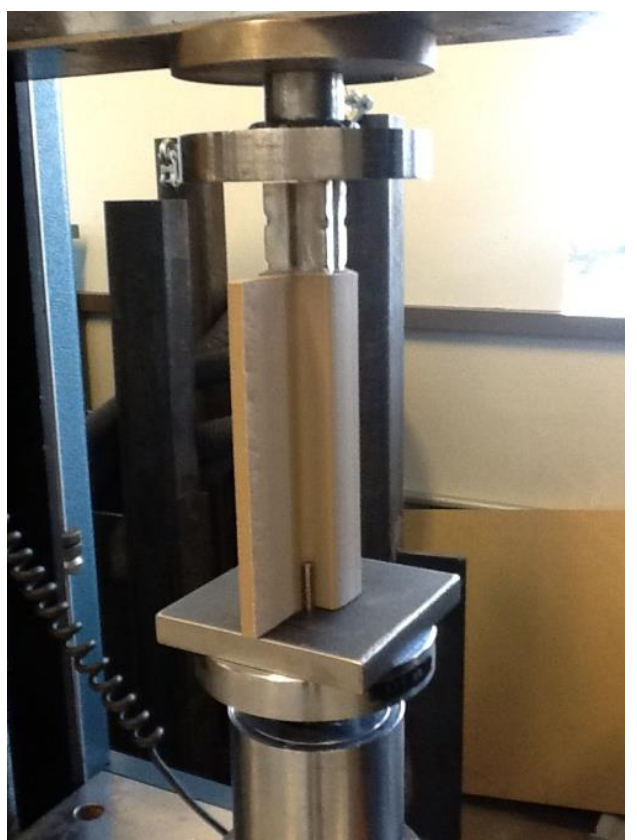

B) 8 in Specimen

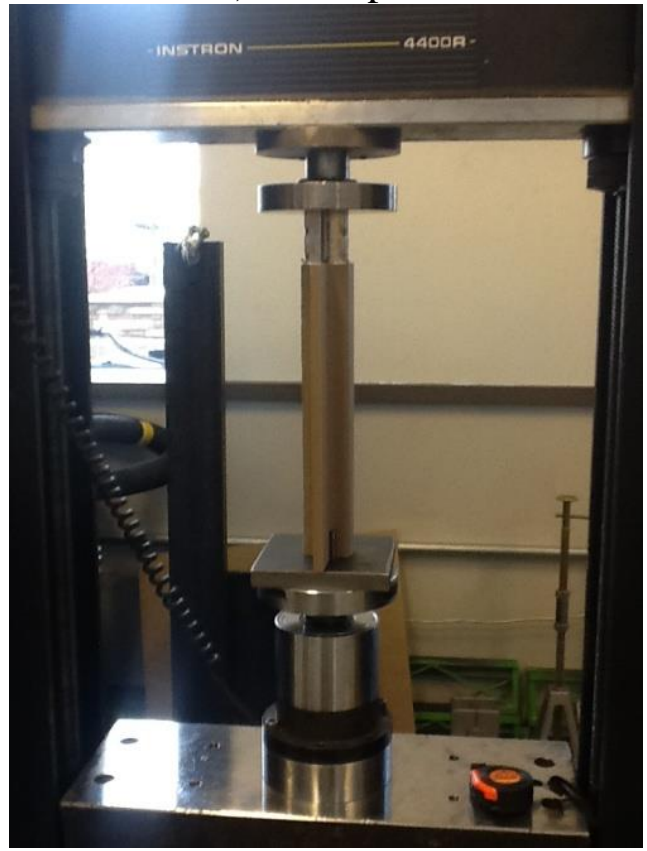

D) $12 \mathrm{in}(\mathrm{b})$ Specimen

Figure 4-3: Specimens loaded on the Instron directly before testing

The second set of Push-Through tests tested the strength between the aluminum and plastic of three different composite I-beam deboss geometries and allowed for strength comparisons between these configurations. Three different types of composite I-beams were tested during this round of testing. Four specimens of each were tested. All specimens were made by cutting 
through the web of the I-beams and using the two flanges. They were each a total of 8 inches long, with 2 inches of plastic removed from one end, exposing the same length of the aluminum. Again, all specimens were made of " $28 / 15$ " flange plastic. The three different aluminum profiles were described and dimensioned in the Materials and Geometry chapter and Figures 4-4 and 4-5 show visuals of these. Specimens 1-4 had aluminum profile 1 (note that this is the exact same beam type as tested during the first set of Push-Through tests), specimens 5-8 had aluminum profile 2 , and specimens 9-12 had aluminum profile 3.

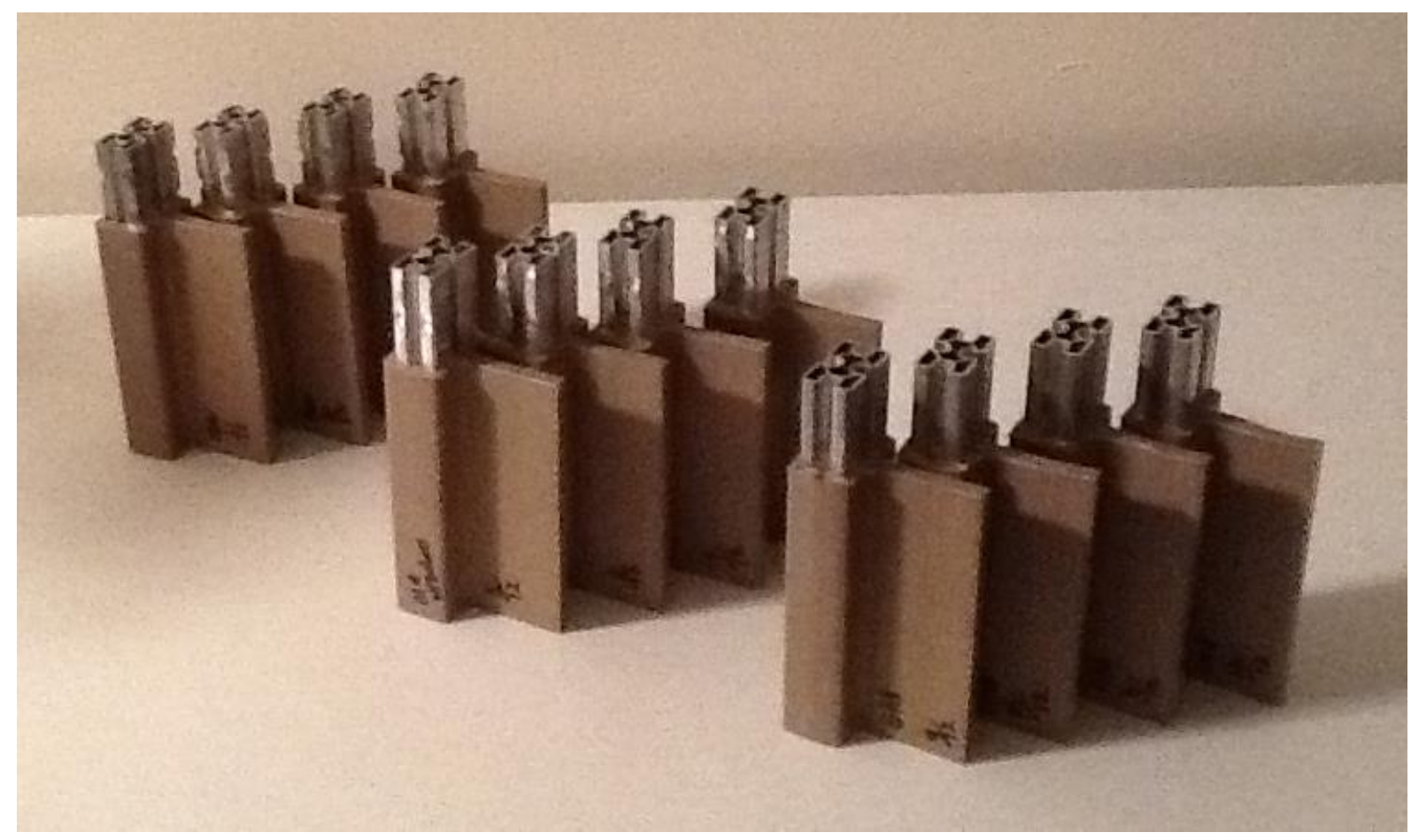

Figure 4-4: 12 Beam specimens for Push-Through tests 


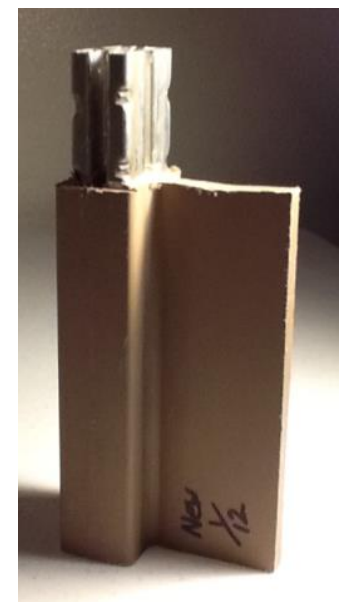

A) Aluminum Profile 1

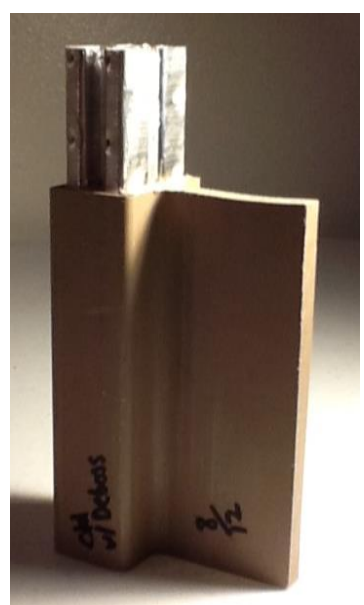

C) Aluminum Profile 2

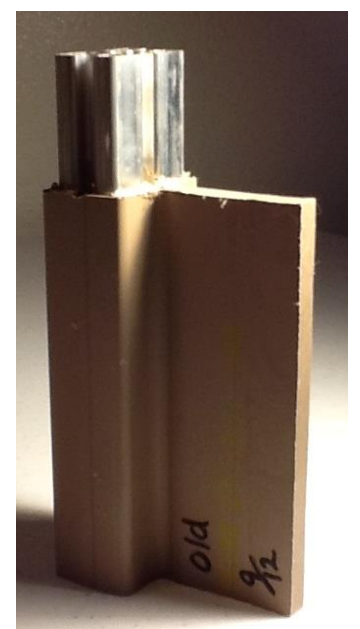

E) Aluminum Profile 3

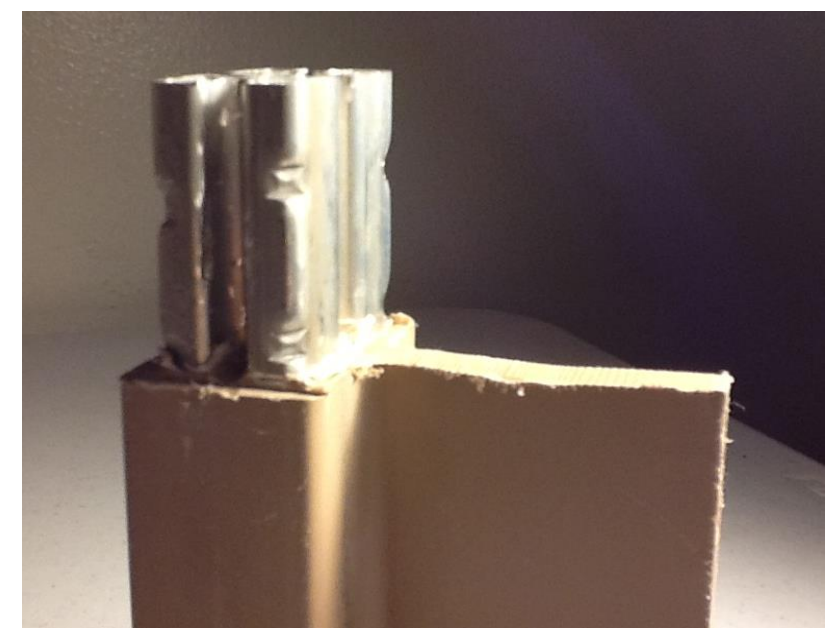

B) Aluminum Profile 1 zoomed view

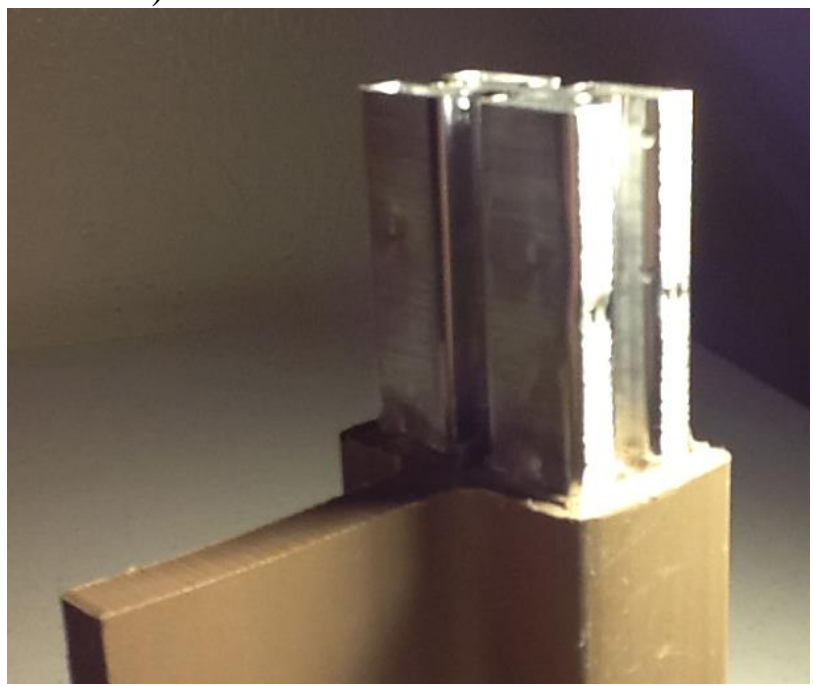

D) Aluminum Profile 2 zoomed view

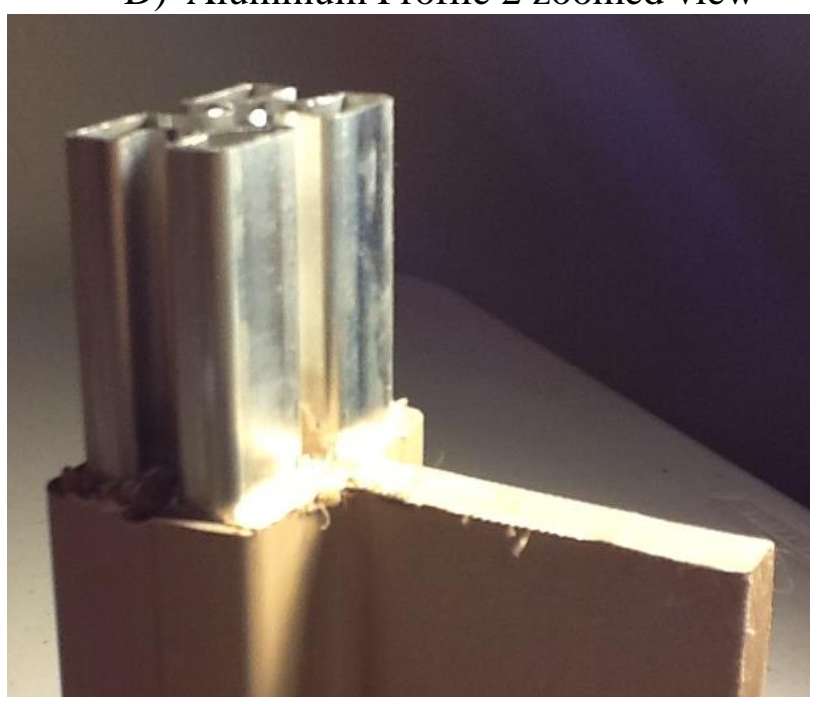

F) Aluminum Profile 3 zoomed view

Figure 4-5: Aluminum profiles' details 
The tests were run using a 5,000 $\mathrm{lb}$ load cell. Figure 4-6 shows an example of the specimens loaded on the Instron directly before testing. The data rate was set to record $5 \mathrm{pts} / \mathrm{sec}$. The testing was displacement controlled and set to $0.1 \mathrm{in} / \mathrm{min}$. In order to obtain a range of data, it was decided to run two specimens from each aluminum profile to 0.5 in displacement, one to $1.0 \mathrm{in}$, and one to $1.5 \mathrm{in}$. The Instron test machine was set to shut off at either these extensions (depending on which specimen was being tested) or a minimum load of $25 \mathrm{lb}$. The range of displacements gave data on how the beams would behave if the deboss plastic nub is separated from the aluminum profile. Although this is extremely unlikely to occur under the typical loading that these plastic-aluminum composite I-beams would see in actual application, the data is still useful for understanding the mechanics of what occurs between the aluminum and the plastic at the deboss regions.

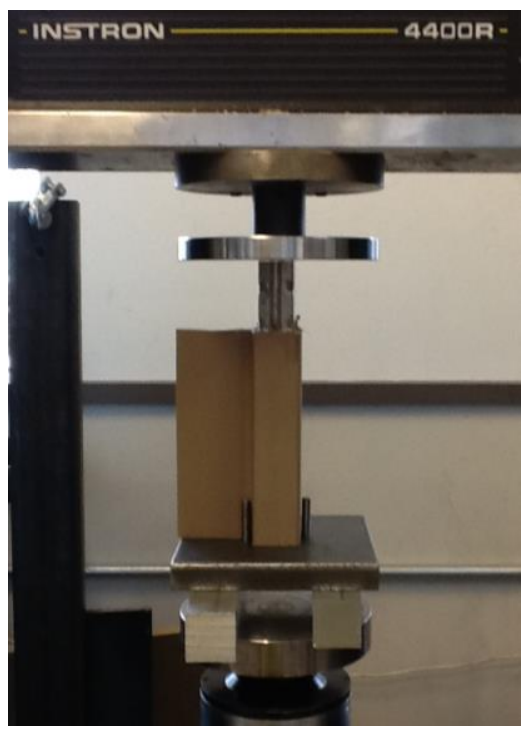

Figure 4-6: Beam specimen directly before testing

The third set of Push-Through tests measured the strength between the aluminum and plastic of seven different plastic formulas. The metal deactivator described in the Materials and Geometry chapter was added to three of the plastics. All of the I-beams tested here had Type 1 deboss geometries (corner stamped deboss described above). Three specimens of each plastic type were 
tested. All specimens were made by cutting through the web of the I-beams and using the two flanges. For this round of testing, 1.75 in of aluminum was exposed on the top of each specimen and 0.25 in was exposed on the bottom to be "inserted" into the push-through plate and ensure alignment. All specimens were 8 inches long, with a total of 2 inches of plastic removed. Table 4-1 details the different plastics that were tested and the numbers in the beam name correlate with the first number in the specimen names shown in Table 4-2. The missing (non-sequential) numbers in the beam names are from beams of differing plastic formulas (mainly consisting of a trial elastomer) that were discarded before testing.

Table 4-1: Plastic formulas for beams

\begin{tabular}{|c|c|c|c|}
\hline $\begin{array}{l}\text { Beam } \\
\text { Name }\end{array}$ & Web Plastic & Flange Plastic & $\begin{array}{c}\text { Metal } \\
\text { Deactivator? }\end{array}$ \\
\hline $1 \mathrm{~B}$ & $\begin{array}{l}\text { "Standard" } 38 \% \text { talc- } \\
\text { filled HDPE }\end{array}$ & $\begin{array}{l}\text { HMW HDPE with UV, color, and } \\
20 \% \text { talc }\end{array}$ & no \\
\hline $3 \mathrm{~B}$ & $\begin{array}{l}\text { "Standard" } 38 \% \text { talc- } \\
\text { filled HDPE }\end{array}$ & $\begin{array}{l}\text { HMW HDPE with UV, color, } 20 \% \\
\text { talc and } 25 \% \text { bonding elastomer }\end{array}$ & no \\
\hline $4 \mathrm{~B}$ & $\begin{array}{l}\text { "Standard" } 38 \% \text { talc- } \\
\text { filled HDPE }\end{array}$ & HMW HDPE with UV and color & no \\
\hline $5 B$ & $\begin{array}{l}\text { HMW HDPE with UV, } \\
\text { color, and } 38 \% \text { talc }\end{array}$ & HMW HDPE with UV and color & yes \\
\hline $8 \mathrm{~B}$ & $\begin{array}{l}\text { HMW HDPE with UV, } \\
\text { color, and } 38 \% \text { talc }\end{array}$ & $\begin{array}{l}\text { HMW HDPE with UV, color, and } \\
20 \% \text { talc }\end{array}$ & yes \\
\hline $9 B$ & $\begin{array}{l}\text { HMW HDPE with UV, } \\
\text { color, and } 38 \% \text { talc }\end{array}$ & $\begin{array}{l}\text { HMW HDPE with UV, color, and } \\
38 \% \text { talc }\end{array}$ & yes \\
\hline $10 \mathrm{~B}$ & $\begin{array}{l}\text { HMW HDPE with UV, } \\
\text { color, and } 38 \% \text { talc }\end{array}$ & $\begin{array}{l}\text { HMW HDPE with UV, color, and } \\
38 \% \text { talc }\end{array}$ & no \\
\hline
\end{tabular}

HDPE: High Density Polyethylene

HMW: High Molecular Weight

UV: ultra violet stabilizer

Because these composite beams were designed with the original motivation of being used for decking understructure, the behavior of the beams with screws placed through the flange is desired. The fourth set of Push-Through tests quantified the additional strength between the aluminum and the plastic due to the addition of screws. Two specimens were prepared: 1) 6 in of plastic containing two screws, 4 in on center, 1 in from each end, and 2) 8 in of plastic containing 
three screws located at 1 in, 3 in, and 7 in from bottom end. Both specimens were made from Beam \#1B described above in Table 4-1 and therefore are directly compared with Specimens 14, 1-5, and 1-6 in the Results and Discussion chapter and figures of one of the specimen during testing are shown in that chapter as well.

The fifth and last set of the Push-Through test was on one specimen: a piece containing only one deboss region. It had a total length of 3.3125 in, with 1.3125 in of plastic centered around the deboss region, 1.75 in aluminum exposed on the top and 0.25 in exposed on the bottom. This specimen was from Beam \#1B as well. This specimen was tested in order to have a direct comparison with the ABAQUS model described in the Numerical Model of Deboss Region chapter. Although there is 0.3125 in more plastic on this test specimen as compared to the ABAQUS model, the model assumes only the deboss region is resisting the load; therefore the hoop stress induced by the extra plastic is assumed not to make a difference and will be discussed further in the Numerical Model of Deboss Region chapter. Figure 4-7 gives visuals and this specimen is referred to as Small on Table 4-2.

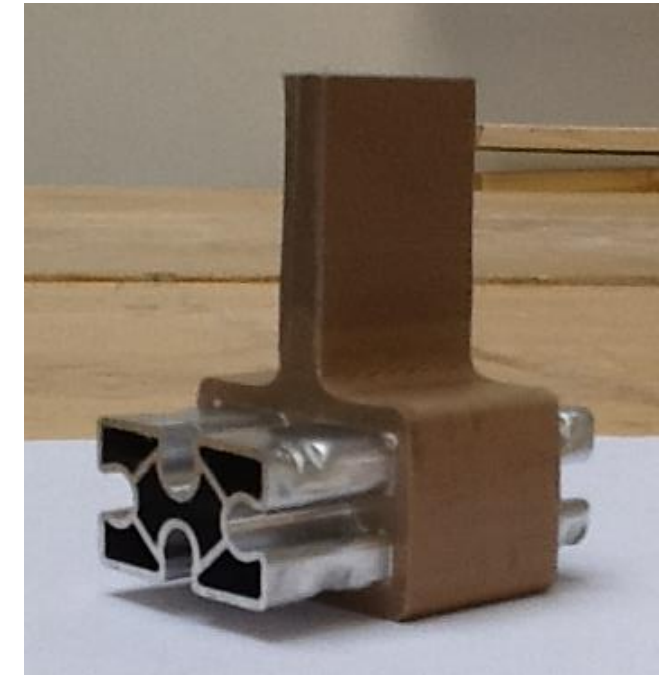

A) Small specimen full view

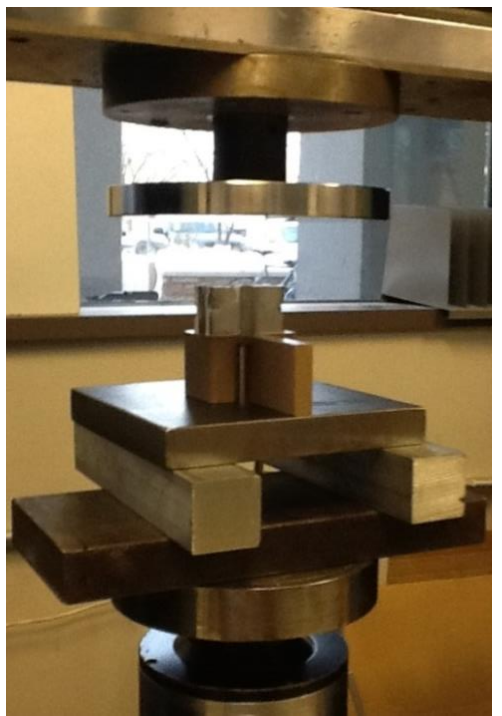

B) Small specimen loaded on Instron directly before testing

Figure 4-7: Small specimen details 
Push-Through Test-All Specimen Details

Table 4-2 gives specimen details for all Push-Through tests. Lengths of exposed aluminum of each specimen are described above in their corresponding Round section.

Table 4-2: Push-Through test specimen details

\begin{tabular}{|c|c|c|c|c|c|}
\hline Name & $\begin{array}{l}\text { Length of plastic } \\
\text { and aluminum (in) }\end{array}$ & Set & Date Tested & $\begin{array}{l}\text { Usable } \\
\text { Data? }\end{array}$ & $\begin{array}{c}\text { Test } \\
\text { stopped at? }\end{array}$ \\
\hline 6 in & 6 & 1 & 13 March, 2013 & yes & $1000 \mathrm{lb}$ \\
\hline 8 in & 8 & 1 & 13 March, 2013 & yes & $0.5 \mathrm{in}$ \\
\hline 12in(a) & 12 & 1 & 13 March, 2013 & yes & $0.5 \mathrm{in}$ \\
\hline $12 \mathrm{in}(\mathrm{b})$ & 12 & 1 & 13 March, 2013 & no & $0.5 \mathrm{in}$ \\
\hline 1 & 6 & 2 & 11 April, 2013 & yes & $0.5 \mathrm{in}$ \\
\hline 2 & 6 & 2 & 11 April, 2013 & yes & $0.5 \mathrm{in}$ \\
\hline 3 & 6 & 2 & 11 April, 2013 & yes & 1.0in \\
\hline 4 & 6 & 2 & 11 April, 2013 & yes & $1.5 \mathrm{in}$ \\
\hline 5 & 6 & 2 & 11 April, 2013 & yes & 0.5 in \\
\hline 6 & 6 & 2 & 11 April, 2013 & yes & 0.5 in \\
\hline 7 & 6 & 2 & 11 April, 2013 & yes & 1.136in \\
\hline 8 & 6 & 2 & 11 April, 2013 & yes & $25 \mathrm{lb}$ \\
\hline 9 & 6 & 2 & 11 April, 2013 & yes & $0.5 \mathrm{in}$ \\
\hline 10 & 6 & 2 & 11 April, 2013 & yes & $0.5 \mathrm{in}$ \\
\hline 11 & 6 & 2 & 11 April, 2013 & no & 1.0in \\
\hline 12 & 6 & 2 & 11 April, 2013 & yes & $1.5 \mathrm{in}$ \\
\hline $1-4$ & 6 & 3 & 13 December, 2013 & yes & 0.5 in \\
\hline $1-5$ & 6 & 3 & 13 December, 2013 & yes & 0.5 in \\
\hline $1-6$ & 6 & 3 & 17 December, 2013 & yes & $1.5 \mathrm{in}$ \\
\hline $3-4$ & 6 & 3 & 13 December, 2013 & yes & $0.5 \mathrm{in}$ \\
\hline $3-5$ & 6 & 3 & 13 December, 2013 & yes & 0.5 in \\
\hline $3-6$ & 6 & 3 & 17 December, 2013 & yes & $1.5 \mathrm{in}$ \\
\hline $4-4$ & 6 & 3 & 13 December, 2013 & yes & $0.5 \mathrm{in}$ \\
\hline $4-5$ & 6 & 3 & 13 December, 2013 & yes & $0.5 \mathrm{in}$ \\
\hline $4-6$ & 6 & 3 & 17 December, 2013 & yes & $1.5 \mathrm{in}$ \\
\hline $5-4$ & 6 & 3 & 13 December, 2013 & yes & $0.5 \mathrm{in}$ \\
\hline $5-5$ & 6 & 3 & 13 December, 2013 & yes & $0.5 \mathrm{in}$ \\
\hline $5-6$ & 6 & 3 & 17 December, 2013 & yes & $1.5 \mathrm{in}$ \\
\hline $8-4$ & 6 & 3 & 13 December, 2013 & yes & $0.5 \mathrm{in}$ \\
\hline $8-5$ & 6 & 3 & 13 December, 2013 & yes & $0.5 \mathrm{in}$ \\
\hline
\end{tabular}




\begin{tabular}{|c|c|c|c|c|c|}
$8-6$ & 6 & 3 & 17 December, 2013 & yes & $1.5 \mathrm{in}$ \\
\hline $9-4$ & 6 & 3 & 13 December, 2013 & yes & $0.5 \mathrm{in}$ \\
\hline $9-5$ & 6 & 3 & 13 December, 2013 & yes & $0.5 \mathrm{in}$ \\
\hline $9-6$ & 6 & 3 & 17 December, 2013 & yes & $1.5 \mathrm{in}$ \\
\hline $10-4$ & 6 & 3 & 13 December, 2013 & yes & $0.5 \mathrm{in}$ \\
\hline $10-5$ & 6 & 3 & 13 December, 2013 & yes & $0.5 \mathrm{in}$ \\
\hline $10-6$ & 6 & 3 & 17 December, 2013 & yes & $1.5 \mathrm{in}$ \\
\hline $\mathrm{N}-1$ & 6 & 4 & 17 December, 2013 & yes & $1.5 \mathrm{in}$ \\
\hline $\mathrm{N}-2$ & 8 & 4 & 17 December, 2013 & yes & $1.5 \mathrm{in}$ \\
\hline Small & 1.3125 & 5 & 13 December, 2013 & yes & $0.5 \mathrm{in}$ \\
\hline
\end{tabular}

\section{Knit-Line Pull Tests}

The bonds between the web and flange plastics, as well as the resulting compliance mismatch, are both major concerns. The plastic formulas for the web and flanges will affect this behavior. The location of the interface between the different plastics is referred to as the knit-line. Testing for this thesis includes the design of a Knit-Line Pull Test that quantifies the bond strength between the web and flange plastics. Because of how the I-beams are extruded, the knit-line generally forms as a semi-circular line on the cross-section. An example of the knit-line is shown in Figure 4-8. 


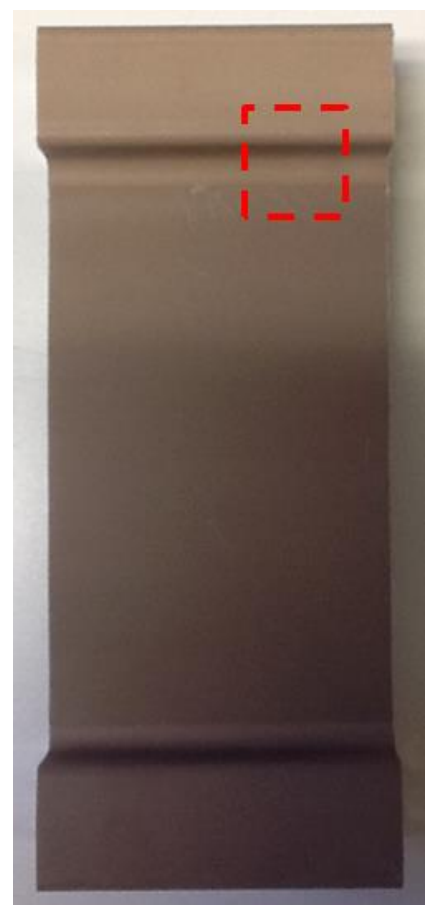

A) Beam side view

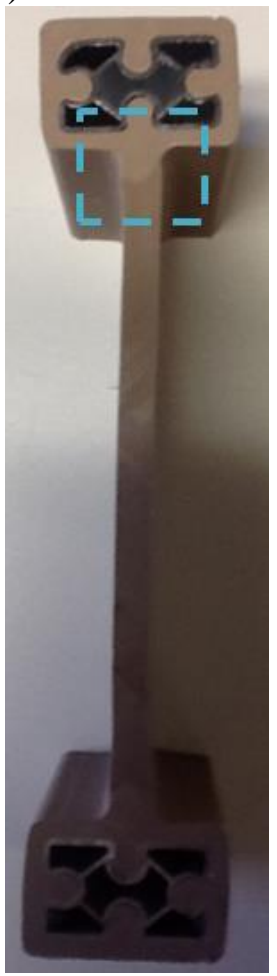

C) Beam profile view

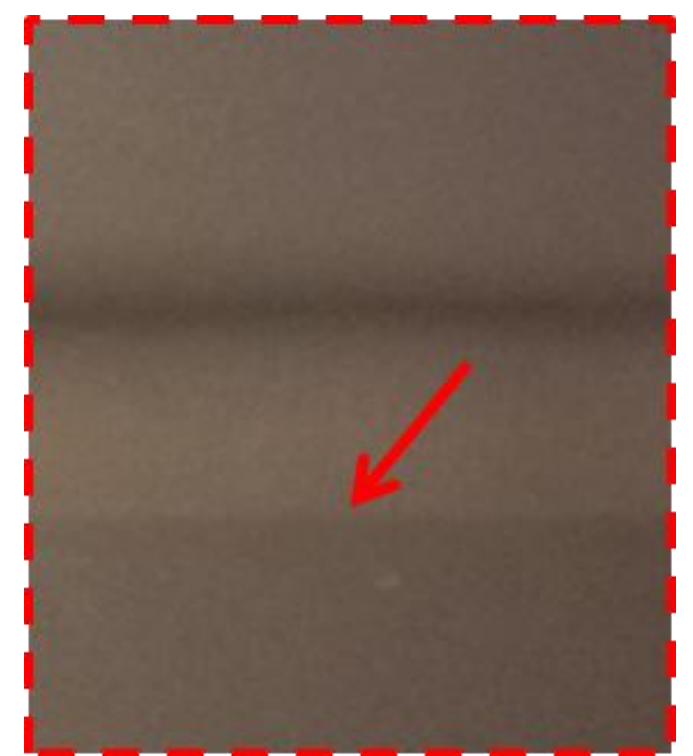

B) Side view of knit-line zoomed in

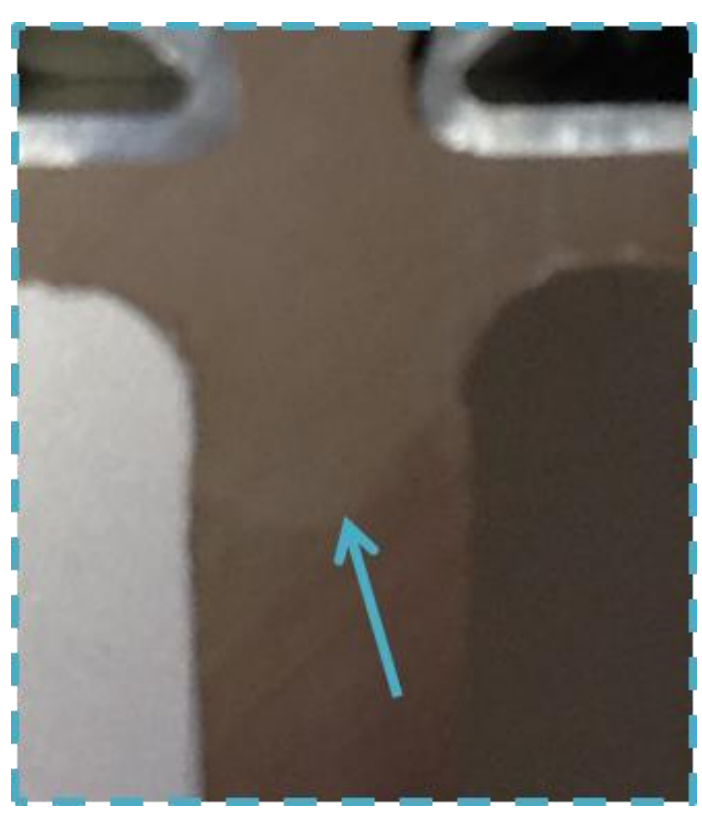

D) Profile view of knit-line zoomed in

Figure 4-8: Example of the knit-line

The composite I-beams were cut down the middle of the web and then into 6 in (flange length) segments. The web portion was cut to about 2 in at the center of each specimen. This length was 
dictated by the size of grips available for the Instron testing machine. To force the failure at the knit-line, the specimens were tapered at the base of the web to approximately 1.5 in centered (1/4 in taper on each side). To ensure uniform pulling from each side of the specimen without introducing any eccentricity or twisting, a fixture was built that could be attached to the flange of each specimen. The end of the fixture was equipped with a piece of metal exactly mimicking the dimensions and position of the web portion being pulled at the top, again, in order to avoid twisting during pulling. The data rate was set to record $5 \mathrm{pts} / \mathrm{sec}$. There were at least two possible failure modes that were originally hypothesized: separation at the knit-line with generally brittle behavior or yielding of one of the plastics. Because of the taper, the failure was forced to occur at the knit-line. However, if the strength of the bond between the plastics was stronger than the yielding of one of the plastics separately, a failure along the knit-line may not actually be observed. Therefore, at first, the extension rate was set very low at $0.05 \mathrm{in} / \mathrm{min}$. After it was determined that the controlling failure mode of the specimen was a more brittle fracture along the knit-line, a constant extension rate of $0.1 \mathrm{in} / \mathrm{min}$ was applied.

The first set of the Knit-Line Pull tests gave data on the strength of the bond between the web plastic and flange plastic of three different types of the composite beams. Refer to Figures 4-9 through 4-12 for further description of the fixture and specimen attachment and Table 4-4 for specimen details. Table 4-3 gives information on the plastics of the specimens tested and Figure 4-13 shows examples of specimens during testing. 


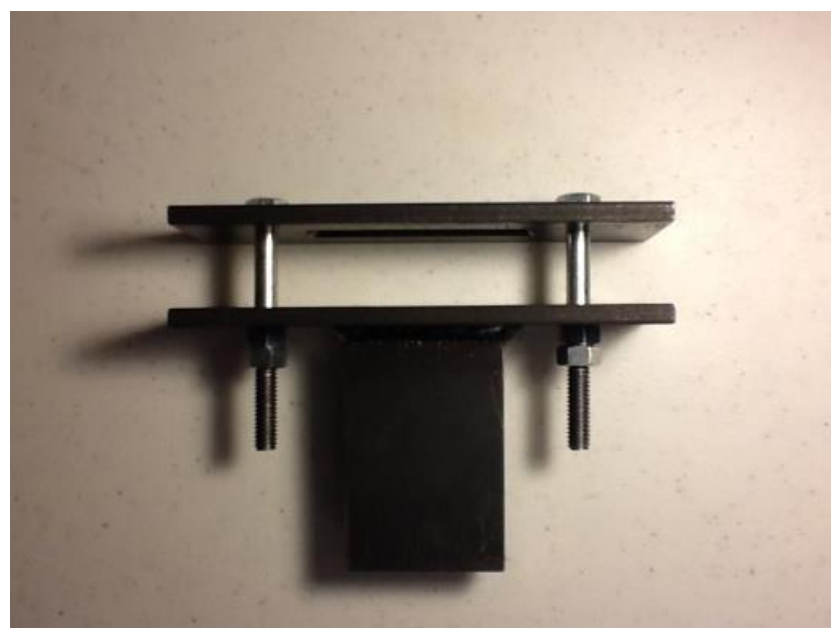

Figure 4-9: Fixture alone

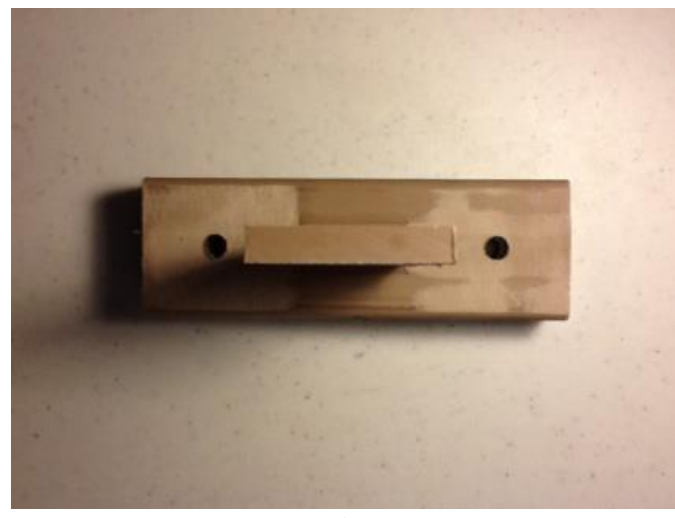

A

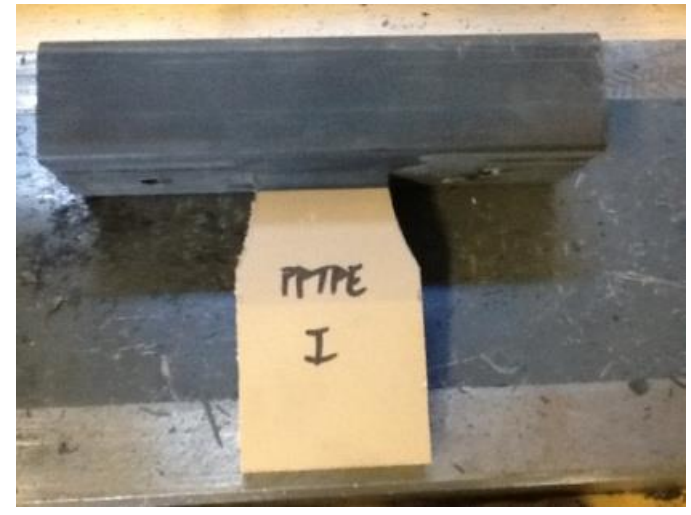

B

Figure 4-10: Example specimens alone

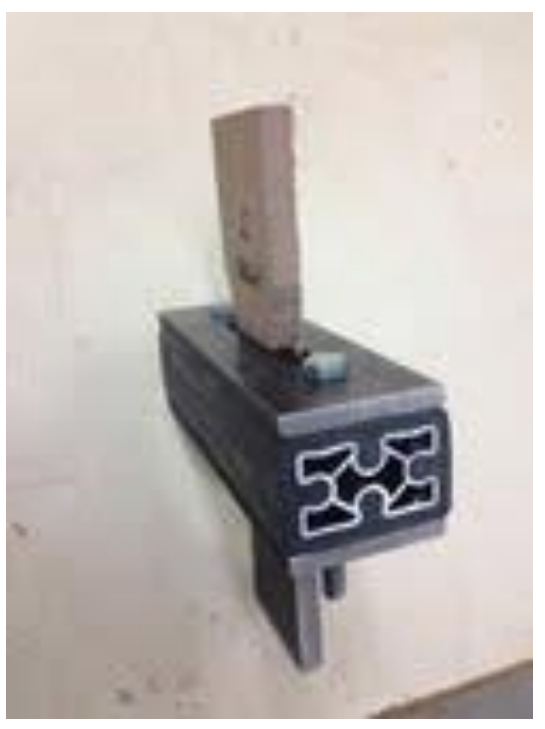

A

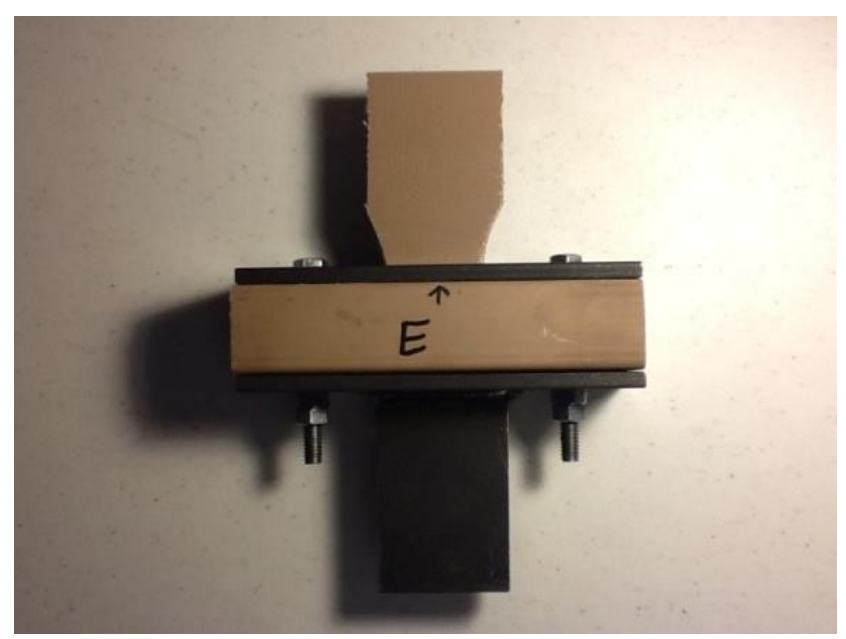

B

Figure 4-11: Specimens connected to fixture before testing 


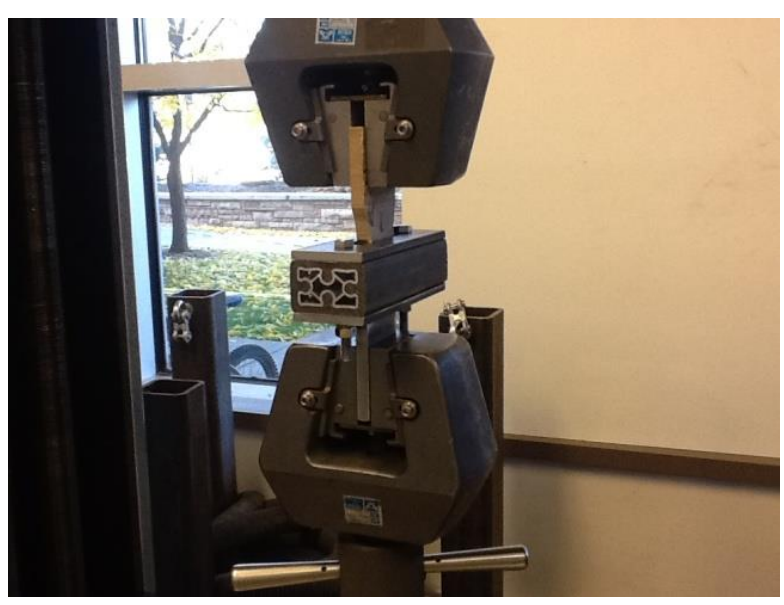

A

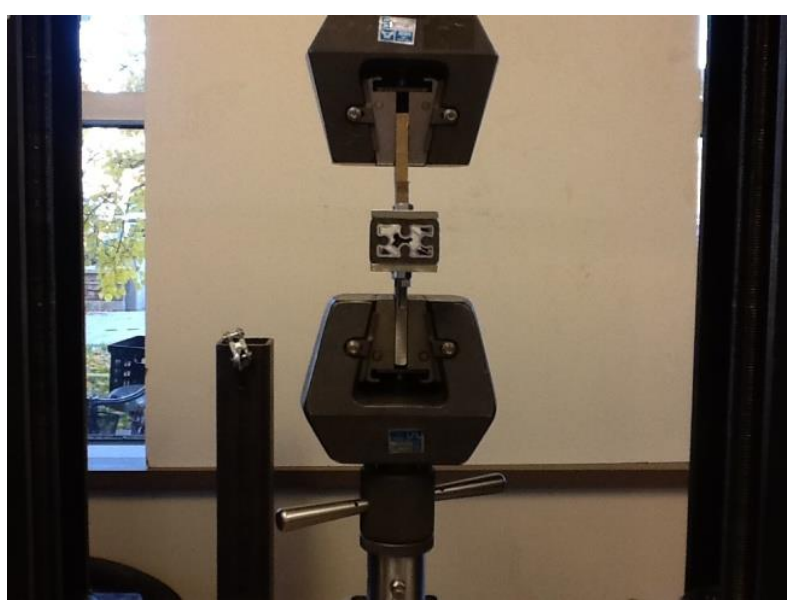

B

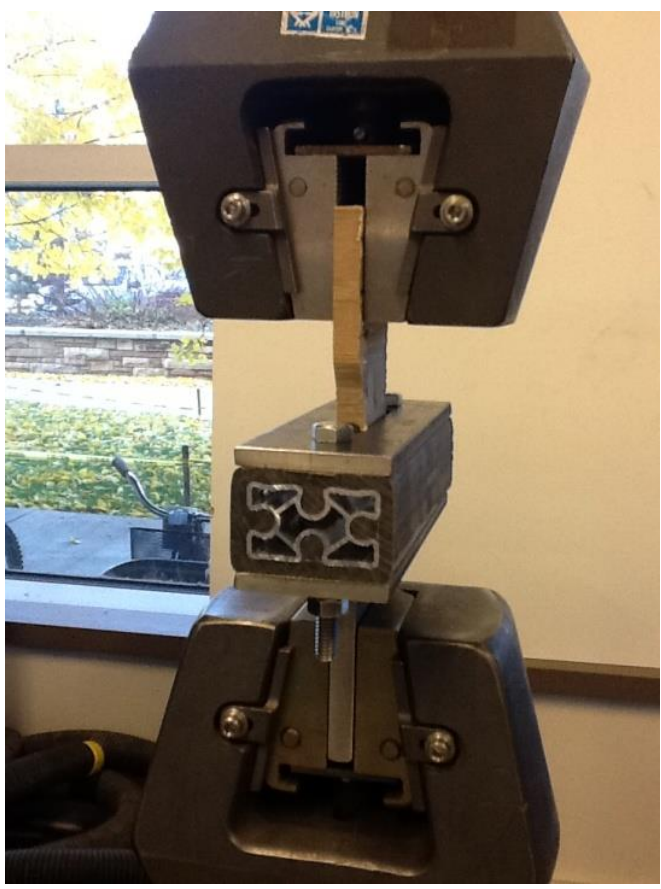

C

Figure 4-12: Specimens and fixture loaded to Instron before testing

Table 4-3: First set of Knit-Line Pull test beam details

\begin{tabular}{|c|c|c|c|}
\hline Beam Identifier & \multicolumn{1}{|c|}{ Specimens } & \multicolumn{1}{|c|}{ Web Plastic } & \multicolumn{1}{c|}{ Flange Plastic } \\
\hline Beam A - "PPTPR" & I, J, K, \& L & HDPE with 42\% talc & $\begin{array}{l}100 \% \text { polypropylene } \\
\text { thermoplastic rubber }\end{array}$ \\
\hline Beam B - "HMW" & A, B, C, \& D & HDPE with 42\% talc & $100 \%$ HMW HDPE \\
\hline Beam C - "28/15" & E, F, G, \& H & HDPE with 38\% talc & $\begin{array}{l}\text { polyethylene with 28\% } \\
\text { talc and 15\% EDPM }\end{array}$ \\
\hline
\end{tabular}




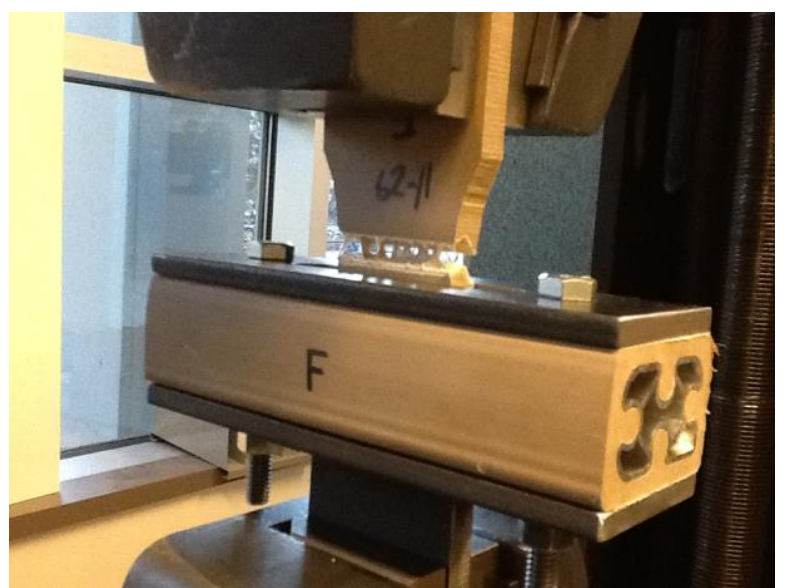

A

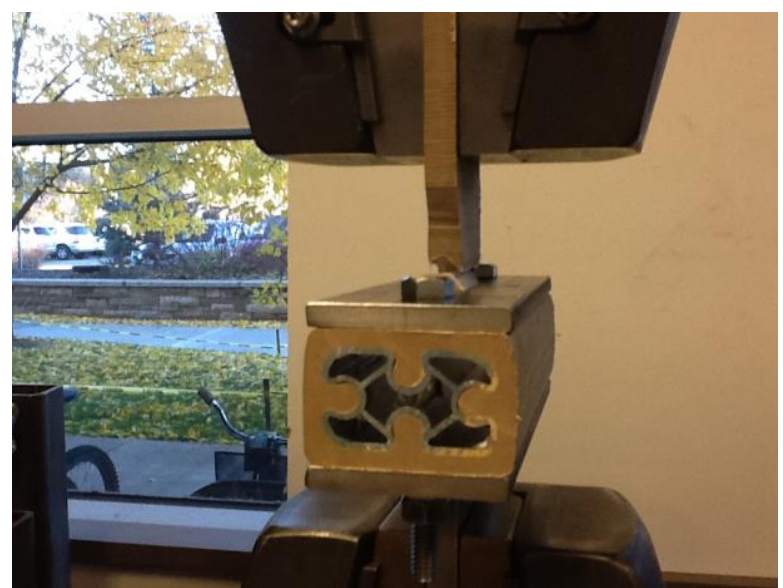

B

Figure 4-13: Example specimens during testing

The second set of Knit-Line Pull tests tested the strength at the knit-line of seven different composite beam plastic formulas. The beam types were the same as the Push-Through test specimens described above in Table 4-1, once more with the specimen numbers corresponding with the beam numbers. Again, the metal deactivator previously described is present in three of the plastics. Three specimens of each plastic type were tested and other specimen details are given in Table 4-4.

Knit-Line Pull Test - All Specimen Details

Table 4-4 gives specimen details for all Knit-Line Pull tests.

Table 4-4: Knit-Line Pull test specimen details

\begin{tabular}{|c|c|c|c|}
\hline Name & Round \# & Date Tested & Usable Data? \\
\hline A & 1 & 1 November, 2013 & yes \\
\hline B & 1 & 1 November, 2013 & yes \\
\hline C & 1 & 1 November, 2013 & yes \\
\hline D & 1 & 1 November, 2013 & yes \\
\hline E & 1 & 1 November, 2013 & yes \\
\hline F & 1 & 1 November, 2013 & yes \\
\hline G & 1 & 1 November, 2013 & yes \\
\hline H & 1 & 1 November, 2013 & yes \\
\hline
\end{tabular}




\begin{tabular}{|c|c|c|c|}
\hline I & 1 & 1 November, 2013 & yes \\
\hline $\mathbf{J}$ & 1 & 1 November, 2013 & no \\
\hline K & 1 & 1 November, 2013 & yes \\
\hline $\mathrm{L}$ & 1 & 1 November, 2013 & yes \\
\hline $1-1$ & 2 & 13 December, 2013 & yes \\
\hline $1-2$ & 2 & 13 December, 2013 & yes \\
\hline $1-3$ & 2 & 13 December, 2013 & yes \\
\hline $3-1$ & 2 & 13 December, 2013 & yes \\
\hline $3-2$ & 2 & 13 December, 2013 & yes \\
\hline $3-3$ & 2 & 13 December, 2013 & yes \\
\hline $4-1$ & 2 & 13 December, 2013 & yes \\
\hline $4-2$ & 2 & 13 December, 2013 & yes \\
\hline $4-3$ & 2 & 13 December, 2013 & yes \\
\hline $5-1$ & 2 & 13 December, 2013 & yes \\
\hline $5-2$ & 2 & 13 December, 2013 & yes \\
\hline $5-3$ & 2 & 13 December, 2013 & yes \\
\hline $8-1$ & 2 & 13 December, 2013 & yes \\
\hline $8-2$ & 2 & 13 December, 2013 & yes \\
\hline $8-3$ & 2 & 13 December, 2013 & yes \\
\hline $9-1$ & 2 & 13 December, 2013 & yes \\
\hline $9-2$ & 2 & 13 December, 2013 & yes \\
\hline $9-3$ & 2 & 13 December, 2013 & yes \\
\hline $10-1$ & 2 & 13 December, 2013 & yes \\
\hline $10-2$ & 2 & 13 December, 2013 & yes \\
\hline $10-3$ & 2 & 13 December, 2013 & yes \\
\hline
\end{tabular}

\section{Tensile Tests}

Tensile tests per ASTM D638-10 [6] covered the determination of the tensile properties of multiple web and flange plastics used for the I-beams. Two different test specimen types were cut in accordance with section 6.1.1 for rigid and semirigid plastics. Type 1 dimensions were used for the flange plastics tested and Type III dimensions for the web plastics, following the directions specified in the ASTM standard for certain thicknesses of plastics. All other details of the procedure, such as loading rate and calculations, were performed per the standard. 
The first set of Tensile tests consisted of 2 specimens, each of the web and flange plastics of the "28/15" Beam described in Table 4-3 for the Knit-Line Pull Tests. Figures 4-14 and 4-15 show the specimens before testing, front and side views, and also during testing.

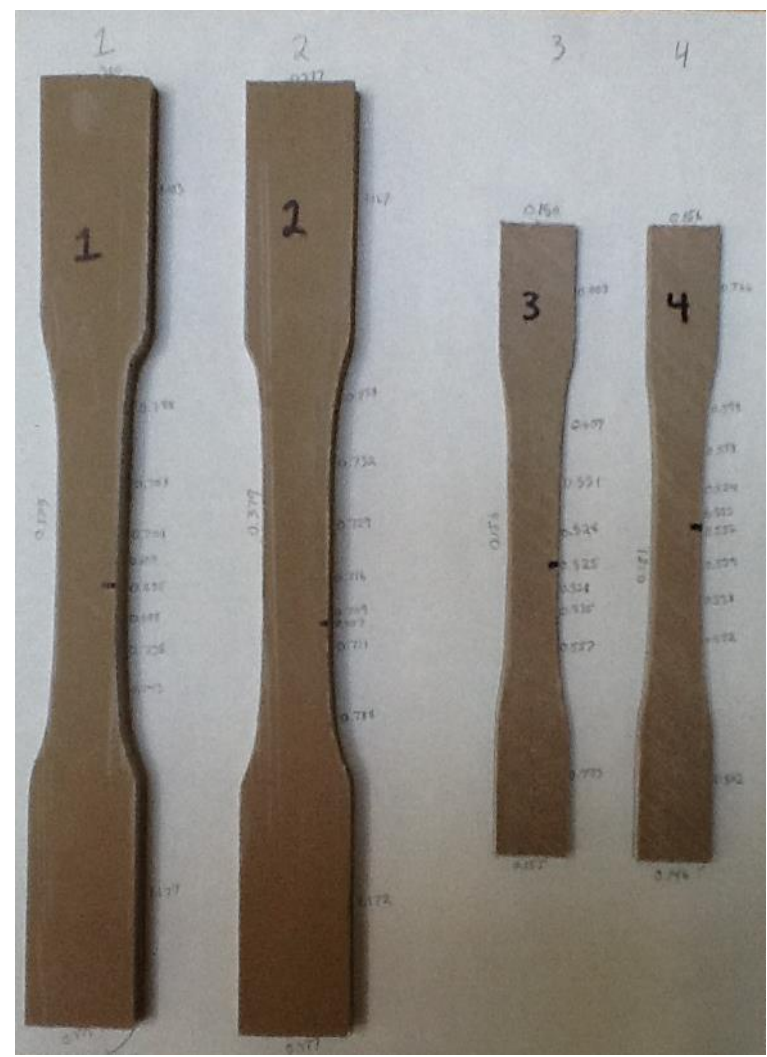

A

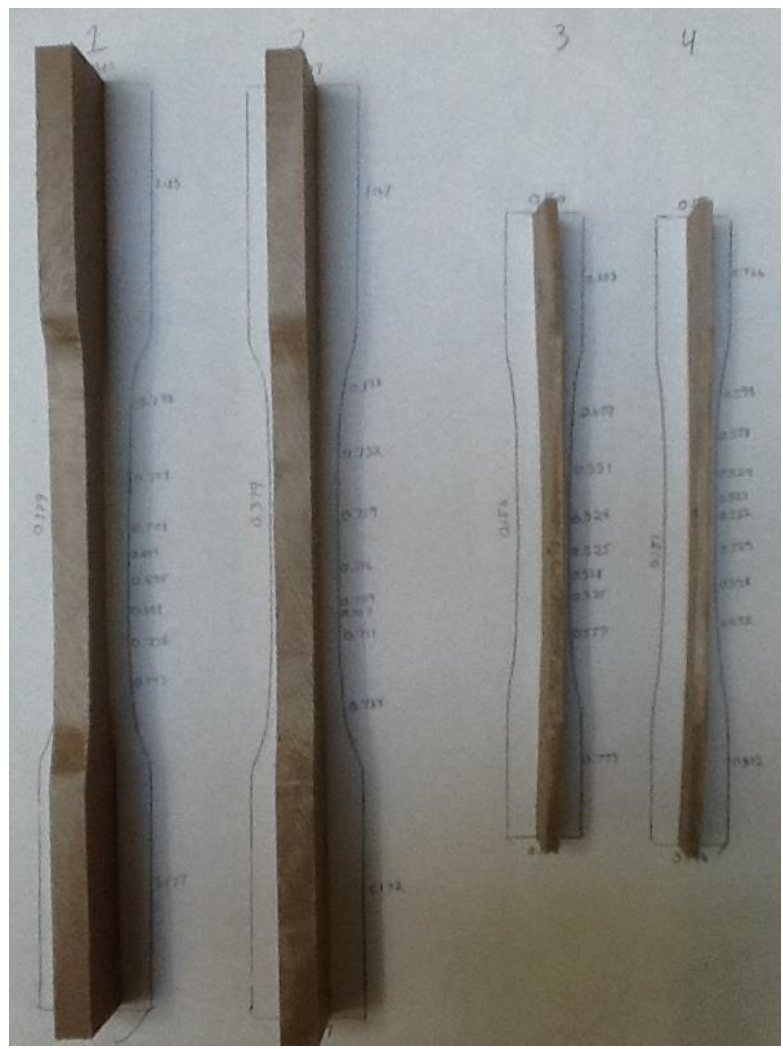

B

Figure 4-14: "28/15" Beam tensile test specimens

*dimensions on paper are not needed for reference, do not need to read 


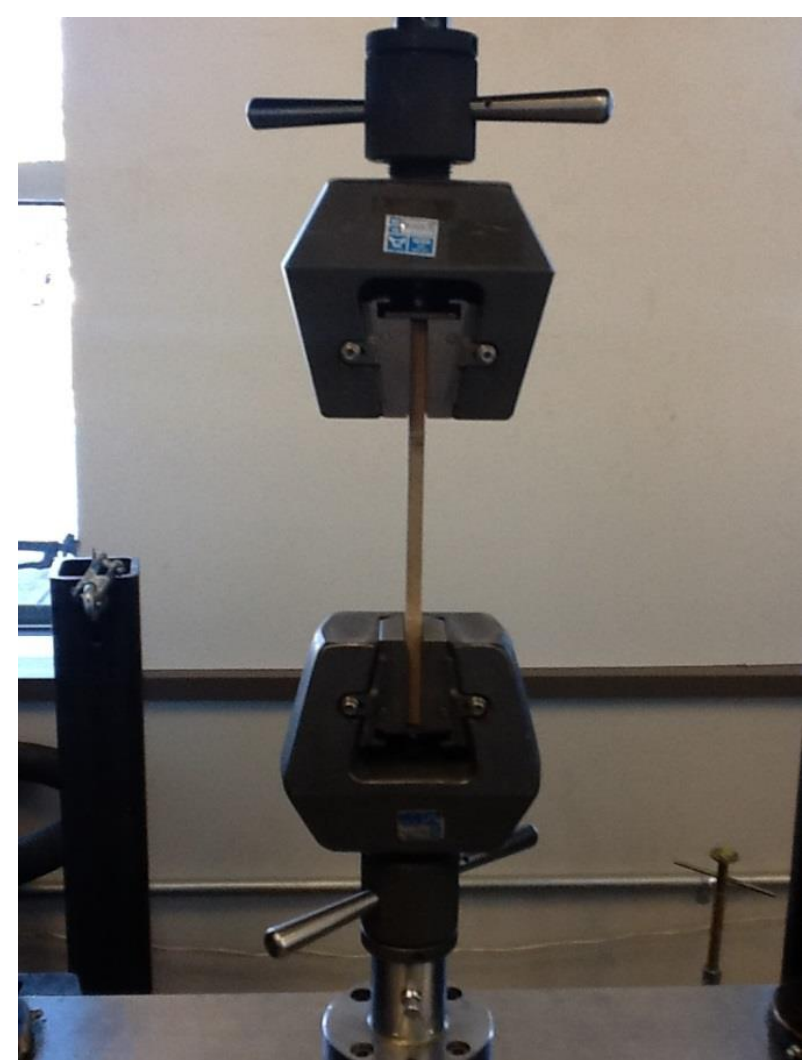

A

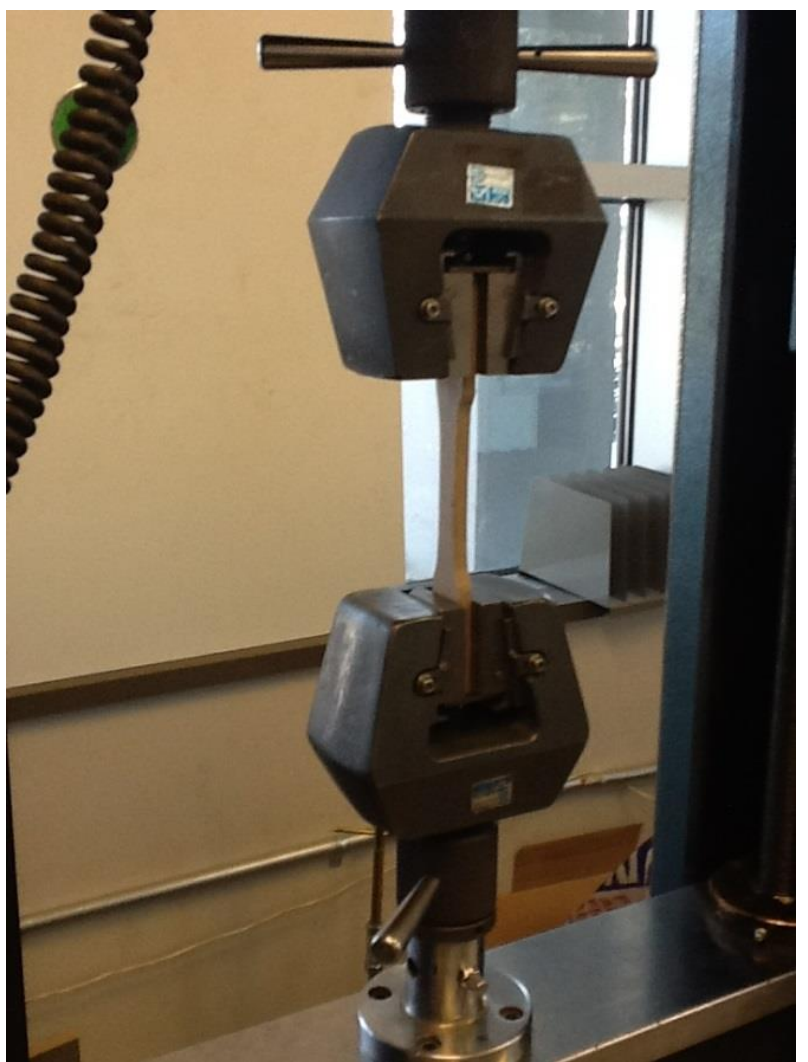

B

Figure 4-15: “28/15” Beam specimens in Instron machine

The second set of Tensile tests were conducted on plastics of the different beams described in Table 4-1. The details of each specimen are given in Table 4-5 and, again, the first number in the specimen name corresponds to the beam number given in Table 4-1 and the F or $\mathrm{W}$ in the specimen name refers to flange or web.

Tensile Test-All Specimen Details

Table 4-5 gives specimen details for all tensile tests. All specimens tested gave usable data. 
Table 4-5: Tensile test specimen details

\begin{tabular}{|c|c|c|c|}
\hline Name & Set & Date Tested & Web or Flange? \\
\hline 1 & 1 & 2 May, 2013 & web \\
\hline 2 & 1 & 2 May, 2013 & web \\
\hline 3 & 1 & 2 May, 2013 & flange \\
\hline 4 & 1 & 2 May, 2013 & flange \\
\hline $4-1 \mathrm{~W}$ & 2 & 13 December, 2013 & web \\
\hline $4-2 W$ & 2 & 13 December, 2013 & web \\
\hline $9-1 \mathrm{~W}$ & 2 & 13 December, 2013 & web \\
\hline $9-2 \mathrm{~W}$ & 2 & 13 December, 2013 & web \\
\hline $10-1 \mathrm{~W}$ & 2 & 13 December, 2013 & web \\
\hline $10-2 \mathrm{~W}$ & 2 & 13 December, 2013 & web \\
\hline $1-1 \mathrm{~F}$ & 2 & 13 December, 2013 & flange \\
\hline $1-2 \mathrm{~F}$ & 2 & 13 December, 2013 & flange \\
\hline $3-1 F$ & 2 & 13 December, 2013 & flange \\
\hline $3-2 F$ & 2 & 13 December, 2013 & flange \\
\hline $4-1 F$ & 2 & 13 December, 2013 & flange \\
\hline $4-2 \mathrm{~F}$ & 2 & 13 December, 2013 & flange \\
\hline $5-1 \mathrm{~F}$ & 2 & 13 December, 2013 & flange \\
\hline $5-2 \mathrm{~F}$ & 2 & 13 December, 2013 & flange \\
\hline $8-1 F$ & 2 & 13 December, 2013 & flange \\
\hline $8-2 \mathrm{~F}$ & 2 & 13 December, 2013 & flange \\
\hline
\end{tabular}

\section{Duration of Load Tests}

All structural materials under loading will experience creep or deform over time, with few exceptions. Creep is a known phenomenon and will be planned for in designs, but tertiary creep is not acceptable in a design. Tertiary creep is defined as increasing creep rate and can reach a point where it begins to increase exponentially. New materials must be tested to see if they exhibit tertiary creep over time and the Duration of Load test tests for this phenomenon. The procedure in ASTM D7031-04 [7] was followed to quantify the effects on multiple beams' deflection rates under a constant static load. This standard is actually in place only for wood- 
plastic composite products. However, it was the closest available standard applicable to these plastic-aluminum composite I-beams. Not all tests were run for the full 90 days if it was determined that sufficient data had been gathered, or if there was another reason to stop the test. These details will be discussed in the Results and Discussion chapter.

To support the beams during the duration of load testing, a fixture was built as shown in Figures 4-16 through 4-20. To restrain the out of plane buckling likely to occur when the beam was loaded, six lateral supports were built: one at each end bearing point and four spaced equally along the length of the fixture in between. The lateral supports were fitted with wood blocks cut to fit firmly against the beam and greased to allow for vertical movement. The end bearing points are $14 \mathrm{ft}$ apart and all beams tested were a total of $17 \mathrm{ft}$ long with $1.5 \mathrm{ft}$ of extra beam on each end. The static load was formed with solid concrete masonry units as seen in Figure 4-20. The load was symmetric about both axes in the plane of the floor so that no eccentricity or load unbalance was introduced. The platform for the load hangs freely on the beam at third points along the beam enforcing a 4-point bending configuration. Support bars were bolted to the floor and they did not touch the loading platform, but were in place for safety and support to keep the load from swinging. A dial indicator mounted at the center of the beam measured the beam's midspan deflection and was manually read at specified intervals. On average (varied slightly from test to test), hourly measurements were taken for the first eight hours, followed by three eight hour measurements, and then daily measurements for the remaining 89 days of the test. Actual loading followed the ASTM standard as closely as possible with the laboratory limitations. There were two different loading techniques used. For the first two beams tested, the bricks were added incrementally with deflection measurements taken in between. Once a final 
load was chosen for the remainder of the tests, the loading platform was lifted with a jack and then slowly brought down over a period of fifteen minutes to load the new beams.

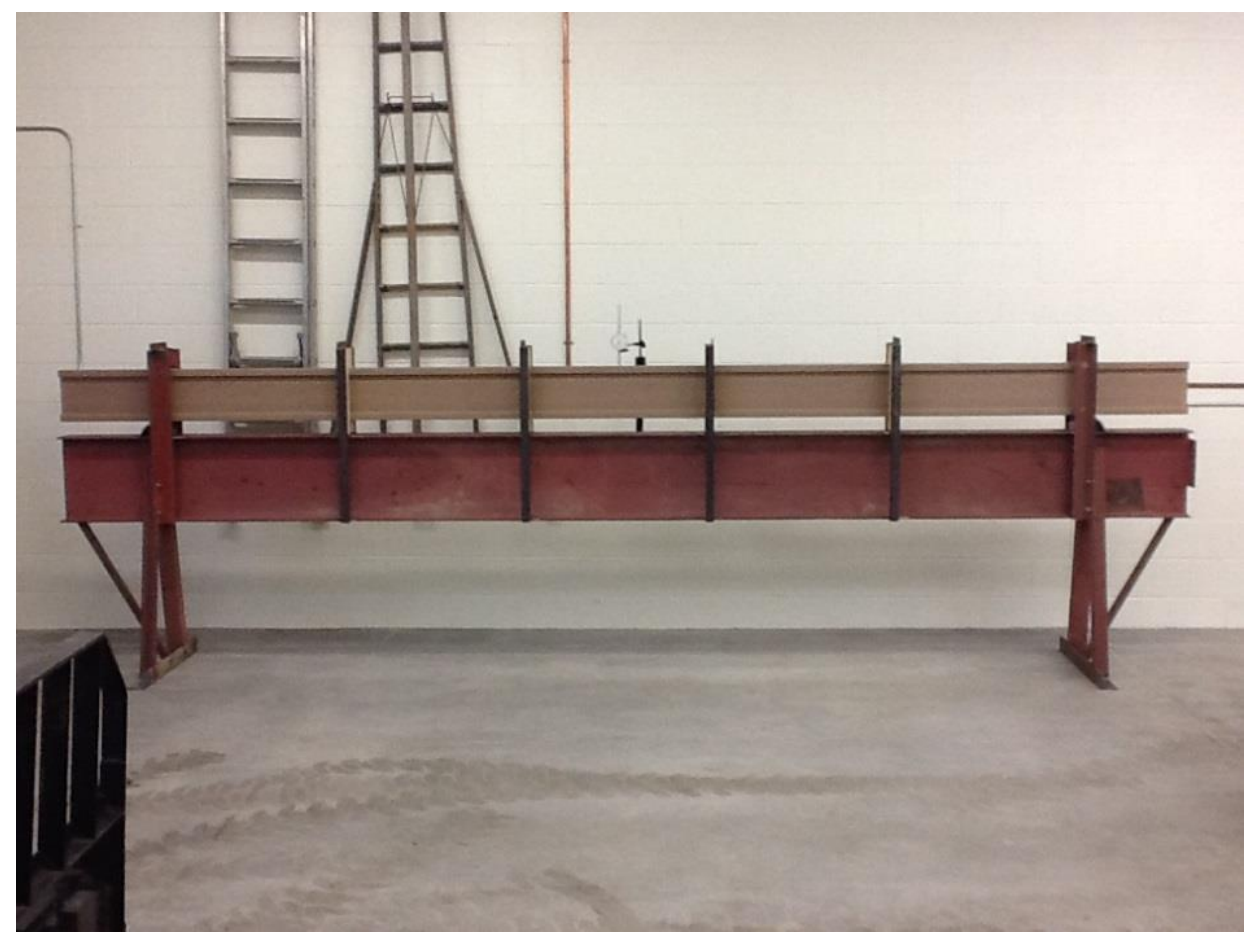

Figure 4-16: Duration of Load fixture with beam placed prior to loading.

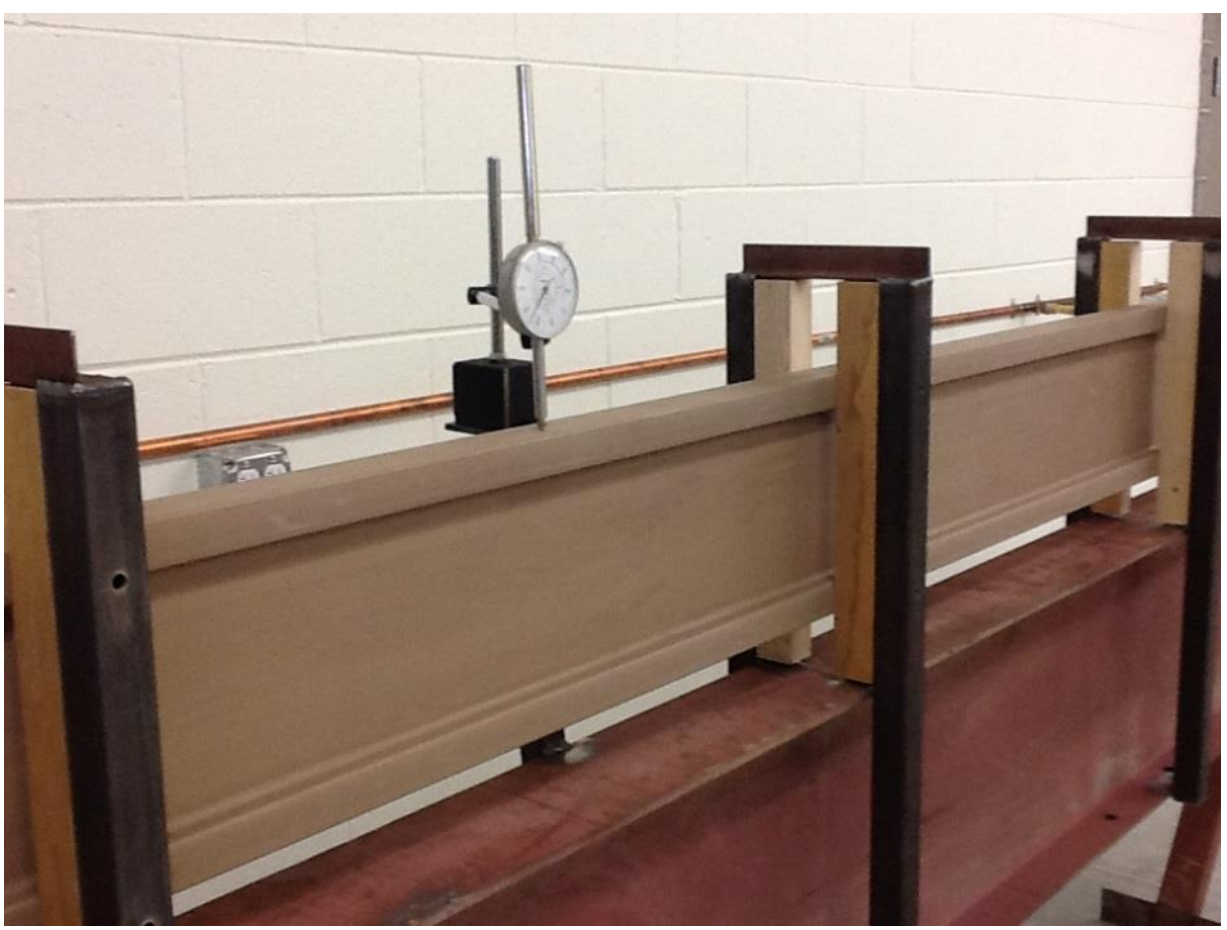

Figure 4-17: Dial indicator located at center of beam 


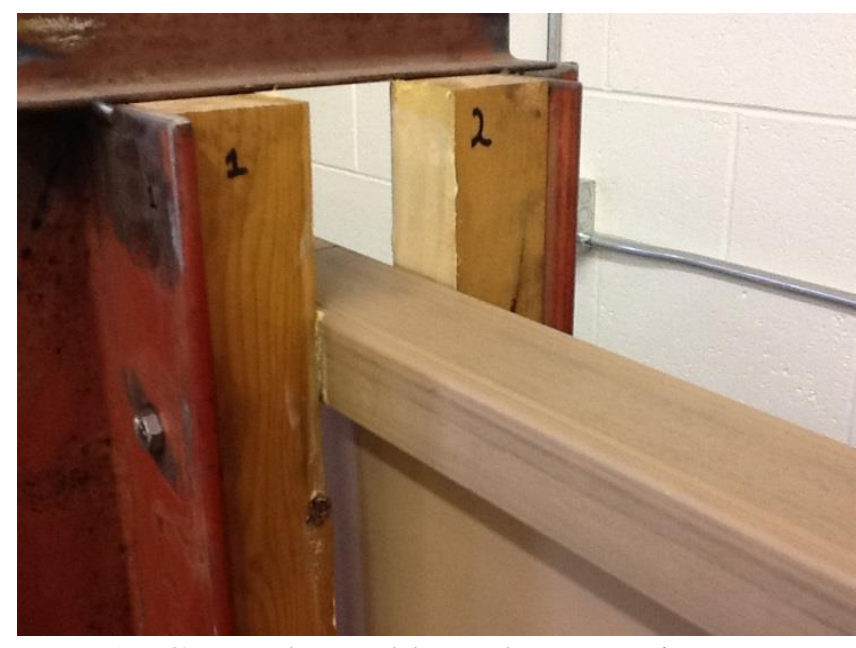

A) Greased wood lateral support inserts

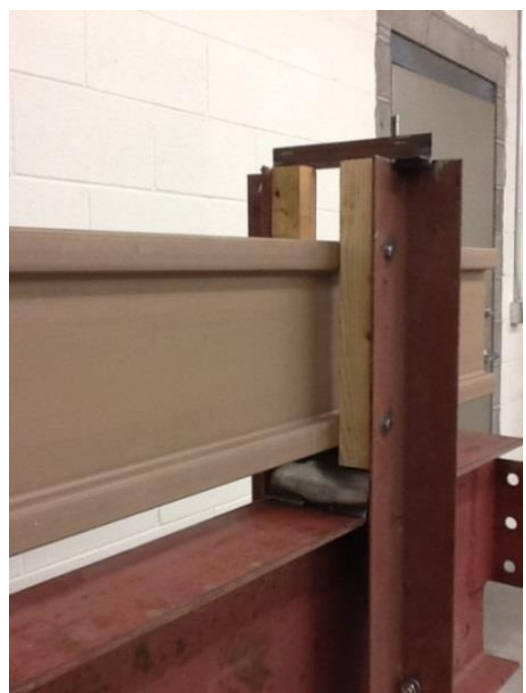

B) End bearing point

Figure 4-18: Duration of Load fixture details

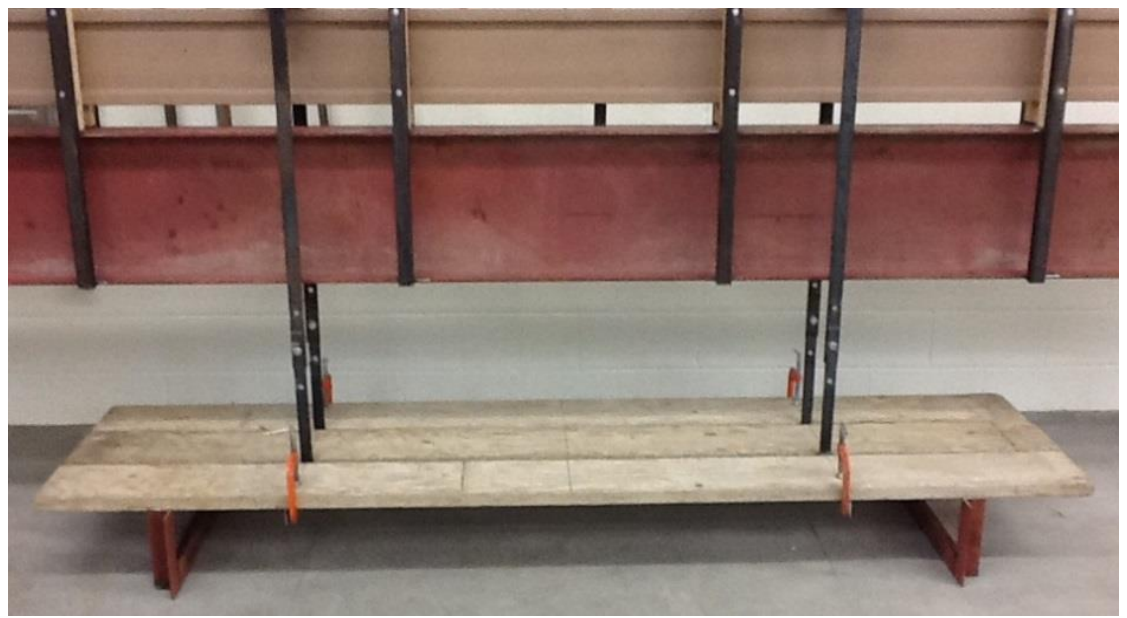

A

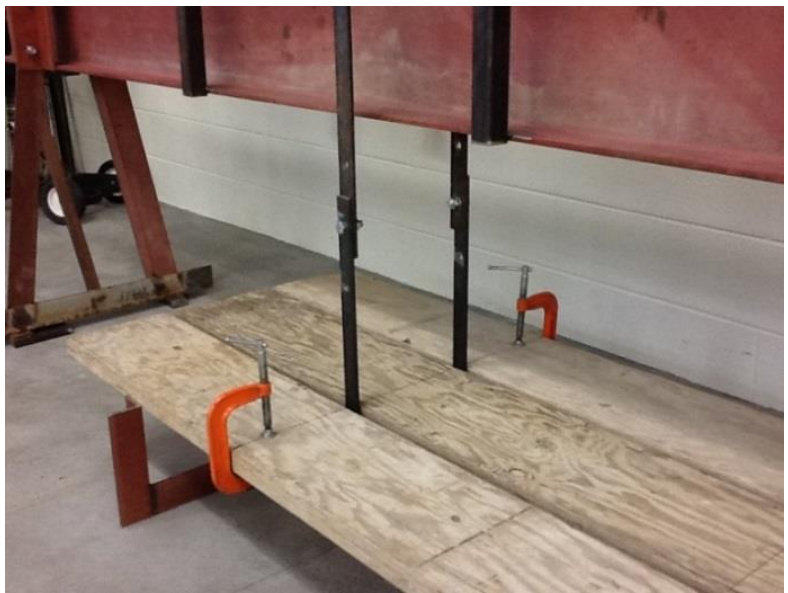

B

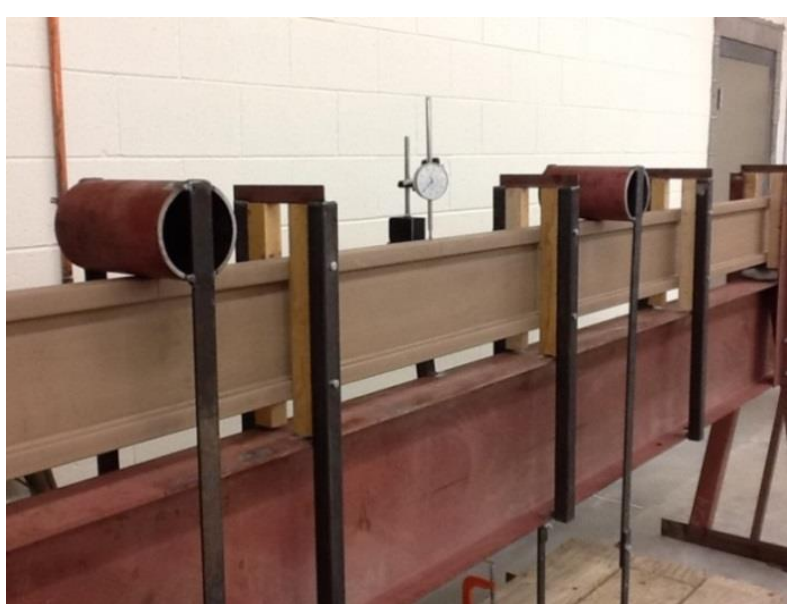

C

Figure 4-19: Loading platform details prior to loading 


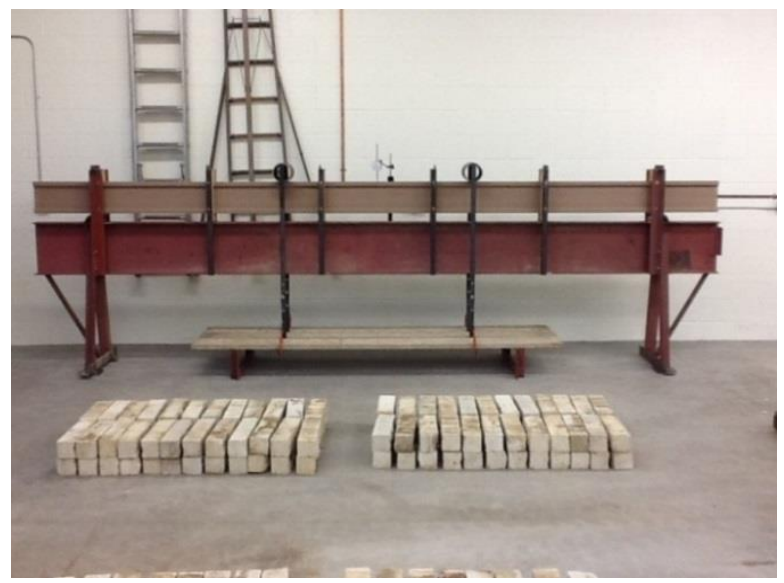

A) Before loading

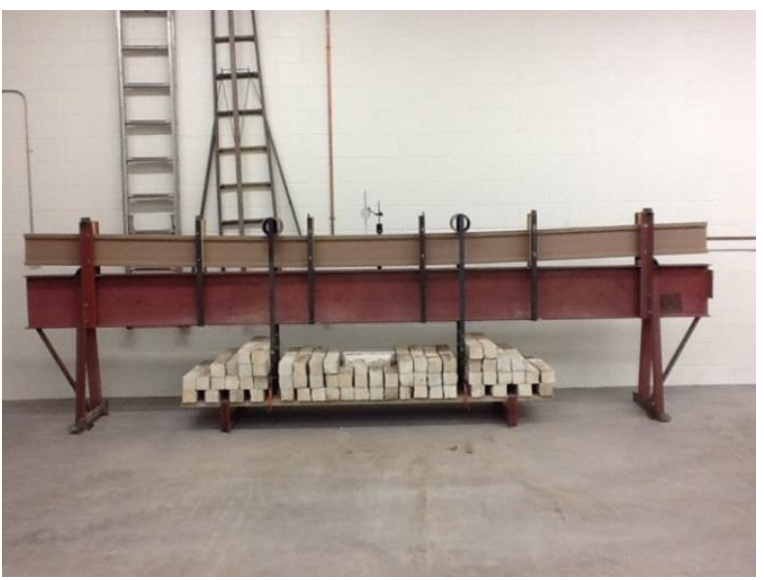

B) After loading

Figure 4-20: First Duration of Load test beam

As can be seen from Figure 4-20, after the first beam was loaded, it was very close to resting on the support beam of the fixture. It was unknown what deflection to expect for these beams and in fact this quantity was initially underestimated. After one day of loading this test was stopped. The end bearing points were cut from the fixture, metal plates were bolted in their place, and the bearing points were re-welded to the top metal plate. This gave adequate deflection spacing for the subsequent tests. The support bars for the loading platform were extended since the loading platform was raised higher. Figures 4-21 and 4-22 show these modifications. Note in Figure 4-23 that after the modifications are made, there is plenty of room left for the beam to continue to deflect as compared to Figure 4-20.

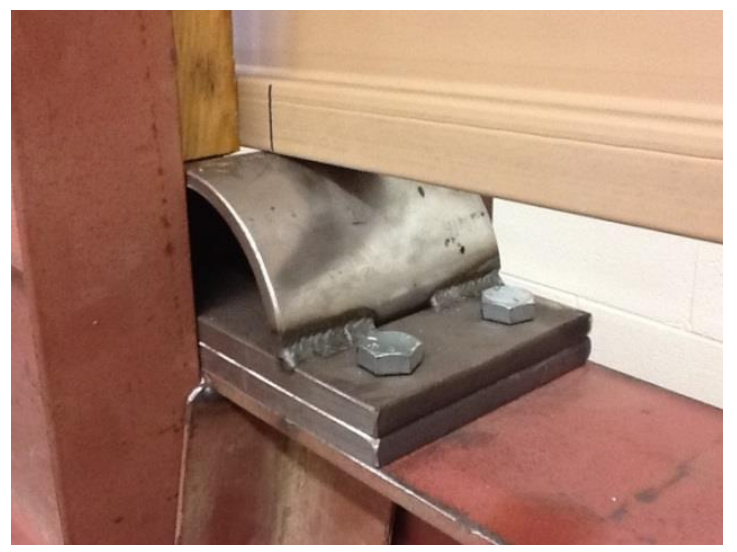

A

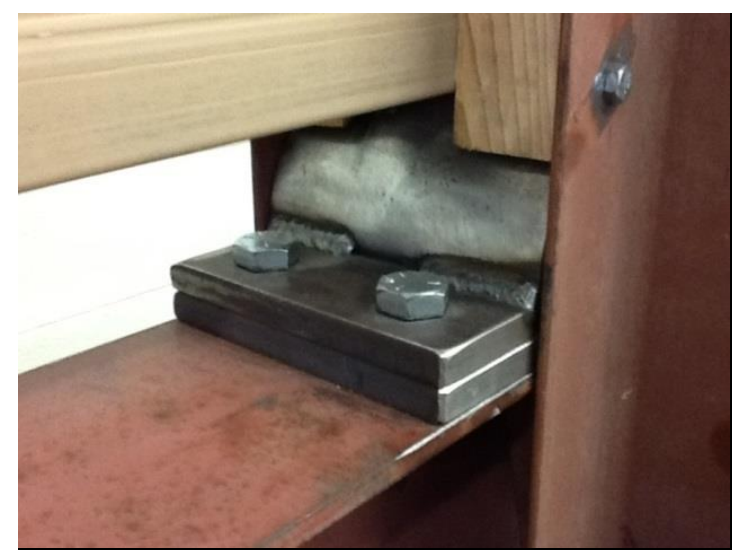

B

Figure 4-21: End bearing points raised with metal plates 


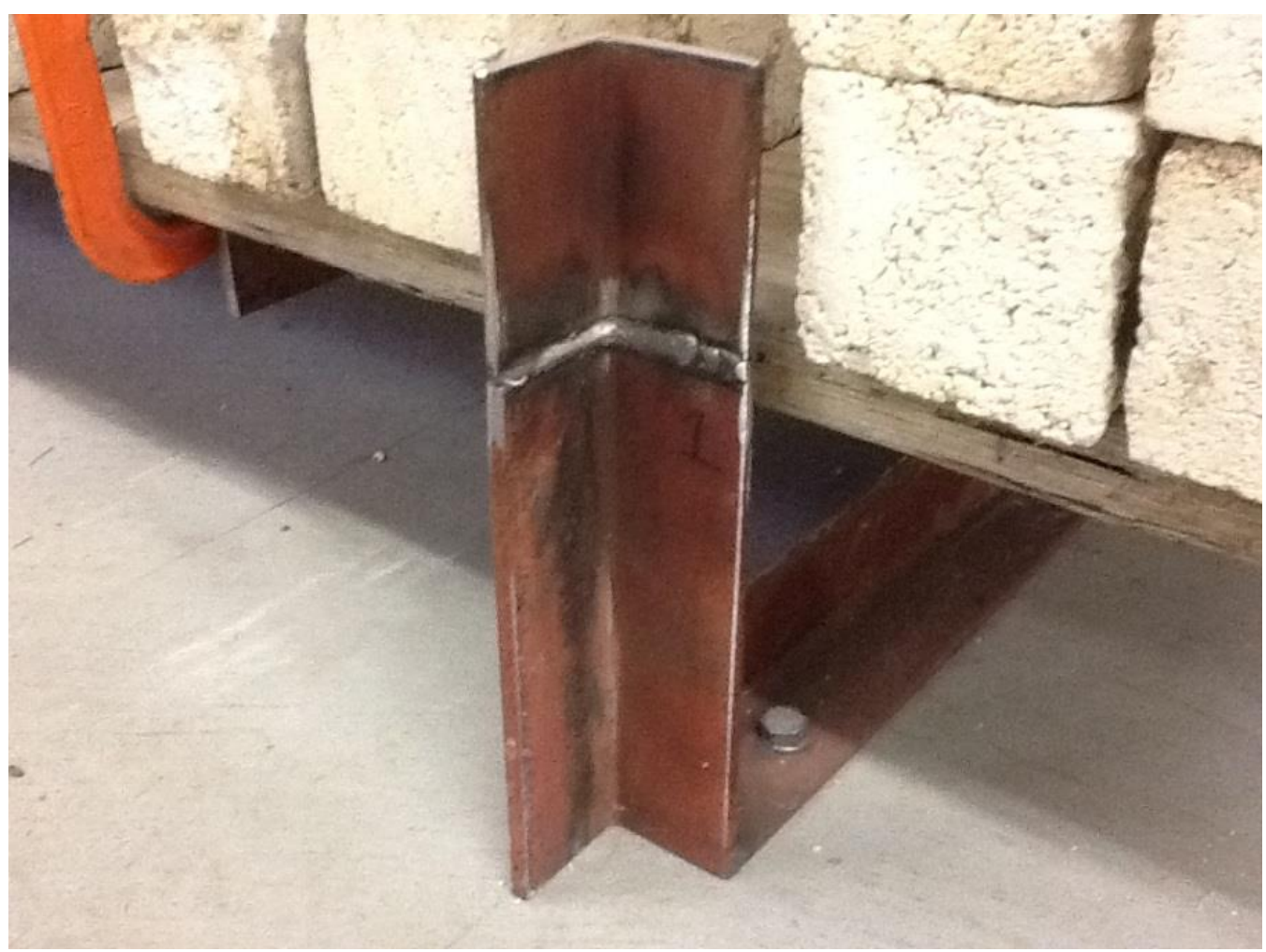

Figure 4-22: Extended support bar for loading platform

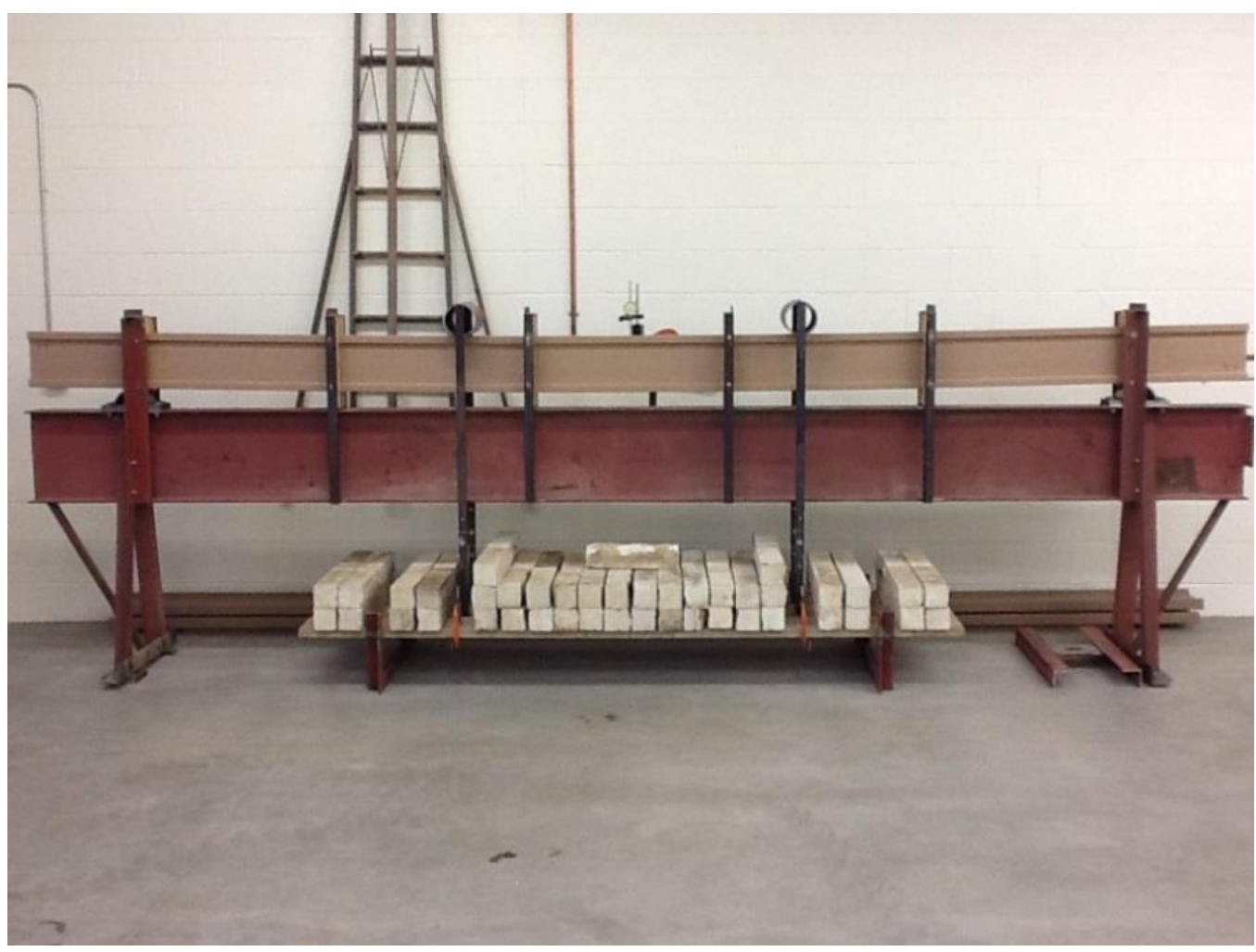

Figure 4-23: Loaded beam after modifications were made to fixture 


\section{Duration of Load Test - All Specimen Details}

Table 4-6 gives specimen details for all duration of load tests. An identical test fixture was constructed for the latest testing and therefore two beams are currently loaded. The Duration of Load Number (DoL \#) refers to a general order that the beams were tested in order to make explanations clearer in the Results and Discussion chapter.

Table 4-6: Duration of Load test specimen details

\begin{tabular}{|c|l|l|r|l|}
\hline DoL \# & \multicolumn{1}{|c|}{ Beam Identification } & \multicolumn{1}{|c|}{ Date Test Started } & \multicolumn{1}{c|}{ Load (lbs) } & \multicolumn{1}{|c|}{ Length of Test } \\
\hline 1 & 28-15 Bandburry Line (1) & 27 April, 2013 & 2464 & 27 hours \\
\hline 2 & 28-15 Bandburry Line (2) & 3 May, 2013 & 1680 & 90 days \\
\hline 3 & WP Production Line Replication & 18 September, 2013 & 1680 & 63 days \\
\hline 4 & 5B from Table 3-2 & 14 December, 2013 & 1680 & 12 days \\
\hline 5 & 1B from Table 3-2 & 8 January, 2014 & 2200 & on going \\
\hline 6 & 10B from Table 3-2 & 8 January, 2014 & 2200 & on going \\
\hline
\end{tabular}




\section{Chapter 5 : Results and Discussion}

\section{Push-Through Tests}

\section{Linear relationship}

The first set of Push-Through tests was performed to evaluate whether or not the strength of the bond between the aluminum and the plastic have a linear relationship with the length of beam. Table 5-1 and Figure 5-1 summarize the results from the specimens of this set of tests and Figure 5-2 gives visuals of the specimens after testing. The strength was calculated by dividing the maximum load by the length of the specimen to quantify it as a force per length. This will normalize all the lengths to be compared with each other and establish if the linear relationship described above exists. One change made after testing the 6 in specimen, was that the test cutoff was changed from a decreasing load limit of $1000 \mathrm{lb}$ to a maximum extension of $0.5 \mathrm{in}$. This was done to gather more data. The highlighted row in Table 5-1 is the specimen whose data was discarded and not used when calculating the average strength for reasons described below. The highlighted cell is the average value.

Table 5-1: Push-Through test linear relationship results

\begin{tabular}{|c|r|r|l|r|}
\hline Specimen & Max Load (lb) & Total Extension (in) & Test Cutoff & Strength (lb/in) \\
\hline 6in & 2049.9 & 0.35 & decreasing to 1000 lb & 341.7 \\
\hline 8in & 2272.2 & 0.50 & 0.5 in extension & 284.0 \\
\hline 12 in(a) & 3492.1 & 0.50 & 0.5 in extension & 291.0 \\
\hline 12 in(b) & 4633.6 & 0.50 & 0.5 in extension & 386.1 \\
\hline \multicolumn{4}{|c|}{ Average [excluding 12in(b)] } & $\mathbf{3 0 5 . 6}$ \\
\hline
\end{tabular}




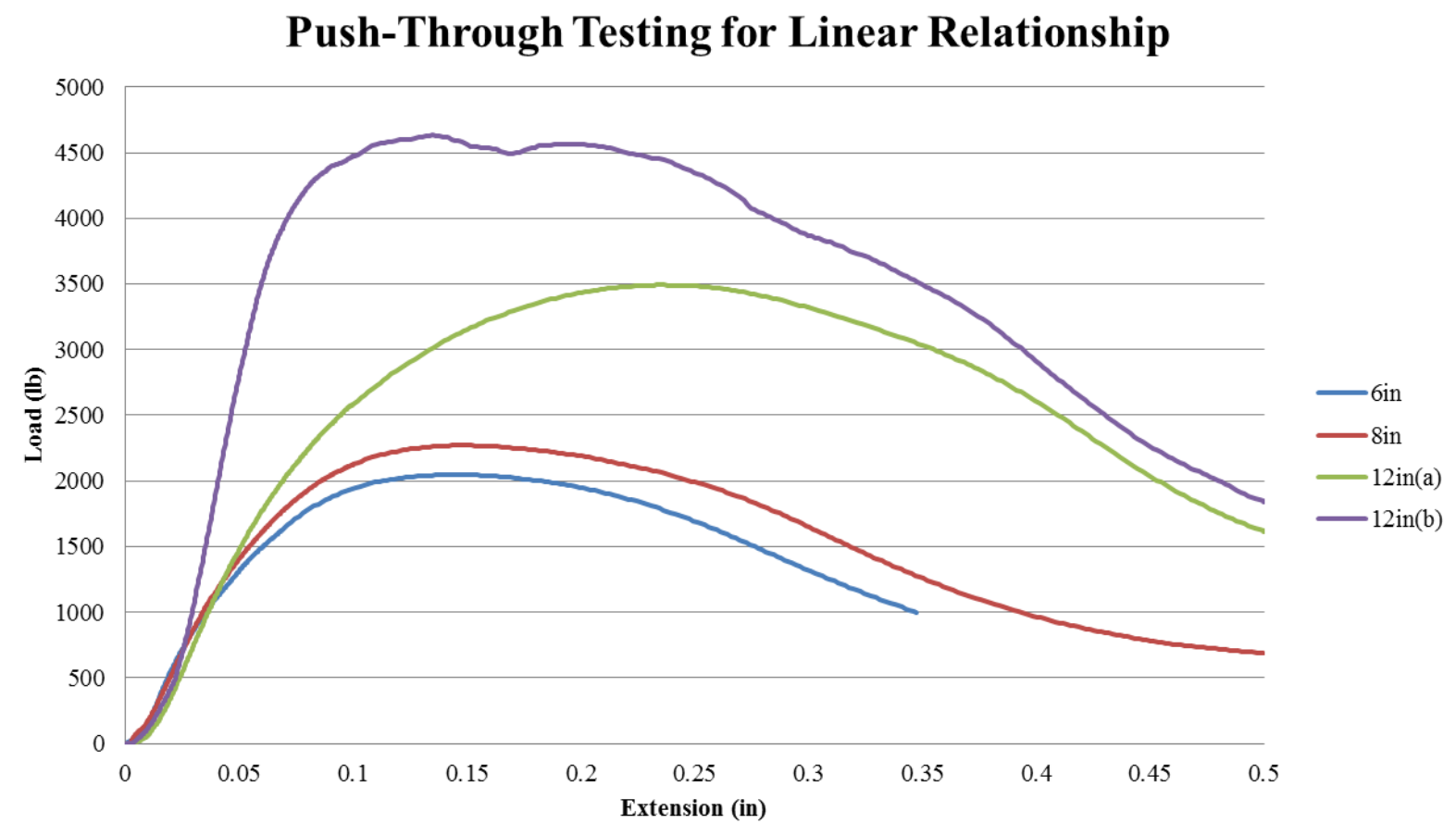

Figure 5-1: Push-Through test results for the 6 in, 8 in, and 12 in specimens

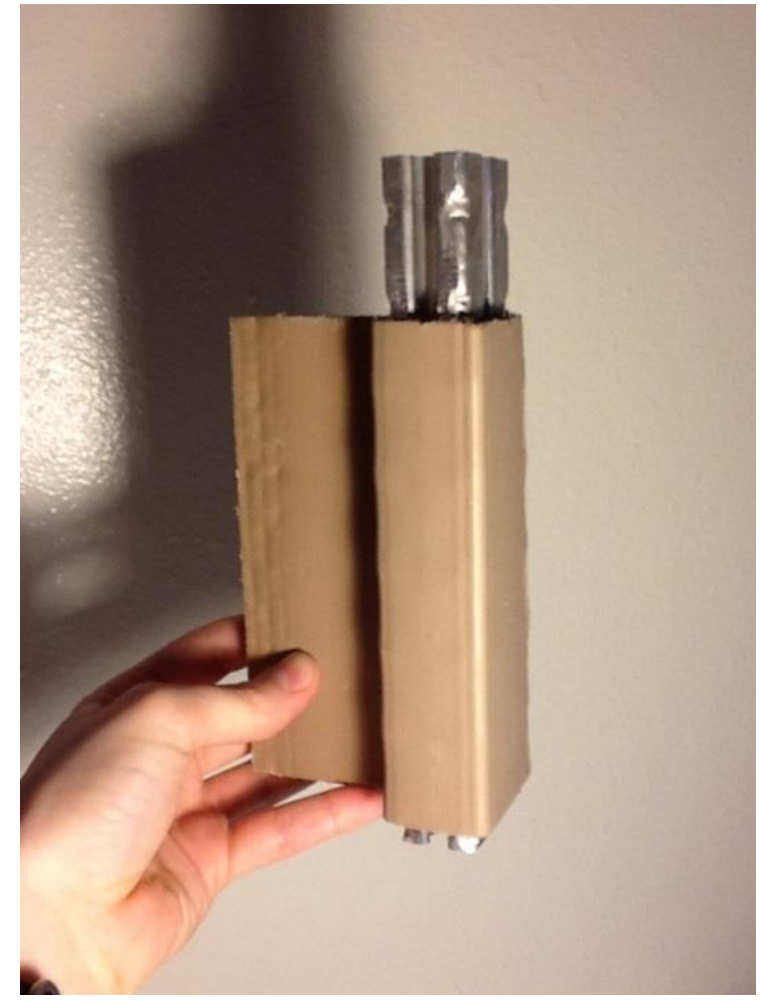

A) 6 in specimen

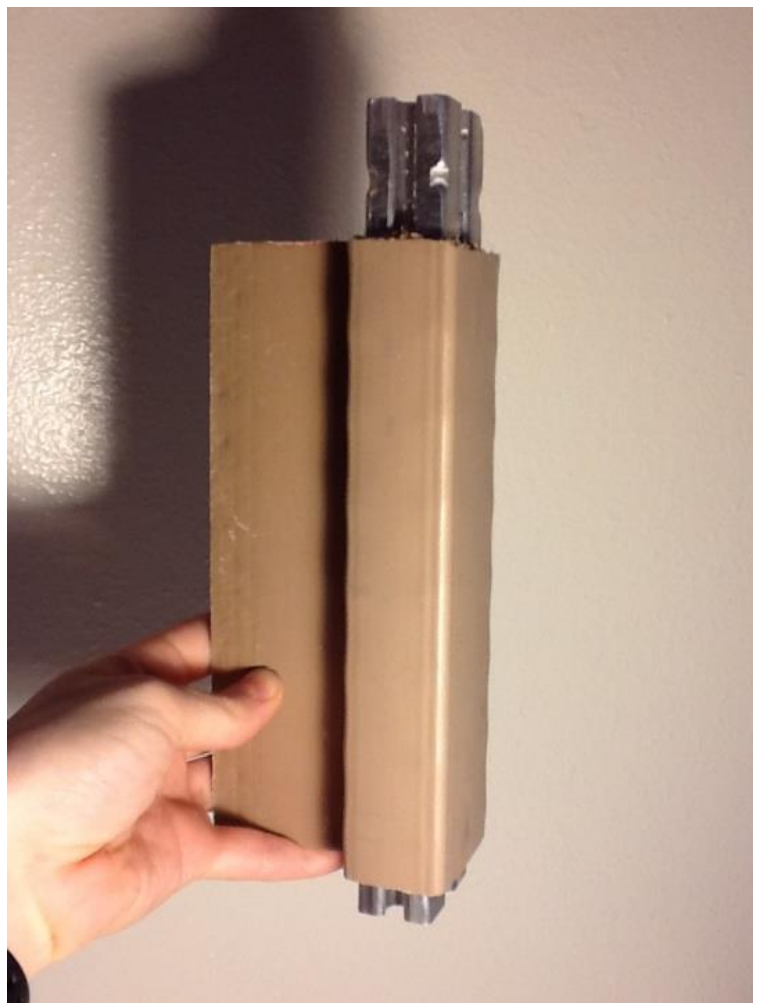

B) 8 in specimen 


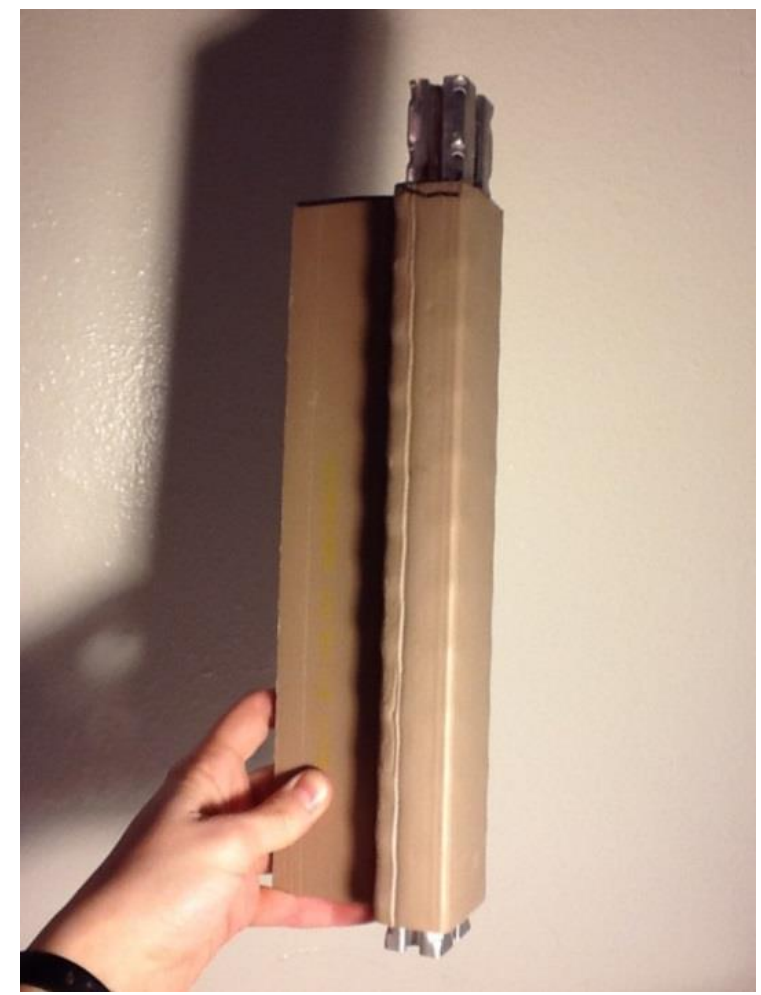

C) 12 in(a) specimen

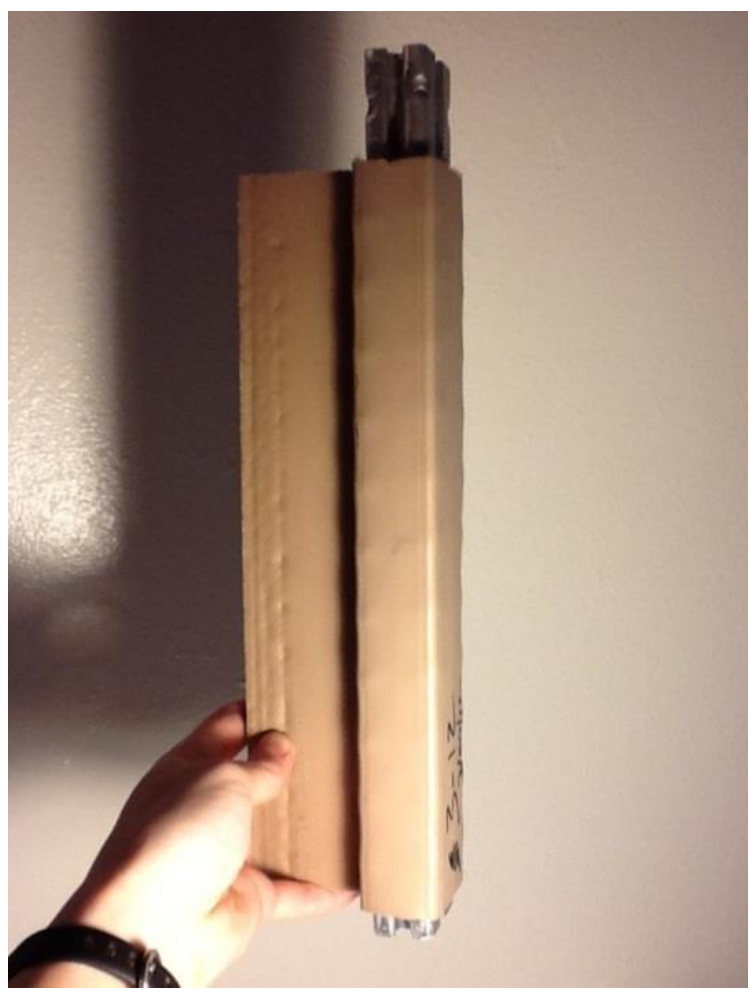

D) 12 in(b) specimen

Figure 5-2: Push-Through linear relationship test specimen after testing

One artifact of the testing was the nature of the surface of the flange after the testing was completed. Figure 5-2 shows that the specimens all "bulged" out along the edges at intervals equal to the distance between the deboss regions along the edges (best shown along left edge of 12in(a) specimen). This is because as the aluminum slipped through the plastic, the plastic originally in the deboss was "pushed" out of the way for the slip to occur, causing the bumps to form.

The strength value of the $12 \mathrm{in}(\mathrm{b})$ specimen was much larger than the values of the other three tests. The line corresponding with the 12in (b) specimen on Figure 5-1 does not match the trends of the other lines. It was discovered after testing that this was due to the specimen not being completely lined up with the support plate and the plate stopped the aluminum from pushing through at first. Figure 5-3 shown below shows where the aluminum in the 12 in(b) specimen 
was being hindered by the plate. The arrows indicate the aluminum that was pushed into the profile during testing. Hence the data from this specimen was not included in any conclusions that resulted from this study.

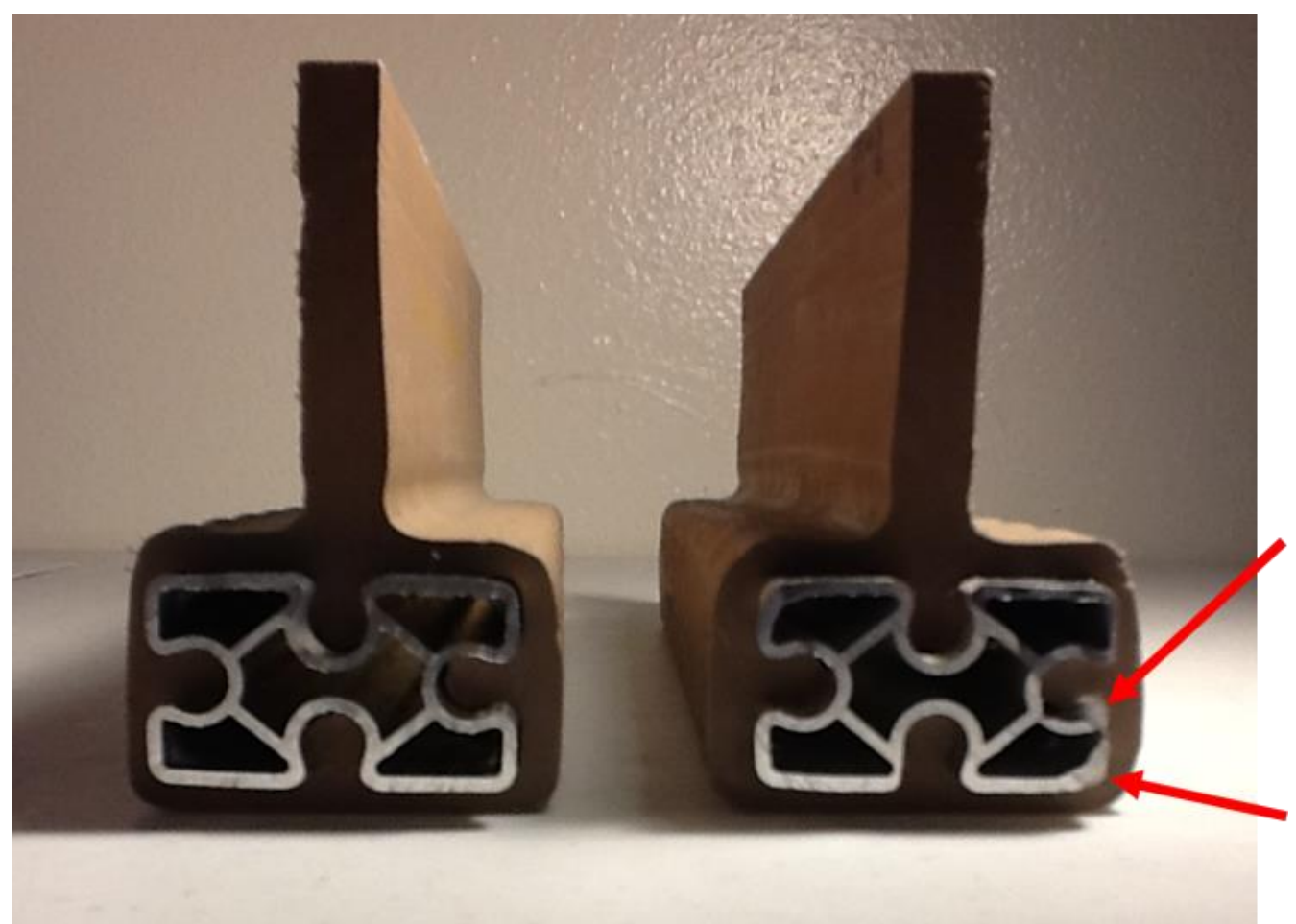

Figure 5-3: 12in(a) Specimen (left) vs. 12in(b) Specimen (right) Showing deformed aluminum that was blocked by push-through plate.

Subsequent tests adjusted for this testing flaw by lifting the support plate higher with two other plates (not blocking the aluminum profile cutout) and then a mirror was used to double check that the specimen was aligned with the plate. This also allowed for the specimen to be tested further than a deflection of 0.5 in, which generated more data. It was also concluded from the gathered data that a smaller load cell could be used, since at this point the general range of the strength and load required was known. Using a smaller load cell will allow for better resolution in the data gathered.

The force required to push the aluminum through the plastic in the 6 in, 8 in, and 12 in(a) (eliminating 12in(b)) specimens were $341.7 \mathrm{lb} / \mathrm{in}, 284.0 \mathrm{lb} / \mathrm{in}$, and $291.0 \mathrm{lb} / \mathrm{in}$, respectively. 
These values are relatively close, with an average value of $305.6 \mathrm{lb} / \mathrm{in}$. This value represents an estimate of the strength between the plastic and aluminum in this type of composite I-beam, "28/15" flange plastic previously described. Also, because the strength values per inch were so close, a linear relationship is assumed between the strength between the two materials and the length of the beam. The strength of the 12 in(a) specimen fell between the 6 in and 8 in specimens. This shows the strength per length is not necessarily increasing or decreasing with longer length, which further proves a linear relationship. The linear relationship is important for future testing because it appears that specimens of any reasonable length can be tested and properties of any length of composite I-beam can be extrapolated from their results.

The failure mechanism at the deboss region is also of critical importance. This property of the composite I-beams was studied using a numerical model built in ABAQUS. This is described in the Numerical Model of Deboss Region chapter. To see what occurred on the inside of the flanges between the aluminum and the plastic at the deboss regions during the Push-Through test, the beams were cut through after testing to expose the failed deboss regions. Examples of the cut specimens are shown in Figure 5-4. As was the case for all failed specimens, the plastic sheared and then was "pushed" out of the way as the deboss continued to extend. The question was to determine at what point during the testing this shearing failure occurred. This was difficult to assess using only the experimental evidence, and is therefore further investigated using the numerical model. 


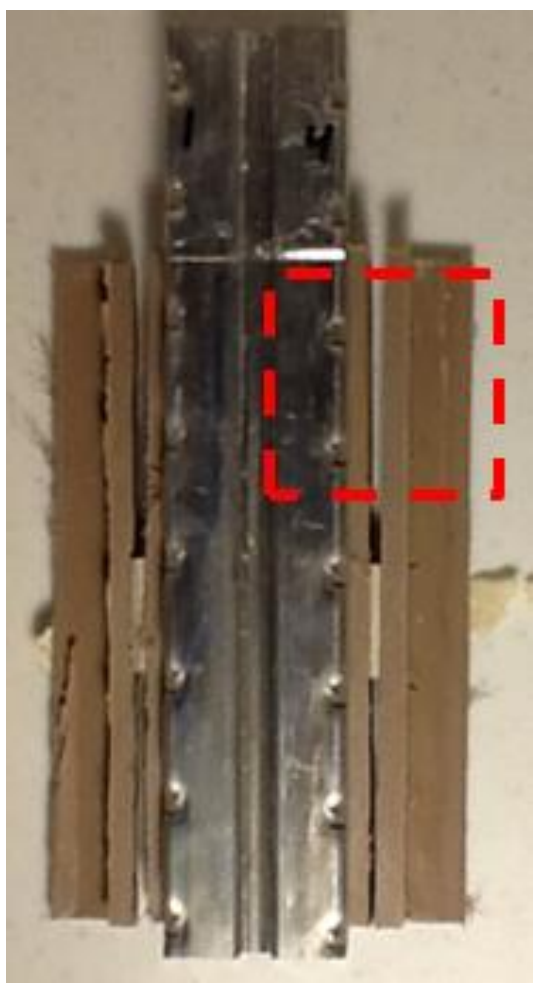

A) Cut specimen

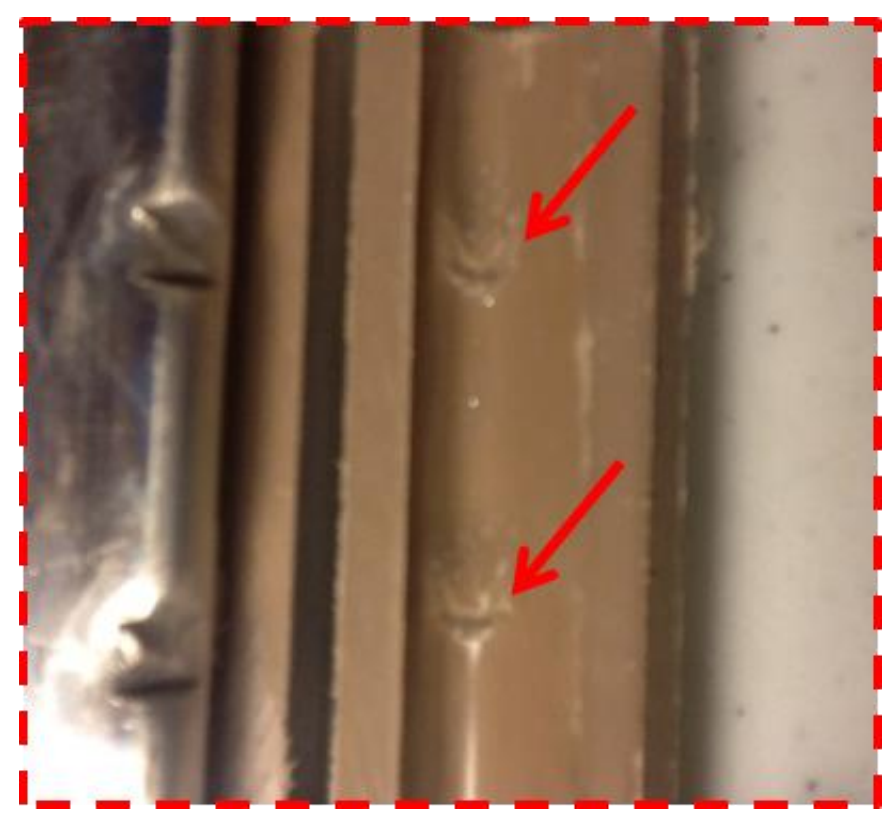

B) Cut specimen zoomed view

Figure 5-4: Example and typical inside of cut specimens. Can see plastic deboss region shearing (shown with arrows) downward from force applied during the testing.

\section{Aluminum profile comparisons}

The second set of Push-Through tests was performed to give strength comparisons between the aluminum and plastic of three different composite I-beam deboss geometries. Details of the geometry dimensions of the three different aluminum profiles can be found in the Materials and Geometry chapter. Again, all specimens had "28/15" flange plastic. Table 5-2 and Figures 5-6, 5-8, and 5-13 summarize the results from the specimens of this set of tests and Figures 5-5, 5-7, and 5-12 give visuals of the specimens after testing. The highlighted rows are the specimens that were discarded for reasons discussed later in this chapter. The highlighted cells are the average strength values for each aluminum profile. Specimens 1-4 had aluminum profile 1, specimens 58 had aluminum profile 2 , and specimens $9-12$ had aluminum profile 3 . The strength was calculated the same way as described for the first set of Push-Through tests. 
Table 5-2: Push-Through test deboss geometry comparison results

\begin{tabular}{|c|c|c|c|c|}
\hline Specimen & Max Load (lb) & Total Extension (in) & Test Cutoff & Strength (lb/in) \\
\hline 1 & 1728.8 & 0.50 & 0.5 in extension & 288.1 \\
\hline 2 & 1780.5 & 0.50 & 0.5 in extension & 296.8 \\
\hline 3 & 1875.8 & 1.00 & 1.0 in extension & 312.6 \\
\hline 4 & 1804.7 & 1.50 & 1.5 in extension & 300.8 \\
\hline \multicolumn{4}{|r|}{ Average } & 299.6 \\
\hline 5 & 1951.0 & 0.50 & 0.5 in extension & 325.2 \\
\hline 6 & 2010.7 & 0.50 & 0.5 in extension & 335.1 \\
\hline 7 & 1924.8 & 1.14 & 1.14 in extension & 320.8 \\
\hline 8 & 1839.6 & 1.10 & decreasing to $25 \mathrm{lb}$ & 306.6 \\
\hline \multicolumn{4}{|c|}{ Average [excluding 7] } & 322.3 \\
\hline 9 & 605.1 & 0.50 & 0.5 in extension & 100.9 \\
\hline 10 & 471.4 & 0.50 & 0.5 in extension & 78.6 \\
\hline 11 & 1442.9 & 1.00 & 1.0 in extension & 240.5 \\
\hline 12 & 496.1 & 1.50 & 1.5 in extension & 82.7 \\
\hline \multicolumn{4}{|c|}{ Average [excluding 11] } & 87.4 \\
\hline
\end{tabular}

\section{Aluminum Profile 1 - Corner stamped deboss}

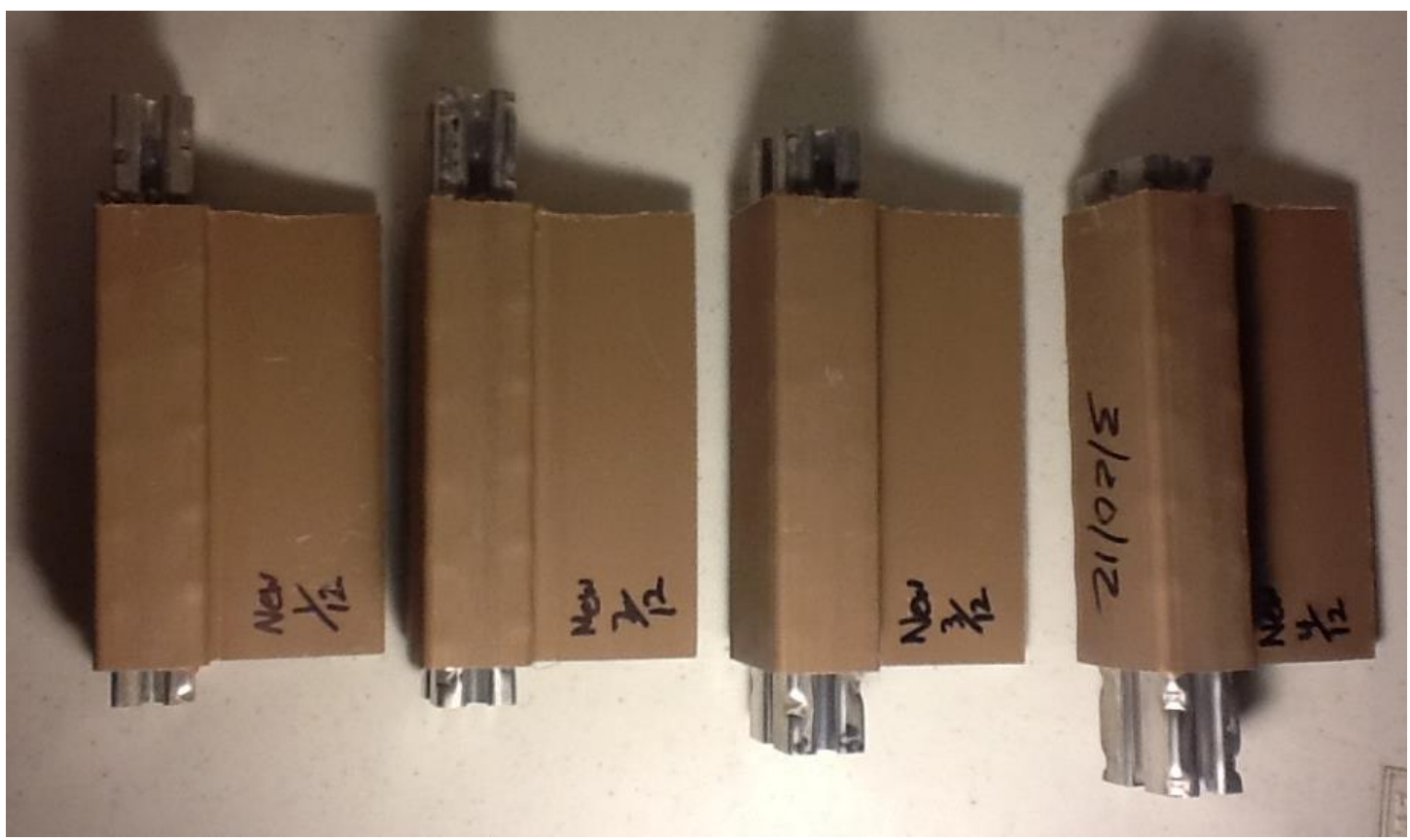

Figure 5-5: Aluminum Profile 1 specimens after testing (1\&2 extended to $0.500 \mathrm{in}, 3$ to $1.000 \mathrm{in}$, and 4 to $1.500 \mathrm{in}$ ) 


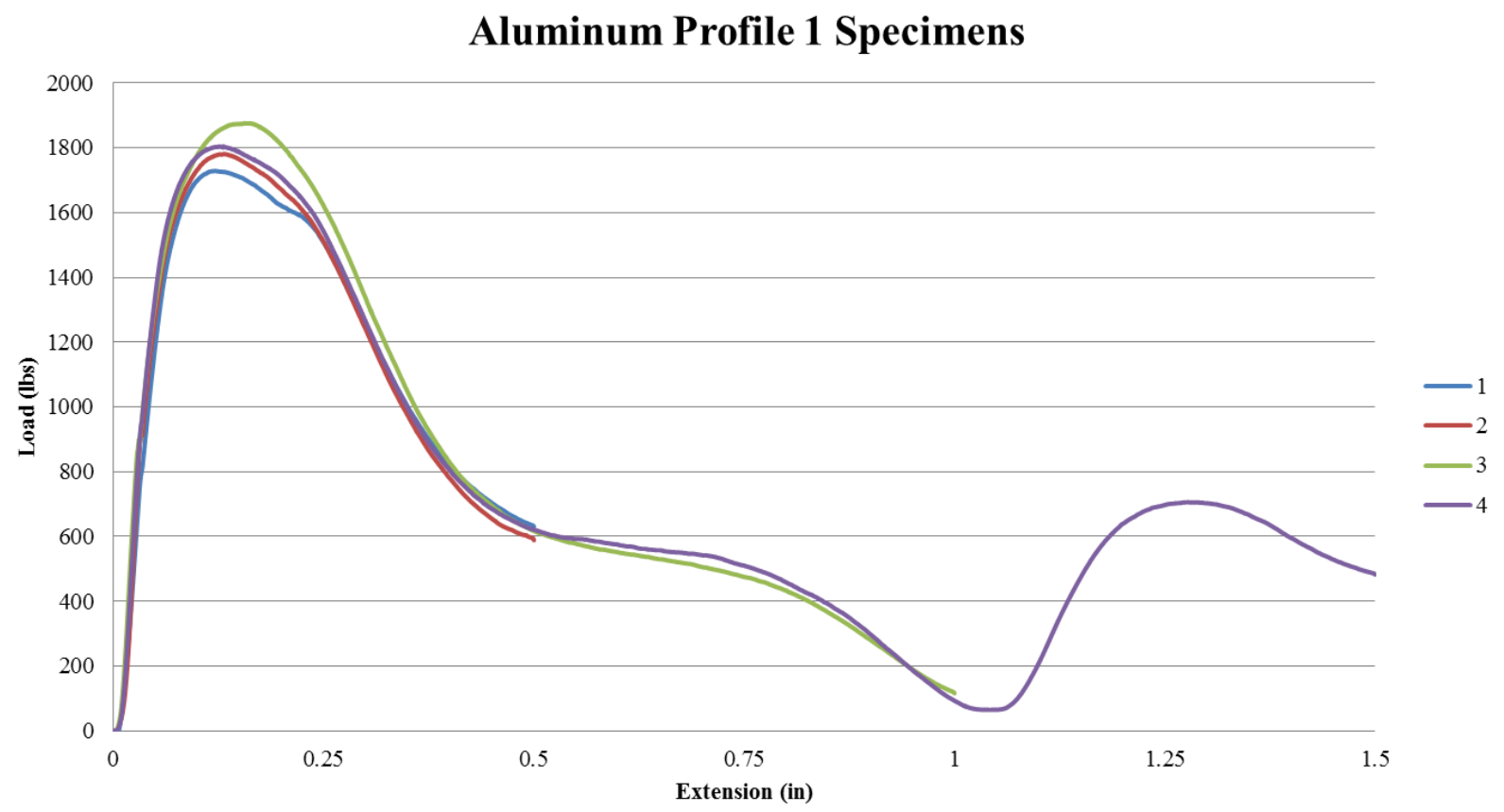

Figure 5-6: Push-Through test deboss comparison Aluminum Profile 1 results

Key observations:

- Very consistent data from specimen to specimen

- Linear relationship between force and displacement up until the maximum load

- Steady decrease in applied load after peak as displacement increases, until the plastic deboss region begins to enter the next deboss region on the aluminum

The deboss zones are spaced at 1 in along the length of the beam, and it can easily be seen in Figure 5-6 that when specimen 4 is extended just past 1 in, it begins to resist the load again. This was expected because this is where the deformed plastic from the prior destroyed zone was reinserted into the next deboss and then began to again bear up against the aluminum. The specimen was then able to build back up to $706 \mathrm{lb}$, which is almost $40 \%$ of its initial maximum load. It would be expected that if a specimen was tested further, then just after each 1 in increment mark, additional small bumps would be visible. However, this is not a failure that 
would occur outside of laboratory testing, so the loads corresponding to each "bump" in the graph are not critical values. The average maximum load for specimens 1-4 was $1797.51 \mathrm{bf}$. With each specimen being 6 in, the average strength between the aluminum and the plastic of Aluminum Profile 1 is $299.6 \mathrm{lb} / \mathrm{in}$. Because these specimen are the exact same beam type as those tested in the first set of Push-Through tests, there was a close correlation to the strength of $305.6 \mathrm{lb} /$ in previously calculated.

Aluminum Profile 2 - Face stamped deboss with scarification

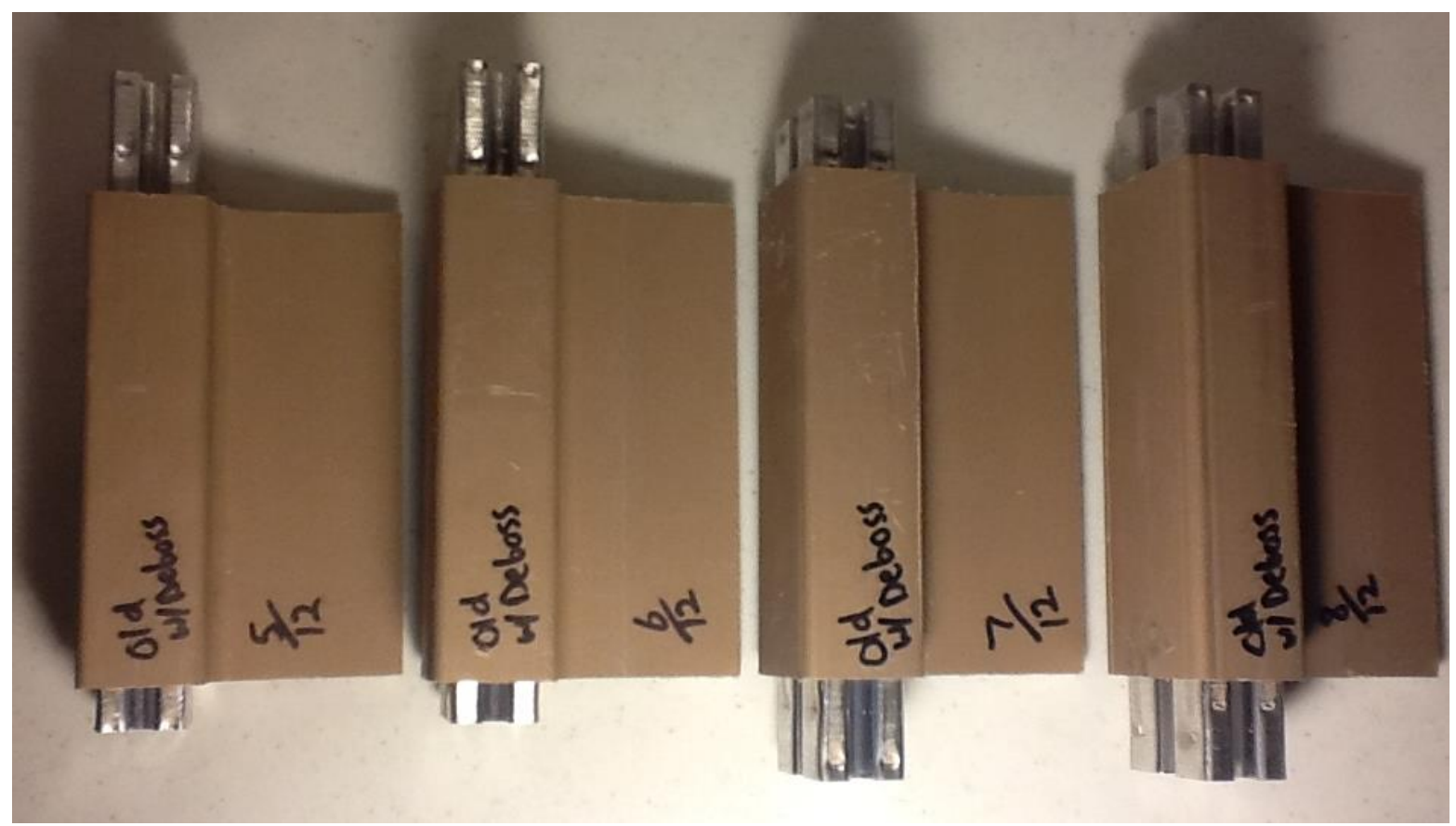

Figure 5-7: Aluminum Profile 2 specimens after testing (5\&6 extended to $0.500 \mathrm{in}, 7$ to $1.136 \mathrm{in}$, and 8 to $1.104 \mathrm{in}$ ) 


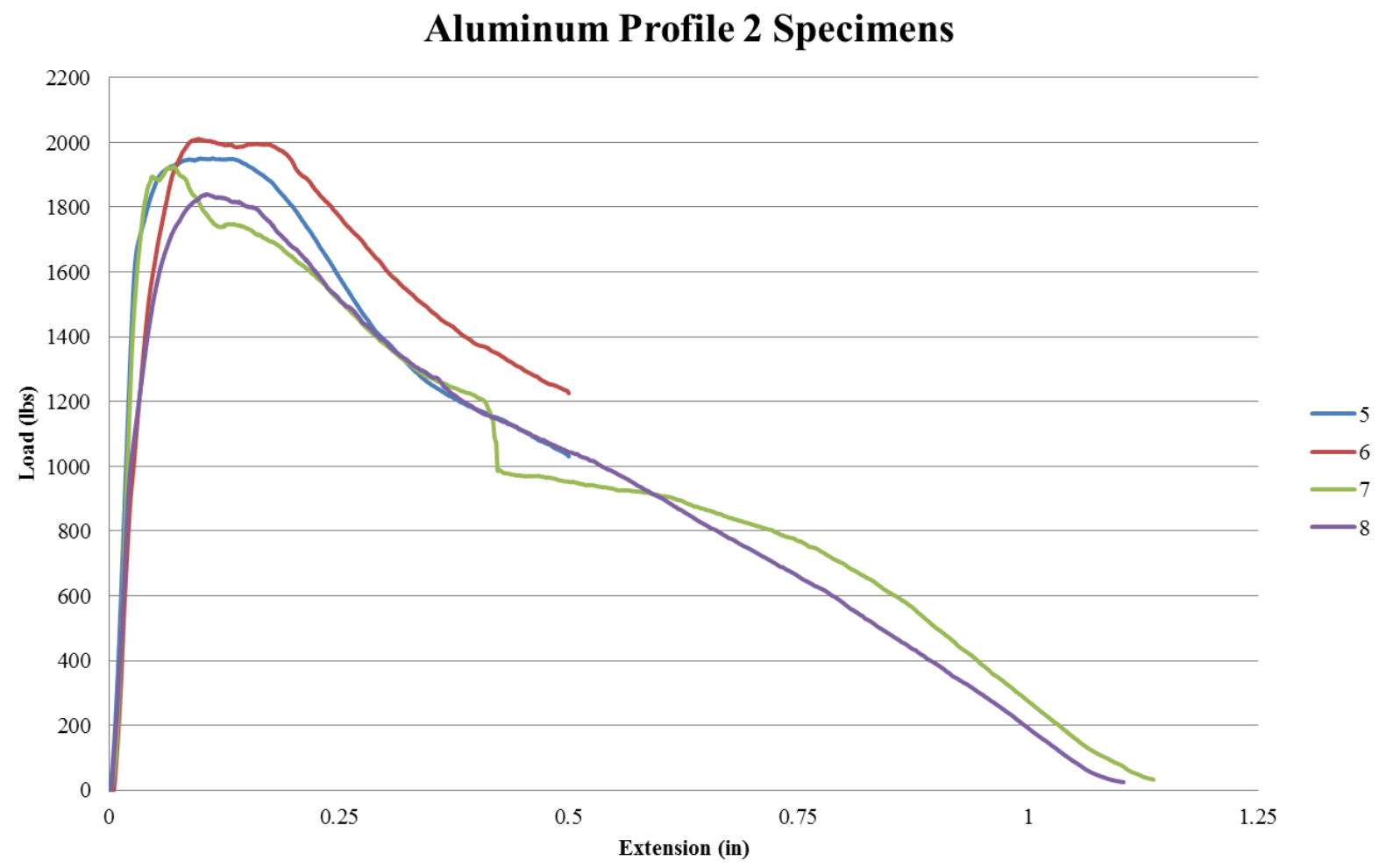

Figure 5-8: Push-Through test deboss comparison Aluminum Profile 2 results

Key observations:

- Consistent data from specimen to specimen (excluding specimen 7)

- Linear up until the maximum load

- Steady decrease in applied load after peak as displacement increases

Note that specimen 7 was extended further than $1 \mathrm{in}$. This is because the testing machine was not zeroed before this test and the data was shifted to the left of the y-axis. This mistake was corrected and the data in Figure 5-8 was shifted over. Also, note that specimen 8 did not extend to the specified 1.50 in cutoff. This is because the specimen reached the minimum $25 \mathrm{lb}$ cutoff first. Cracks formed in every specimen of Aluminum Profile 2, and an audible "pop" was heard during specimen 7's test (note the sudden drop off of this specimen's line on Figure 5-8 just after 0.40 in displacement). The reasoning for these cracks is due to the type and age of the plastic. 
Figure 5-9 and Figure 5-10 show examples of the cracks, which are located at the end of the arrows.

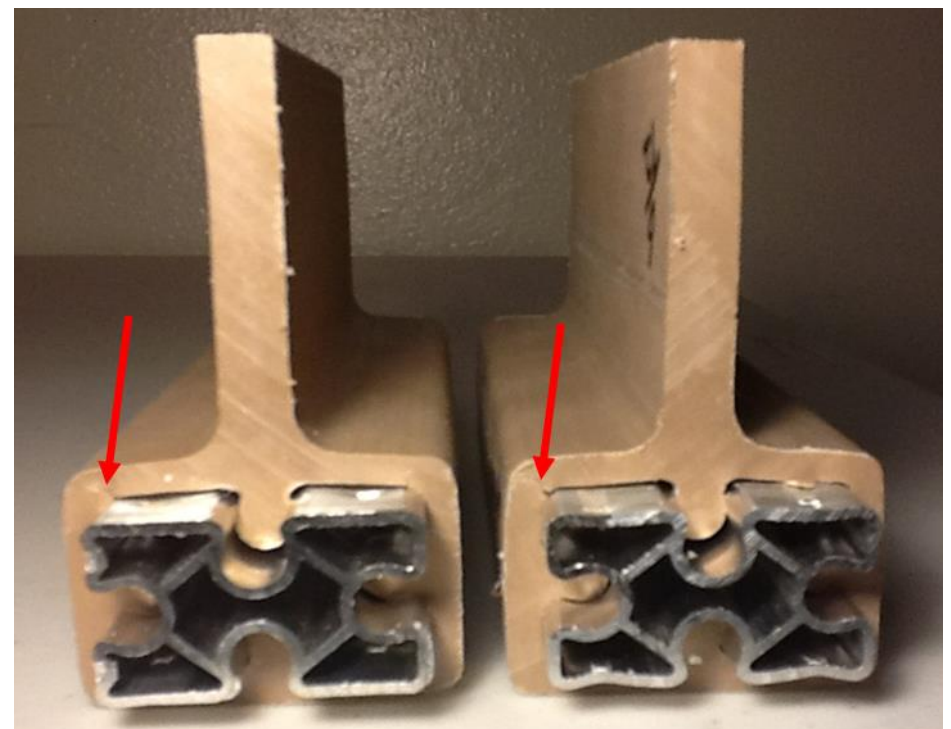

Figure 5-9: Cracks formed in ends of specimens 5 (left) \& 6 (right)

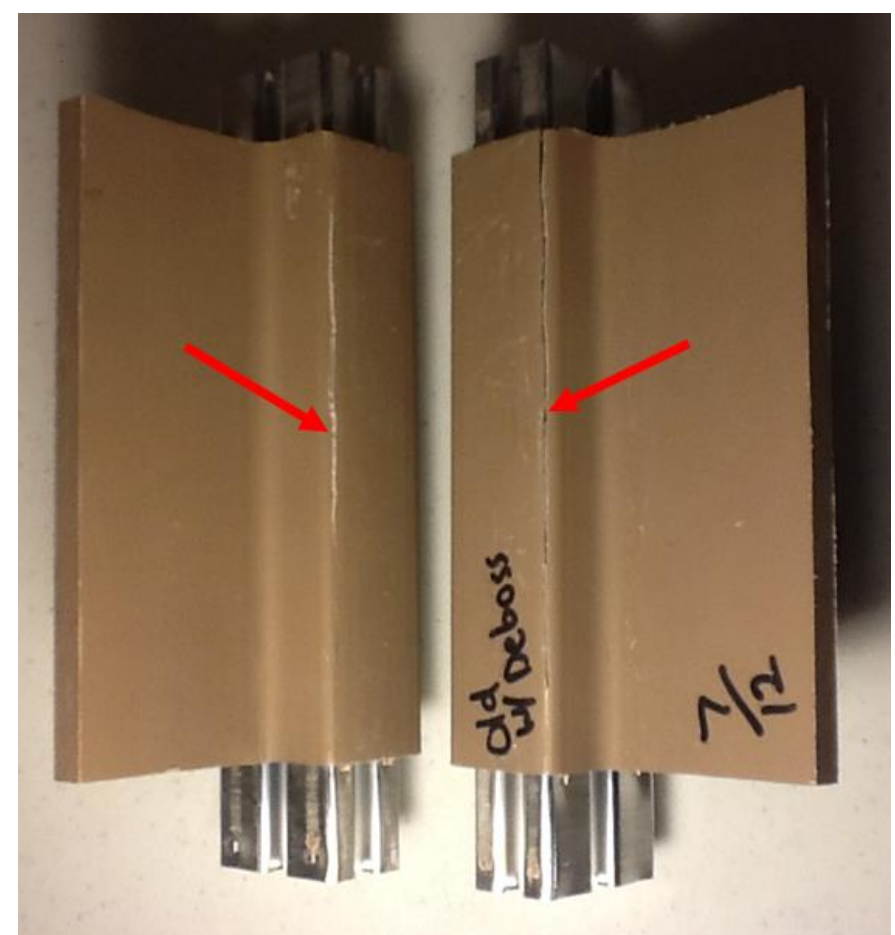

Figure 5-10: Cracks formed in specimens 7 (right) \& 8 (left)

Specimen 7 was not properly aligned before testing and therefore its data is skewed in comparison with the other specimens. Figure 5-11 shows the consequences of the misalignment. 
Although, specimen 7 was misaligned with the plate, its maximum load still fell within the other specimens and it can be concluded that the results were not significantly hindered and this specimen's data could be included in the results. However, for consistency with the other PushThrough testing (excluding results when the aluminum profile was not perfectly aligned), specimen 7's results are not included in the strength calculation for Aluminum Profile 2. The average maximum load for specimens 5, 6, and 8 is $1933.8 \mathrm{lb}$. With each specimen being 6 in, the average strength between the aluminum and the plastic of Aluminum Profile 2 is $322.3 \mathrm{lb} / \mathrm{in}$.

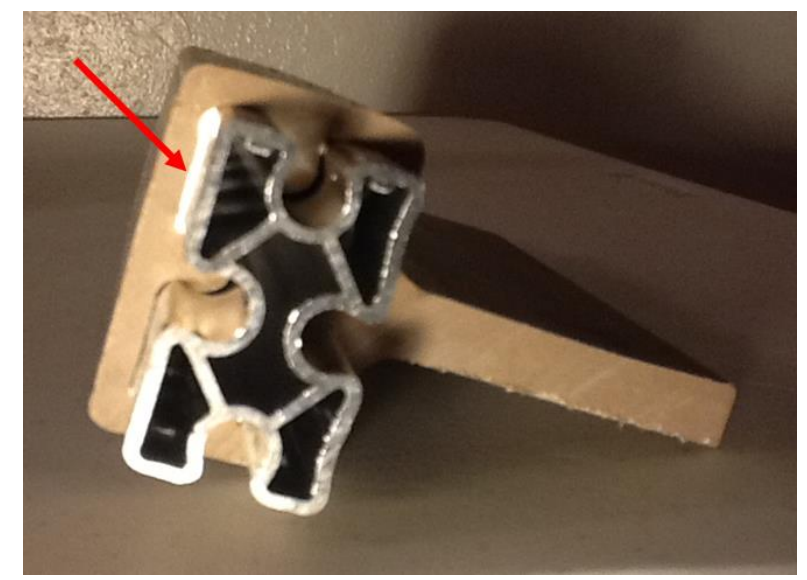

Figure 5-11: End view of specimen 7 after testing Shiny region (indicated with arrow) is crushed aluminum.

\section{Aluminum Profile 3 - Completely smooth aluminum}

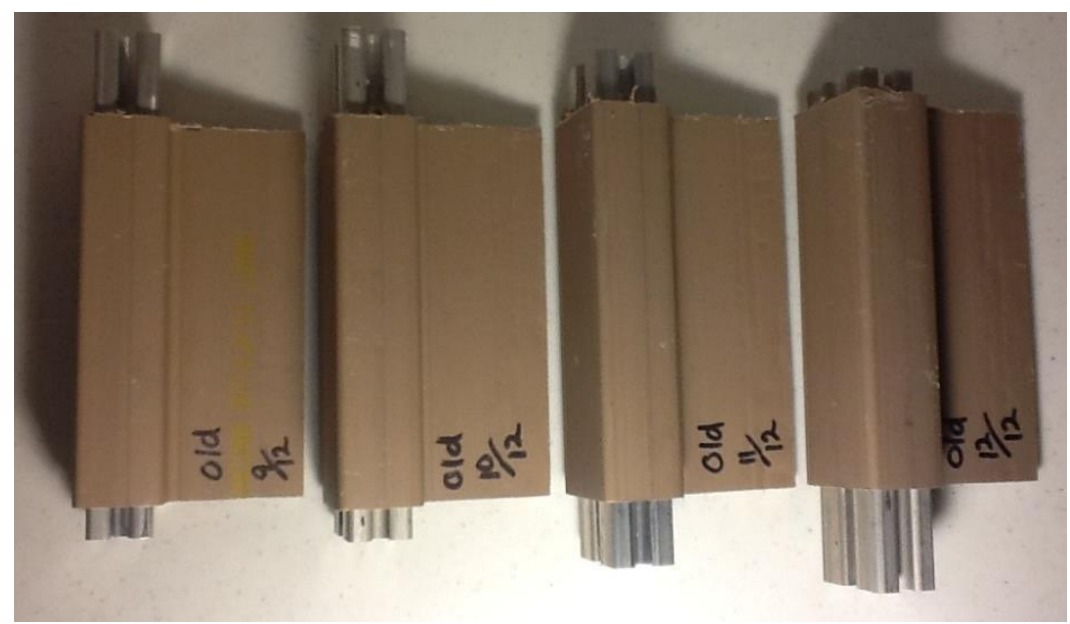

Figure 5-12: Aluminum Profile 3 specimens after testing (9\&10 extended to $0.500 \mathrm{in}, 11$ to $1.000 \mathrm{in}$, and 12 to $1.500 \mathrm{in}$ ) 


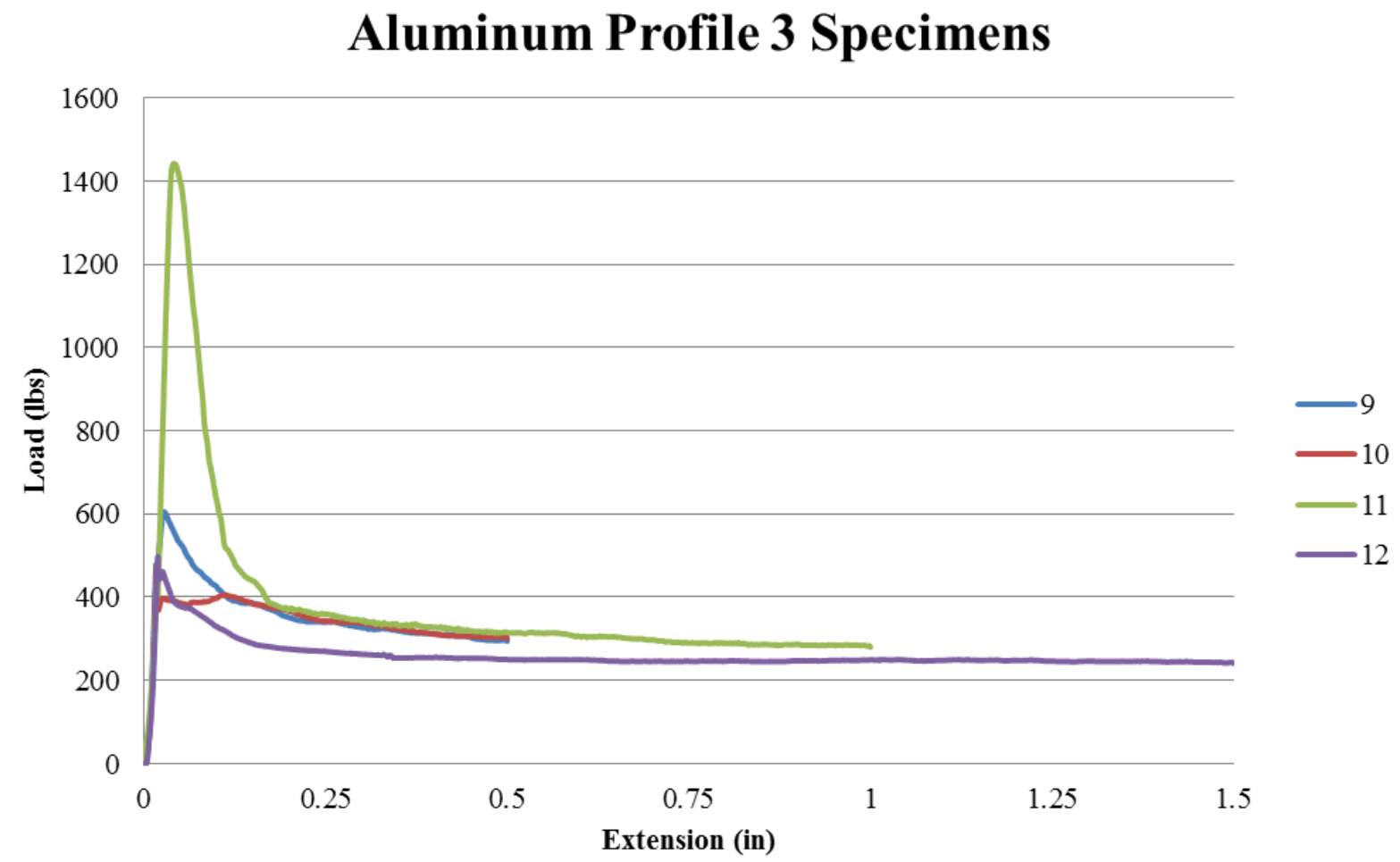

Figure 5-13: Push-Through test deboss comparison Aluminum Profile 3 results

Key Observations:

- Somewhat consistent data from specimen to specimen (excluding specimen 11)

- Linear up until the maximum load

- Almost constant applied load following the initial decrease after the peak as displacement increases

The leveling off of these specimens' graphs is expected, because once the initial bond between the plastic and aluminum is broken, at the peak, there is a constant force needed to continue the displacement. This force decreases very slowly and is most likely caused by a temperature increase between the aluminum and plastic (resulting in decreased friction) as time passes during the tests. Specimen 11 has a much higher maximum load than the other specimens of Aluminum Profile 3 because of a large misalignment with the plate. Since the aluminum in Aluminum 
Profile 3 is smooth and does not have any deboss, its aluminum profile is slightly larger than the other two beam types. Therefore, it was extremely difficult to completely align these specimens with the plate.

Every specimen of Aluminum Profile 3 was at least slightly misaligned, while 11 was extremely misaligned and eliminated from the average maximum load calculation. Therefore, the final strength between the aluminum and plastic of Aluminum Profile 3 is most likely actually slightly smaller than the calculated value below. The average maximum load for specimens 9, 10, and 12 is $524.2 \mathrm{lb}$. With each specimen being 6 inches of plastic and aluminum, the average strength between the aluminum and the plastic before initial bond is broken of Aluminum Profile 3 is $87.4 \mathrm{lb} / \mathrm{in}$.

Because there is no deboss or scarification present in Aluminum Profile 3 to slow down displacement rate after the initial bond between the aluminum and plastic is broken, the constant force needed to continue displacement is also an important value. Once the misaligned aluminum sheared off and the test continued, the constant force portion of its graph closely follows the other specimens of Aluminum Profile 3 and it is included in the following calculation. The constant forces for specimens 9-12 were about $300 \mathrm{lb}, 305 \mathrm{lb}, 290 \mathrm{lb}$, and $245 \mathrm{lb}$, respectively. The average of these values is $285 \mathrm{lb}$ and with each specimen being 6 in long, the constant force needed to continue displacement of Aluminum Profile 3 is $47.5 \mathrm{lb} / \mathrm{in}$.

\section{Comparisons between all 3 aluminum profiles}

The strengths between the aluminum and plastic of Aluminum Profiles 1, 2, and 3 are 299.6 lb/in, $322.3 \mathrm{lb} / \mathrm{in}$, and $87.4 \mathrm{lb} / \mathrm{in}$, respectively. There is close agreement between Aluminum Profiles 1 and 2. The slopes of specimens 5-8 after the maximum load are much less steep than the slopes of specimens 1-4 after the maximum load. This is thought to be because of the 
scarification present in Aluminum Profile 2. In this case there is more friction between the plastic and the aluminum after the initial bond is broken, causing the load to drop off more gradually. In terms of manufacturing chronology, Aluminum Profile 2's geometry was constructed first. Its properties and behavior under loading was very promising considering the comparison to wood beams of similar dimensions and applications. The problem with Aluminum Profile 2 was the amount of time and effort that goes into the scarification process. From a manufacturing standpoint, minimizing this effort was a priority. The goal was to develop a deboss geometry that could exhibit the same properties and behavior under loading as the deboss/scarification combination of Aluminum Profile 2. Aluminum Profile 1 was the result of that process. Although the strength per inch is approximately $20 \mathrm{lb}$ less than Aluminum Profile 2, the amount of time and effort (and therefore money) saved with Aluminum Profile 1 by eliminating the scarification process greatly outweighs the small loss of strength. This is especially true considering the already huge deficit of comparable wood beams' strengths compared to these plastic-aluminum composite I-beams. The rest of the Push-Through tests conducted are all on beams with the Aluminum Profile 1 deboss geometry.

\section{Different plastic comparisons}

A third set of Push-Through tests was performed to compare strengths between the aluminum and seven different plastic formulas. (Refer to Table 3-2 for details on the different plastics (labeled Beams 1B, 3B, 4B, 5B, 8B, 9B, and 10B)). Table 5-3 summarizes the results from the specimens of this set of tests. Figure 5-14 shows an example of an individual beam's results. All other beams' graphs looked very similar to this and are not included, but the cells containing average strengths are highlighted on Table 5-3. As a reminder, the first number in the specimen 
name corresponds to the number in the beam name, i.e. Specimen 1-4 was cut from Beam 1B. The strength was calculated the same way as described for the first set of Push-Through tests.

Table 5-3: Push-Through test 7 different plastics comparison results

\begin{tabular}{|c|c|c|c|c|}
\hline Specimen & Max Load (lb) & Total Extension (in) & Test Cutoff & Strength (lb/in) \\
\hline $1-4$ & 2255.0 & 0.50 & 0.5 in extension & 375.8 \\
\hline $1-5$ & 2508.7 & 0.50 & 0.5 in extension & 418.1 \\
\hline $1-6$ & 2416.1 & 1.50 & 1.5 in extension & 402.7 \\
\hline \multicolumn{4}{|r|}{ Average } & 398.9 \\
\hline $3-4$ & 1616.7 & 0.50 & 0.5 in extension & 269.5 \\
\hline $3-5$ & 1644.9 & 0.50 & 0.5 in extension & 274.2 \\
\hline $3-6$ & 1557.0 & 1.50 & 1.5 in extension & 259.5 \\
\hline \multicolumn{4}{|r|}{ Average } & 267.7 \\
\hline $4-4$ & 2136.9 & 0.50 & 0.5 in extension & 356.1 \\
\hline $4-5$ & 2264.4 & 0.50 & 0.5 in extension & 377.4 \\
\hline $4-6$ & 2149.0 & 1.50 & 1.5 in extension & 358.2 \\
\hline \multicolumn{4}{|r|}{ Average } & 363.9 \\
\hline $5-4$ & 2330.2 & 0.50 & 0.5 in extension & 388.4 \\
\hline $5-5$ & 2383.8 & 0.50 & 0.5 in extension & 397.3 \\
\hline $5-6$ & 2381.2 & 1.50 & 1.5 in extension & 396.9 \\
\hline \multicolumn{4}{|r|}{ Average } & 394.2 \\
\hline $8-4$ & 2385.2 & 0.50 & 0.5 in extension & 397.5 \\
\hline $8-5$ & 2693.9 & 0.50 & 0.5 in extension & 449.0 \\
\hline $8-6$ & 2269.1 & 1.50 & 1.5 in extension & 378.2 \\
\hline \multicolumn{4}{|r|}{ Average } & 408.2 \\
\hline $9-4$ & 2892.6 & 0.50 & 0.5 in extension & 482.1 \\
\hline $9-5$ & 2636.2 & 0.50 & 0.5 in extension & 439.4 \\
\hline $9-6$ & 2452.3 & 1.50 & 1.5 in extension & 408.7 \\
\hline \multicolumn{4}{|r|}{ Average } & 443.4 \\
\hline $10-4$ & 2653.6 & 0.50 & 0.5 in extension & 442.3 \\
\hline $10-5$ & 2503.3 & 0.50 & 0.5 in extension & 417.2 \\
\hline $10-6$ & 2400.0 & 1.50 & 1.5 in extension & 400.0 \\
\hline \multicolumn{4}{|r|}{ Average } & 419.8 \\
\hline
\end{tabular}




\section{Beam 3B Specimens}

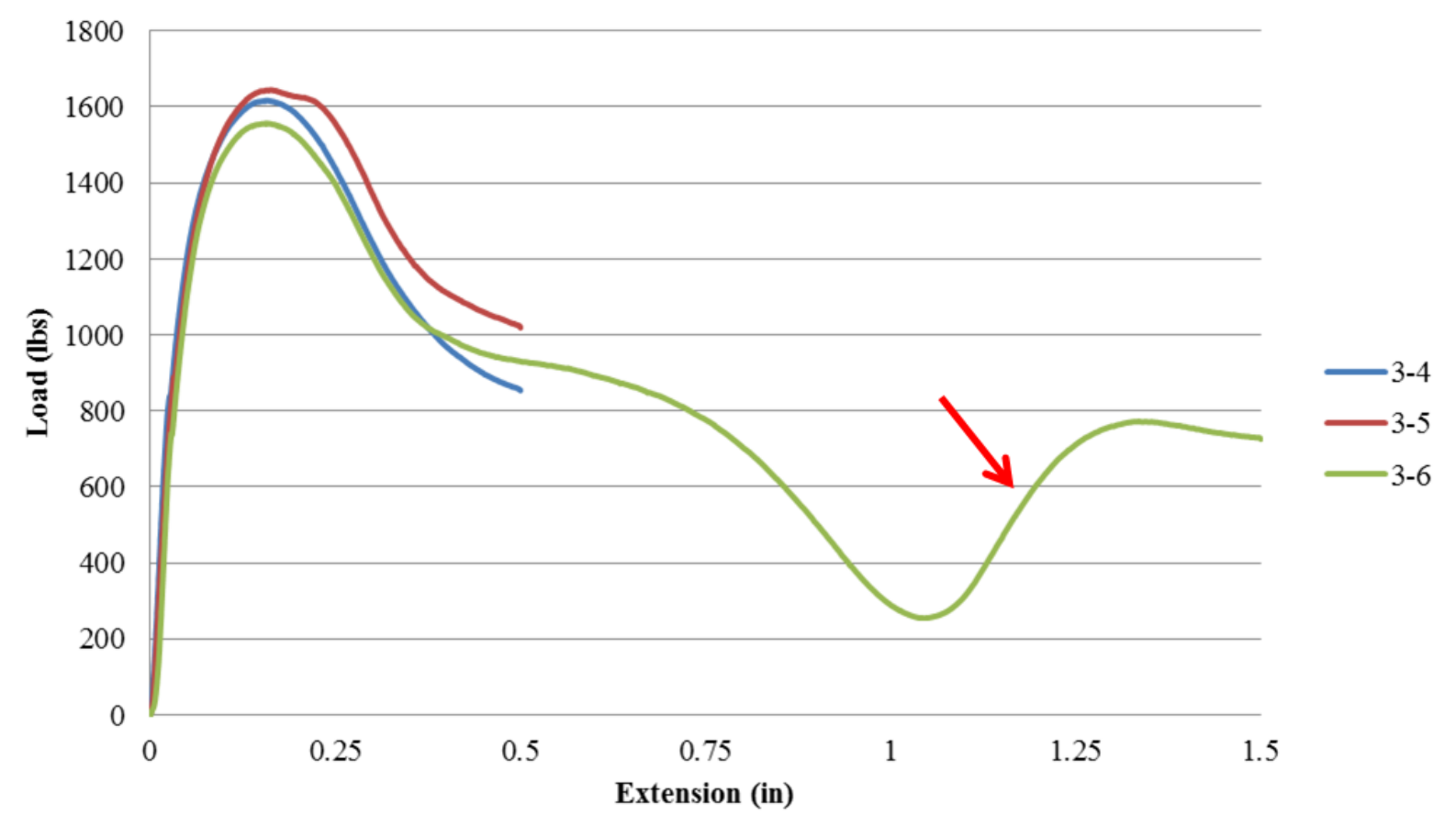

Figure 5-14: Push-Through test Beam 3B results (for example of trends)

Key observations:

- Very consistent data from specimen to specimen for each beam type

- Linear up until the maximum load

- All specimens' data was used

- Every beam type reloaded once the plastic entered the next deboss region and this portion of the data is shown by the arrow on Figure 5-14

Beam 3B's average strength was significantly lower than the other beam types. This is caused in part by the addition of elastomer material described in the Materials and Geometry chapter. As mentioned in the Testing chapter, the other beams with elastomer were not tested with the PushThrough test, because these beams were discarded before testing occurred. However, Beam 3B was tested just to verify this decision and it is assumed that the other beams with elastomer 
would have had similar results, although whether or not this is true does not make a difference for the purposes of this research.

The other six plastics tested consist of three pairs of the same flange plastic formula with the exception of the metal deactivator additive, described in the Materials and Geometry chapter, added to one of them. For the following comparison, the beams with the metal deactivator will be labeled with an (md) after their name. Beams $1 \mathrm{~B}$ and $8 \mathrm{~B}(\mathrm{md})$ have the same flange plastic, and this same relationship exists between Beams 4B and 5B(md) and Beams 9B(md) and 10B. Therefore, comparing the results between these pairs of beams will show the effect of the metal deactivator. From Table 5-4, it can be seen that the metal deactivator increases the strength of the flange plastics in each case. The increase is not very significant, but has the most impact in between Beams $4 \mathrm{~B}$ and $5 \mathrm{~B}(\mathrm{md})$, which are the beams without any talc filler in the flange plastics.

Table 5-4: Metal deactivator additive comparison

\begin{tabular}{|l|r|c|}
\hline \multicolumn{1}{|c|}{ Beam } & Average Strength (lb/in) & \% Difference \\
\hline $1 \mathrm{~B}$ & 398.9 & \multirow{2}{*}{$2 \%$} \\
\cline { 1 - 2 } 8B $(\mathrm{md})$ & 408.2 & \\
\cline { 1 - 2 } $4 \mathrm{~B}$ & 363.9 & \multirow{2}{*}{$8 \%$} \\
\cline { 1 - 2 } $5 \mathrm{~B}(\mathrm{md})$ & 394.2 & \\
\cline { 1 - 2 } 10B & 419.8 & \multirow{2}{*}{$5 \%$} \\
\cline { 1 - 2 } 9B $(\mathrm{md})$ & 443.4 & \\
\hline
\end{tabular}

One of the main reasons for this set of Push-Through tests was to compare the effects of different talc filler contents. Only considering the plastics without the metal deactivator additive, the beam order of increasing talc filler contents $(0 \%, 20 \%$, and 38\%) are 4B, 1B, and 9B, respectively. These beams' average push-through strengths are $363.9 \mathrm{lb} / \mathrm{in}, 398.9 \mathrm{lb} / \mathrm{in}$, and $443.4 \mathrm{lb} / \mathrm{in}$, respectively. As expected, the strength increases with the increase in talc filler content. This is 
clearly a desired result considering the decrease in cost associated with an increase in filler content.

\section{Addition of Screws}

The fourth set of Push-Through tests quantified the additional strength of bond between the aluminum and the plastic due to the addition of screws. Both specimens were cut from Beam 1B and therefore will be compared with 1B's results previously given. Table 5-5 and Figure 5-15 summarize the results from the specimens of this set of tests and Figure 5-16 gives visuals of one of the specimens during testing. The strength was calculated the same way as described for the first set of Push-Through tests.

The screws add to the strength of the flange by increasing the attachment of the plastic to the aluminum. It was unknown whether or not the screws would shear off or get pulled through the plastic. This behavior depends on the type and strength of screws used and could differ from case to case in the field. In this case, the screws remained completely intact (they did not shear off). The load per screw given in Table 5-5 was calculated by assuming the average strength calculated for Beam 1B acted on these specimens and the remaining differences in the maximum loads were divided by the number of screws ( 2 for Specimen $\mathrm{N}-1$ and 3 for $\mathrm{N}-2$ ). This gave an average of just above $400 \mathrm{lb}$ added to the maximum load of each specimen per screw. The average load per screw is much larger than average screw strength ratings. This could be because once the specimen started deforming and the screws were pulled through the plastic, they were no longer being loaded in pure shear, but an axial load was introduced and increased as the screws were pulled further. Although not of complete importance to this research, these results are interesting and it is beneficial to see the potential behavior that could occur in the field. Also, 
it is important to see that these plastic-aluminum composite I-beams can be screwed into similarly to their wood counterparts.

Table 5-5: Push-Through test screw comparison results

\begin{tabular}{|c|r|r|r|}
\hline Specimen & Max Load (lb) & Strength of one flange (lb/in) & Load per screw (lb) \\
\cline { 1 - 3 } N-1 & 3202.6 & 533.8 & 404.7 \\
\cline { 1 - 2 } N-2 & 4528.9 & 566.1 & 446.0 \\
\cline { 1 - 2 } & Average: & $\mathbf{5 4 9 . 9}$ & \\
\cline { 1 - 2 } 1B Average for comparison: & 398.9 & \\
\hline
\end{tabular}

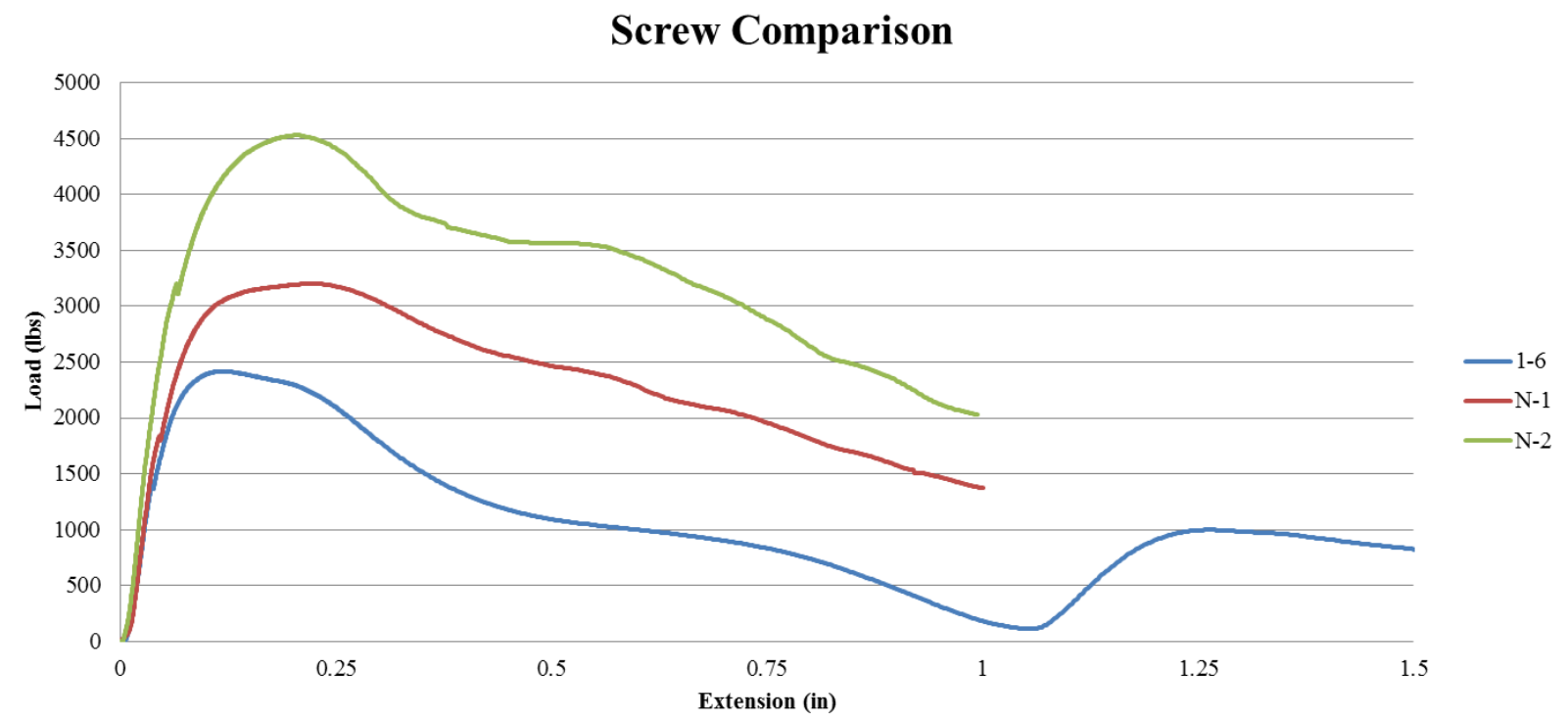

Figure 5-15: Push-Through test screw comparison results 


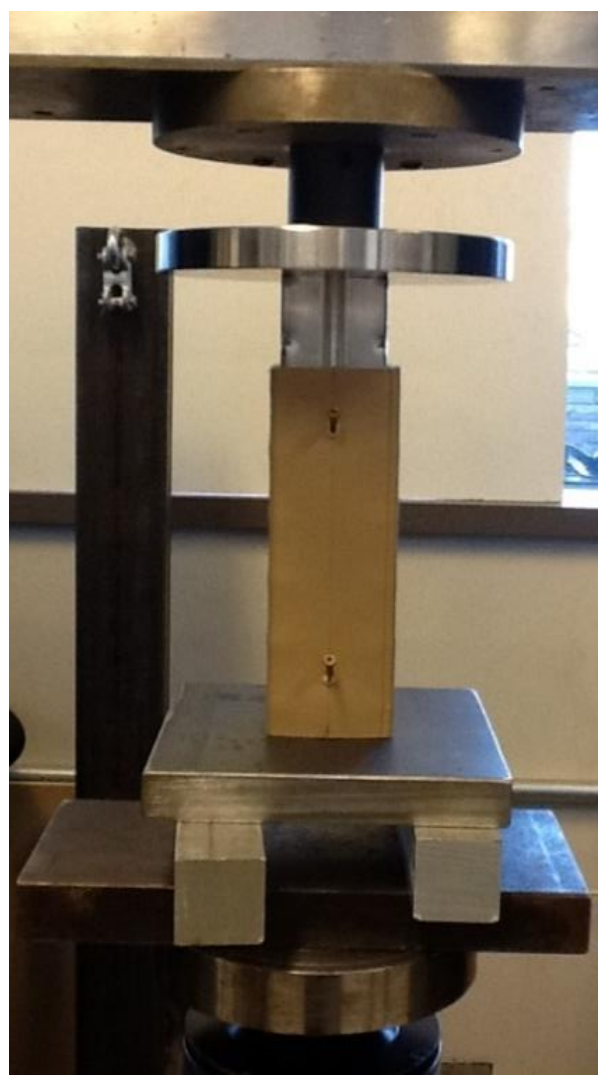

A

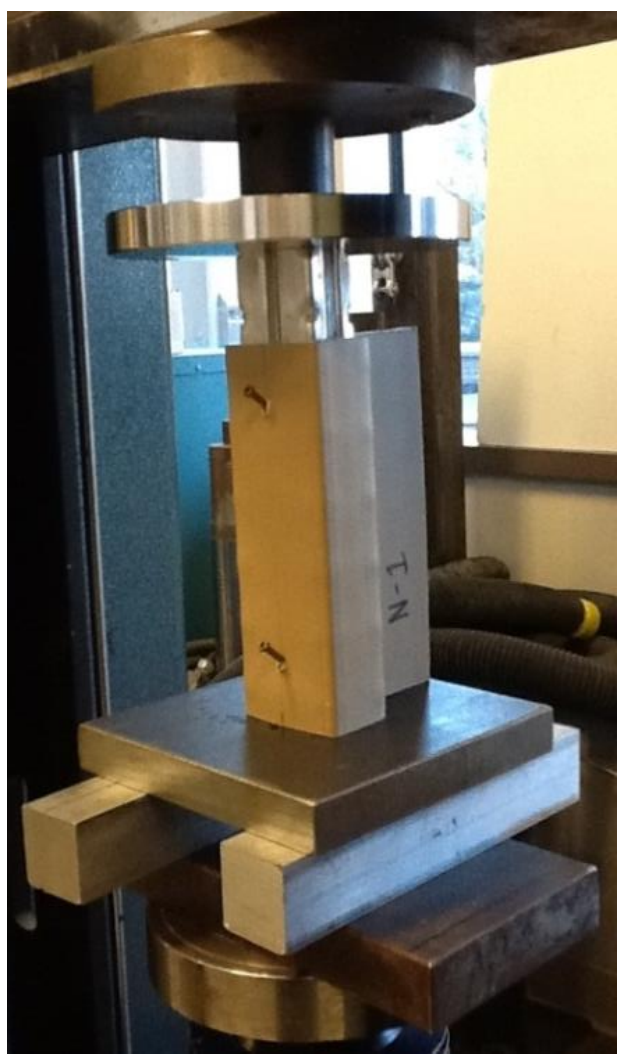

B

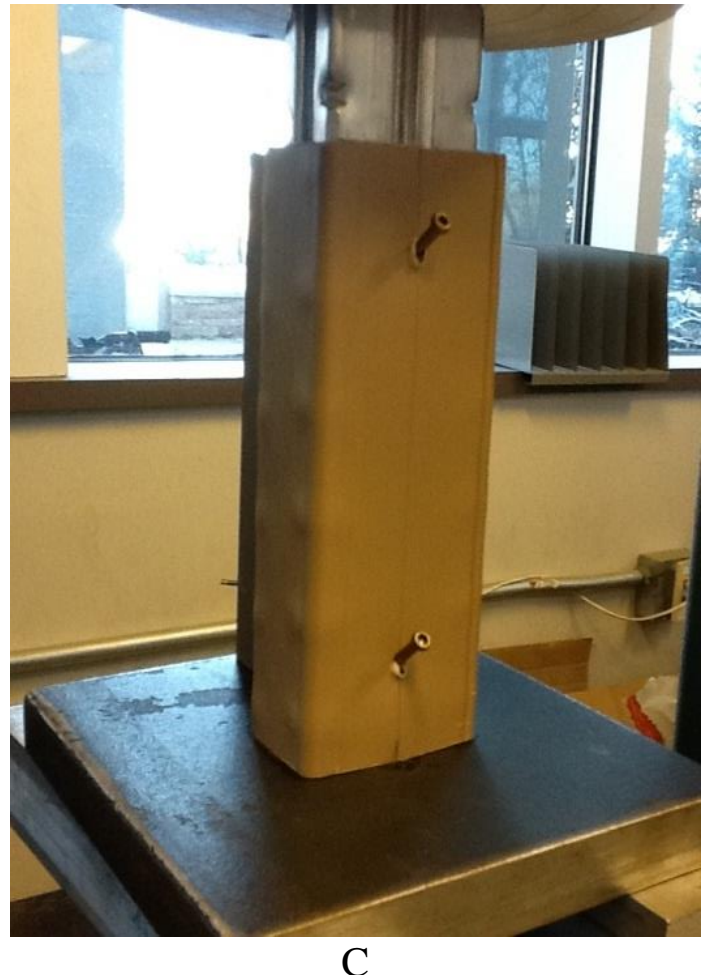

Figure 5-16: Specimen N-1 during testing 
As discussed in the Testing chapter, a beam specimen containing only one deboss region was tested with the Push-Through test in order to have a direct comparison with the ABAQUS model. For clarity and ease of reading, results from this special case will be in the Numerical Model of Deboss Region chapter.

\section{Knit-Line Pull Tests}

Both sets of the Knit-Line Pull tests gave data on the strength of the bond between the web plastic and flange plastic for several different types of composite beams. All results are presented together since there was no change in the testing procedure or specimen preparation between sets.

Specimen J (beam type A) was tested first. Initial issues concerning attachment of the fixture and specimen into the grips caused specimen $\mathbf{J}$ to break at the knit-line before testing occurred. The web and flange were still minimally connected and therefore the test could still be performed, but the data collected is not comparable to the other specimens; therefore it is not included here. However, it was useful to work out the loading and securing issues on this specimen to gain confidence in the remainder of the testing. Figure 5-17 shows examples of the specimens during testing. 


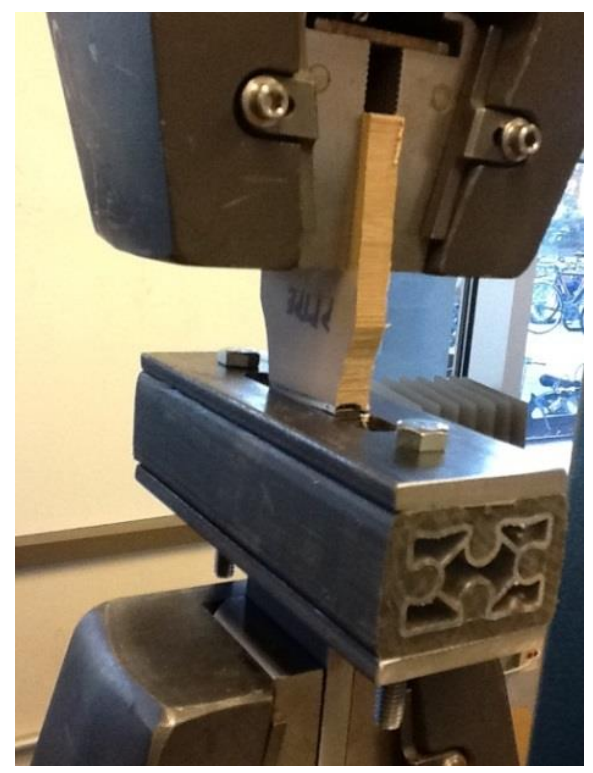

A

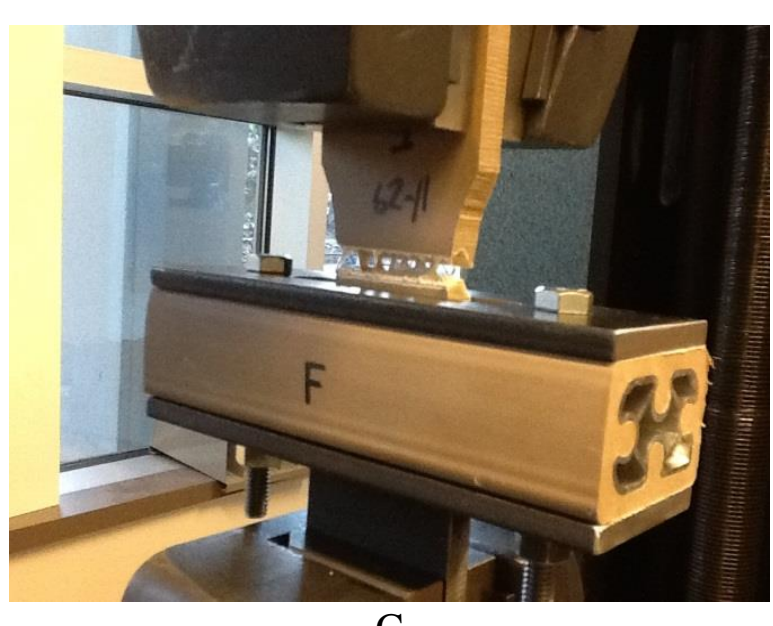

C

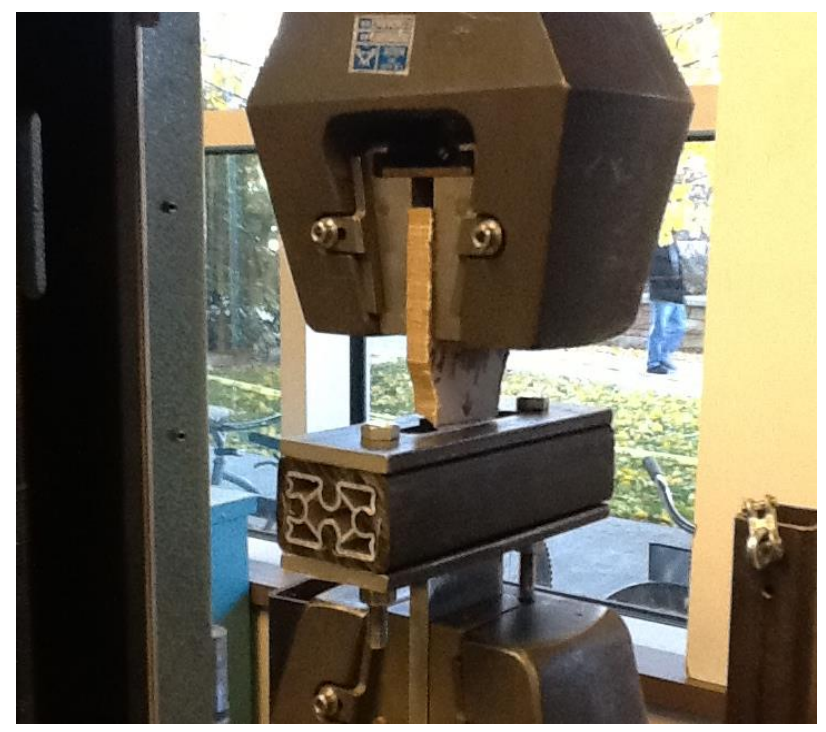

B

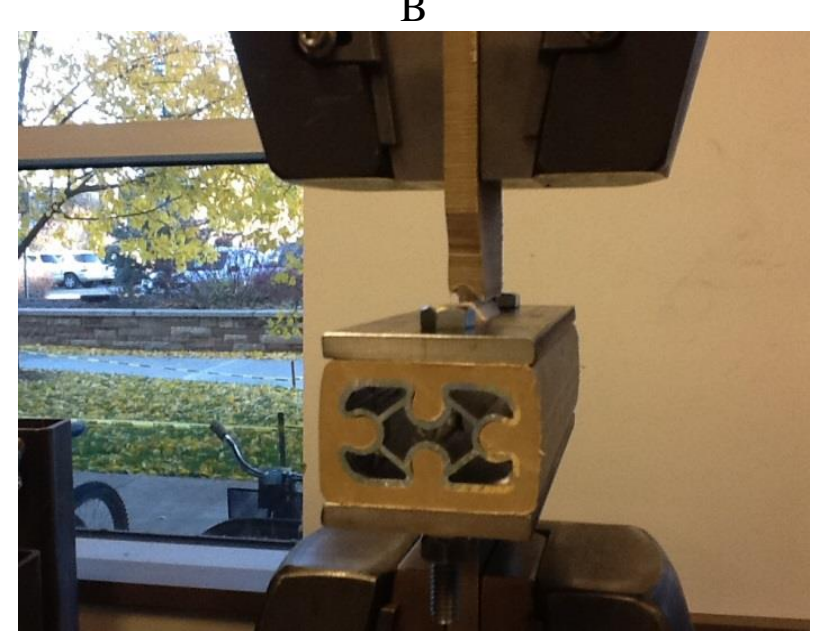

D

Figure 5-17: Example specimens during testing

Two different types of failures were observed during the knit-line pull tests. All specimens excluding those from beams $\mathrm{C}$ and $3 \mathrm{~B}$ failed in a brittle fashion (these will be referred to as complete brittle failure) with an audible "pop" being heard. All of the complete brittle failure specimens had a failure surface that followed the general shape of the knit-line. All specimens from beams $\mathrm{C}$ and 3B failed initially in a semi-brittle fashion (these will be referred to as partial brittle failure), but remained connected for continued extension as the plastic yielded. As a reminder, beam C's flange is composed of 15\% EPDM and beam 3B's flange has $25 \%$ of the 
Bonding Elastomer. These two beam types are the only beams tested in the Knit-Line Pull Test that consist of rubbery material in the flanges. Therefore, the failure type of these beams relative to the others is expected. Figures 5-18 and 5-19 show example specimen of each type of failure and Figures 5-20 and 5-21 show close-ups of the different types of failure.

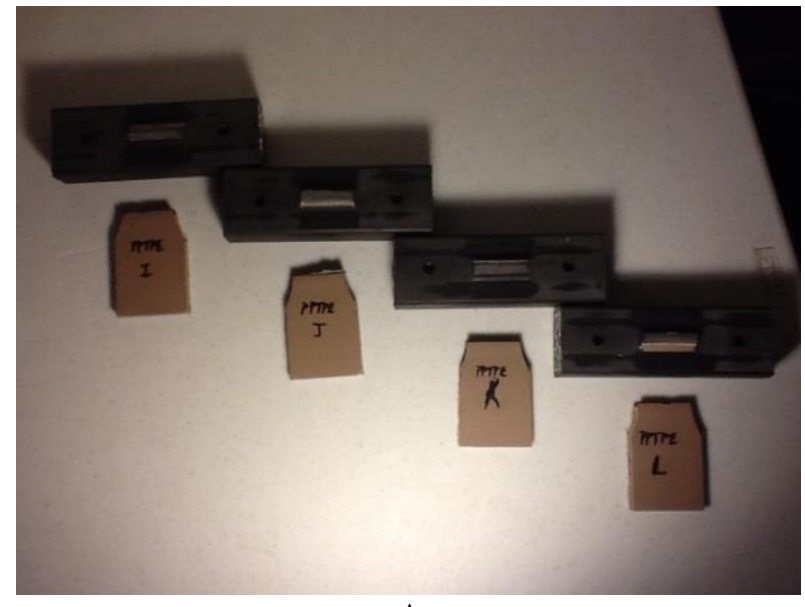

A

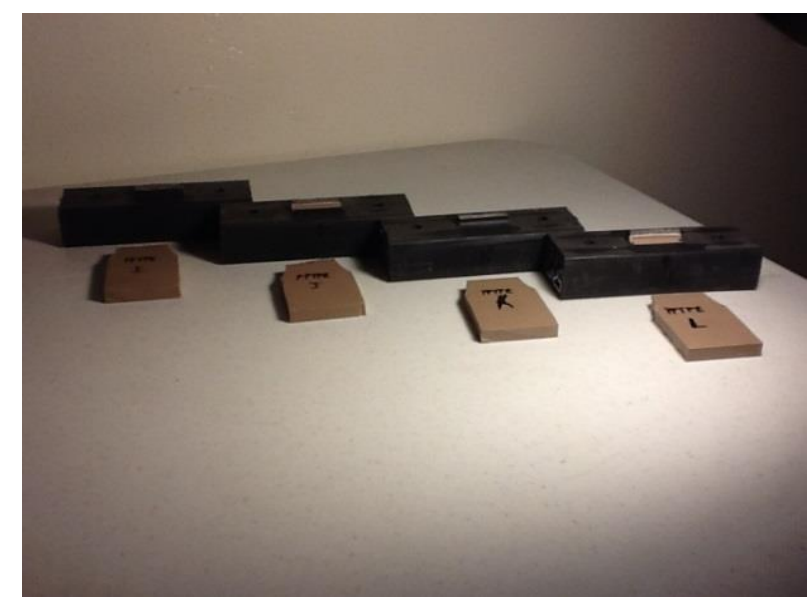

B

Figure 5-18: Example specimens with complete brittle failures

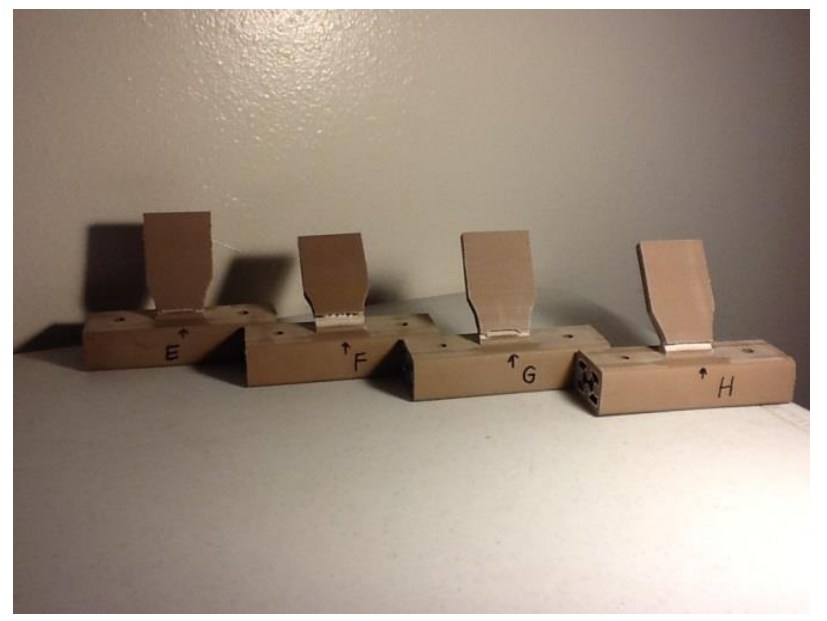

A

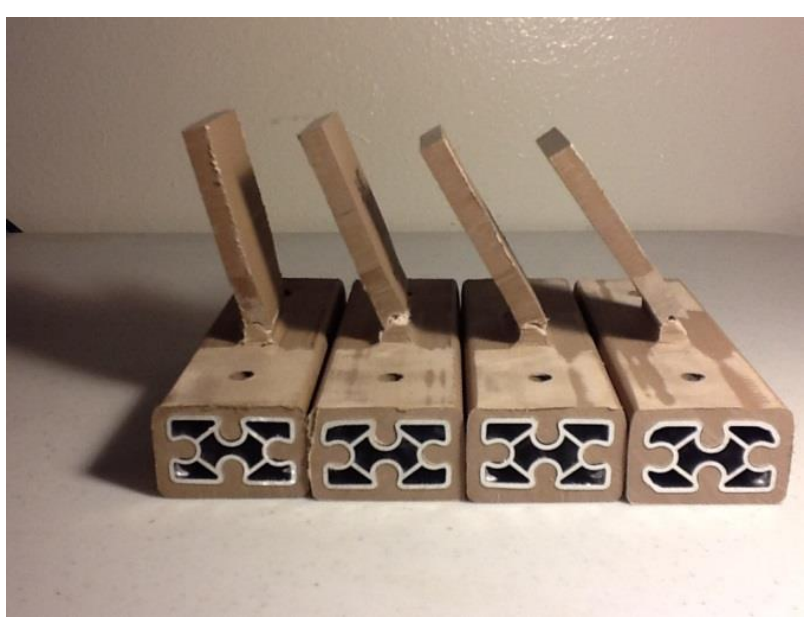

B

Figure 5-19: Example specimens with partial brittle failures 


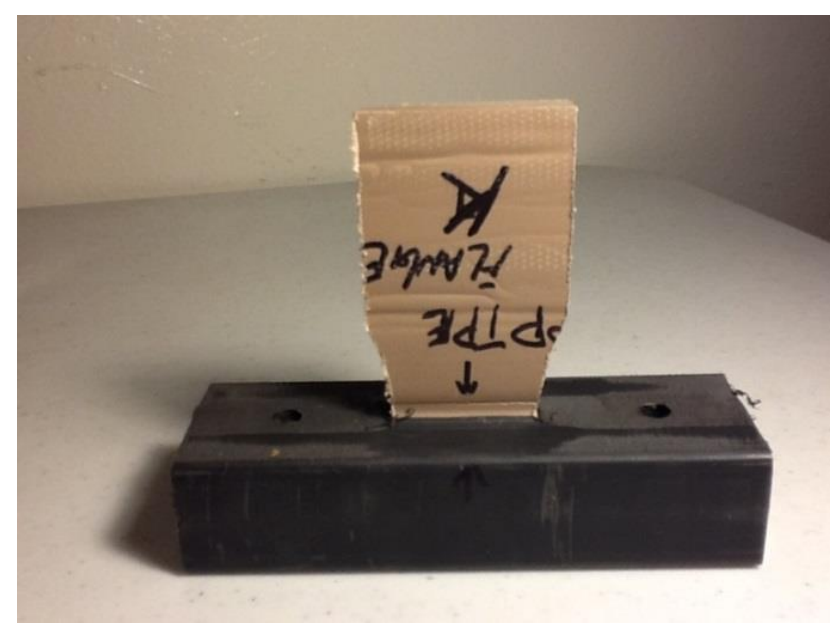

A

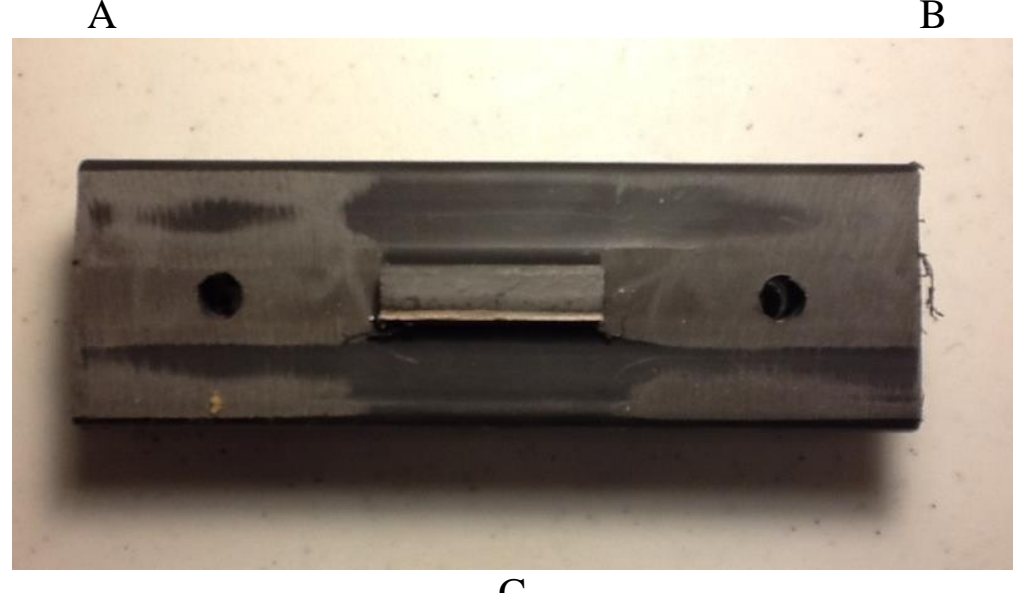

C

Figure 5-20: Example complete brittle failure surface after testing

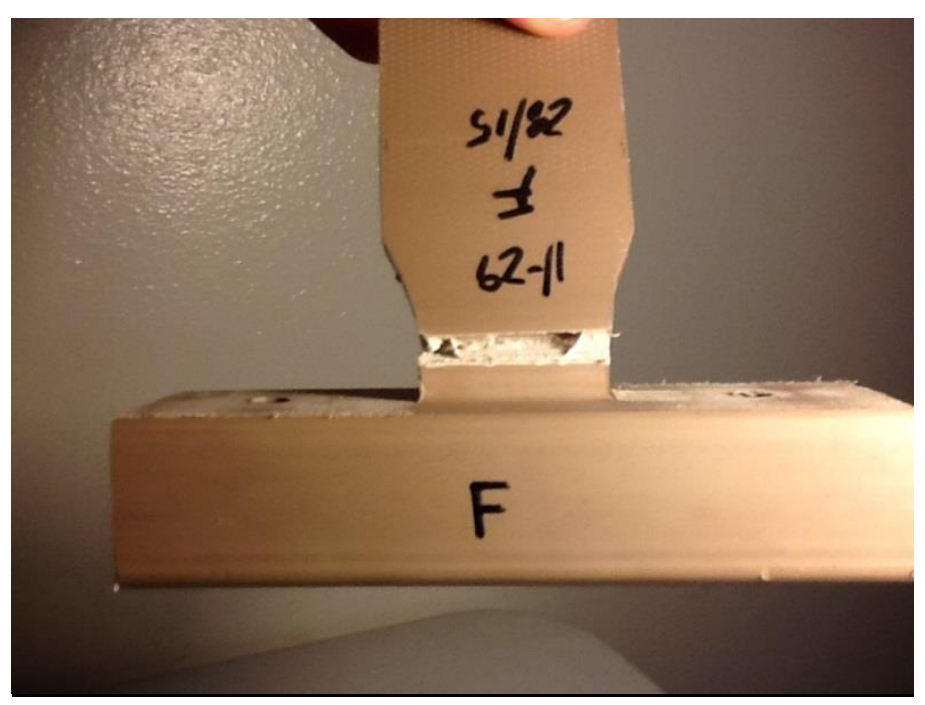

Figure 5-21: Example partial brittle failure outside surface after testing 
To compare the two different failure types, a stress versus displacement graph was constructed and is shown in Figure 5-22. One specimen from each failure type was chosen: 1-1 for complete brittle failure and 3-1 for partial brittle failure. The complete brittle line shows the completely vertical drop-off once the complete brittle fracture at the knit-line occurs. This drop-off was typical of all specimens that failed in this way. After about 600 psi, the partial brittle failure line shows a steadily decreasing slope as the maximum load is approached and then a sudden dropoff followed by continued load resistance. Therefore it can be seen that although both specimens reached almost the same load per area, and thus almost identical strengths at the knit-line as defined later in this chapter, there is a significantly larger area under the partial brittle failure curve. Integrating these areas shows that the specimen exhibiting a partial brittle failure absorbed over three times as much energy as the specimen exhibiting a complete brittle failure.

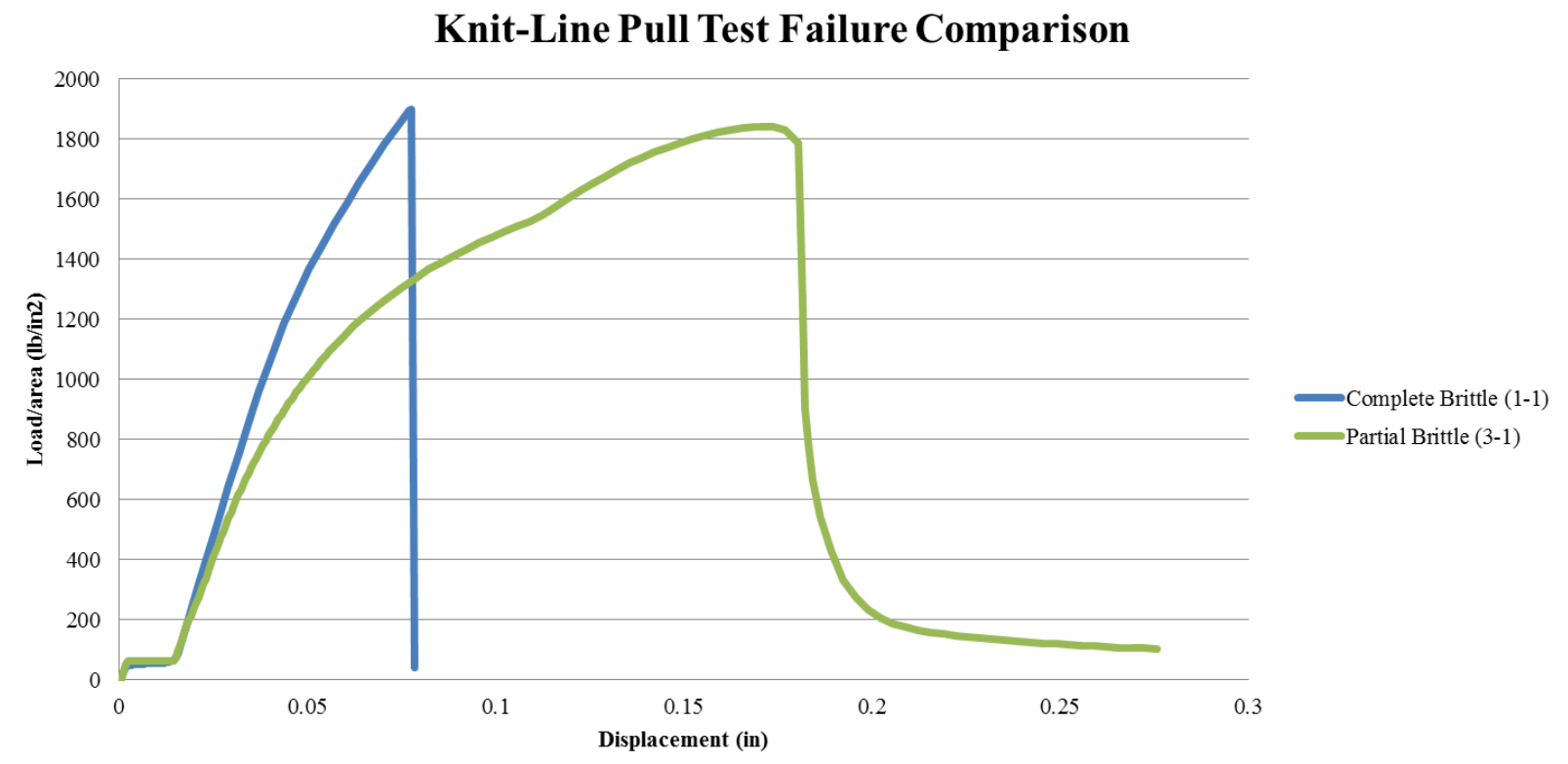

Figure 5-22: Knit-Line Pull test failure comparison graph

The "strength of knit-line" was determined by dividing the maximum load taken by each specimen by its web width; therefore is presented in units of force per length. The nominal web thickness is 0.375 in and it was found that the thickness at the knit-line is slightly higher than this 
value. The thickness at the knit-line is close to uniform along the length of all beams, therefore was not included in the strength calculation so that a standard force per length strength calculation would be possible. These units will allow for better visualization when considering a beam of a certain length. Final values were converted to $\mathrm{lb} / \mathrm{ft}$. Data for all specimens are shown in Table 5-6. Note that each specimen's web thickness was given for completeness although not used in the strength calculation. Cells containing final averaged values are highlighted and then summarized in Table 5-7 in order from least to greatest for an easier comparison between all beam types.

Table 5-6: Knit-Line Pull test results

\begin{tabular}{|c|c|c|c|c|c|}
\hline $\begin{array}{l}\text { Beam } \\
\text { Name }\end{array}$ & $\begin{array}{l}\text { Specimen } \\
\text { Name }\end{array}$ & $\begin{array}{c}\text { Web } \\
\text { thickness (in) } \\
\end{array}$ & $\begin{array}{l}\text { Web width at } \\
\text { knit-line (in) }\end{array}$ & $\begin{array}{l}\text { Max Load } \\
\text { (lb) }\end{array}$ & $\begin{array}{l}\text { "Strength of Knit- } \\
\text { Line" (lb/ft) }\end{array}$ \\
\hline \multirow{4}{*}{$\mathbf{A}$} & I & 0.391 & 1.535 & 995.3 & 7780.7 \\
\hline & K & 0.39 & 1.54 & 901.5 & 7024.4 \\
\hline & $\mathrm{L}$ & 0.432 & 1.591 & 986.6 & 7441.0 \\
\hline & \multicolumn{4}{|l|}{ Average: } & 7415.4 \\
\hline \multirow{5}{*}{ B } & A & 0.408 & 1.503 & 1068.4 & 8530.4 \\
\hline & B & 0.414 & 1.511 & 1185.9 & 9418.0 \\
\hline & $\mathrm{C}$ & 0.424 & 1.555 & 1112.7 & 8587.0 \\
\hline & $\mathrm{D}$ & 0.413 & 1.486 & 1093.3 & 8828.5 \\
\hline & \multicolumn{4}{|l|}{ Average: } & 8841.0 \\
\hline \multirow{5}{*}{ C } & E & 0.404 & 1.539 & 995.3 & 7760.5 \\
\hline & $\mathrm{F}$ & 0.402 & 1.545 & 1126.2 & 8746.8 \\
\hline & $\mathrm{G}$ & 0.399 & 1.556 & 1014.1 & 7820.6 \\
\hline & $\mathrm{H}$ & 0.405 & 1.474 & 1123.5 & 9146.3 \\
\hline & \multicolumn{4}{|l|}{ Average: } & 8368.6 \\
\hline \multirow{4}{*}{ 1B } & $1-1$ & 0.383 & 1.537 & 1118.8 & 8734.7 \\
\hline & $1-2$ & 0.377 & 1.472 & 1211.4 & 9875.4 \\
\hline & $1-3$ & 0.381 & 1.508 & 1134.9 & 9030.9 \\
\hline & \multicolumn{4}{|l|}{ Average: } & 9213.7 \\
\hline \multirow{4}{*}{ 3B } & $3-1$ & 0.37 & 1.475 & 1004.7 & 8173.7 \\
\hline & $3-2$ & 0.367 & 1.513 & 1138.2 & 9027.6 \\
\hline & $3-3$ & 0.376 & 1.52 & 1136.2 & 8970.2 \\
\hline & \multicolumn{4}{|l|}{ Average: } & 8723.8 \\
\hline
\end{tabular}




\begin{tabular}{|c|c|c|c|c|c|}
\hline \multirow{4}{*}{ 4B } & $4-1$ & 0.379 & 1.536 & 1540.9 & 12038.4 \\
\hline & $4-2$ & 0.375 & 1.502 & 1175.8 & 9394.0 \\
\hline & $4-3$ & 0.379 & 1.463 & 1352.3 & 11092.2 \\
\hline & \multicolumn{4}{|c|}{ Average: } & 10841.5 \\
\hline \multirow{4}{*}{ 5B } & $5-1$ & 0.385 & 1.531 & 1214.1 & 9515.9 \\
\hline & $5-2$ & 0.38 & 1.474 & 951.0 & 7742.1 \\
\hline & $5-3$ & 0.381 & 1.556 & 1081.2 & 8338.2 \\
\hline & \multicolumn{4}{|c|}{ Average: } & 8532.1 \\
\hline \multirow{4}{*}{ 8B } & $8-1$ & 0.389 & 1.537 & 1342.3 & 10479.6 \\
\hline & $8-2$ & 0.384 & 1.505 & 1195.3 & 9530.5 \\
\hline & $8-3$ & 0.384 & 1.538 & 1384.5 & 10802.6 \\
\hline & \multicolumn{4}{|c|}{ Average: } & 10270.9 \\
\hline \multirow{4}{*}{ 9B } & $9-1$ & 0.378 & 1.508 & 1240.2 & 9869.3 \\
\hline & $9-2$ & 0.378 & 1.494 & 1324.1 & 10635.6 \\
\hline & $9-3$ & 0.384 & 1.501 & 1241.6 & 9926.1 \\
\hline & \multicolumn{4}{|c|}{ Average: } & 10143.7 \\
\hline \multirow{4}{*}{ 10B } & $10-1$ & 0.377 & 1.547 & 1237.6 & 9599.7 \\
\hline & $10-2$ & 0.38 & 1.535 & 1243.6 & 9722.0 \\
\hline & $10-3$ & 0.381 & 1.529 & 1233.5 & 9681.1 \\
\hline & \multicolumn{4}{|c|}{ Average: } & 9667.6 \\
\hline
\end{tabular}

Table 5-7: Knit-Line Pull test summary of results

\begin{tabular}{|c|l|l|c|c|}
\hline $\begin{array}{c}\text { Beam } \\
\text { Name }\end{array}$ & \multicolumn{1}{|c|}{ Web Plastic } & \multicolumn{1}{|c|}{ Flange Plastic } & $\begin{array}{c}\text { Metal } \\
\text { Deactivator? }\end{array}$ & $\begin{array}{c}\text { Average Strength } \\
\text { of Knit-Line (lb/ft) }\end{array}$ \\
\hline A & HDPE with 42\% talc & PPTPE & no & 7415.37 \\
\hline C & HDPE with 38\% talc & HDPE, 28\% talc, and 15\% EDPM & no & 8368.56 \\
\hline 5B & $\begin{array}{l}\text { HMW HDPE with UV, } \\
\text { color, and 38\% talc }\end{array}$ & HMW HDPE with UV and color & yes & 8532.07 \\
\hline 3B & HDPE with 38\% talc & $\begin{array}{l}\text { HMW HDPE with UV, color, 20\% } \\
\text { talc and 25\% bonding elastomer }\end{array}$ & no & 8723.82 \\
\hline B & HDPE with 42\% talc & HMW HDPE & no & 8840.99 \\
\hline 1B & HDPE with 38\% talc & $\begin{array}{l}\text { HMW HDPE with UV, color, and } \\
\text { 20\% talc }\end{array}$ & no & 9213.67 \\
\hline 10B & $\begin{array}{l}\text { HMW HDPE with UV, } \\
\text { color, and 38\% talc }\end{array}$ & $\begin{array}{l}\text { HMW HDPE with UV, color, and } \\
\text { 38\% talc }\end{array}$ & no & 9667.58 \\
\hline 9B & $\begin{array}{l}\text { HMW HDPE with UV, } \\
\text { color, and 38\% talc }\end{array}$ & $\begin{array}{l}\text { HMW HDPE with UV, color, and } \\
\text { 38\% talc }\end{array}$ & yes & 10143.68 \\
\hline 8B & $\begin{array}{l}\text { HMW HDPE with UV, } \\
\text { color, and 38\% talc }\end{array}$ & $\begin{array}{l}\text { HMW HDPE with UV, color, and } \\
\text { 20\% talc }\end{array}$ & yes & 10270.89 \\
\hline 4B & HDPE with 38\% talc & HMW HDPE with UV and color & no & 10841.52 \\
\hline
\end{tabular}


The strengths of the knit-line of the specimens with flanges composed of HMW HDPE were all greater than the PPTPE flange beam. In terms of manufacturing chronology, beams $\mathrm{A}, \mathrm{B}$, and C were developed before the others tested and the additives and formula strategies used in the other beams was theorized to be stronger and have better properties than beams A, B, and C. It is promising, considering the strength of the bond at the knit-line, that beams $\mathrm{A}$ and $\mathrm{C}$ are the weakest and beam B is towards the bottom of the strength list of Table 5-7. This trend shows that the bond strength between the HMW HDPE plastics is greater than the older beams.

The talc content of the web plastics only differs from $38 \%$ to $42 \%$ (relatively quite close to each other) and there is no apparent pattern in the strength at the knit-line due to the talc content of the web plastic. Therefore, only the flange plastics will be considered for evaluating strength trends due to filler content. Overall, for the $38 \%$ talc content HMW HDPE web plastic and HMW HDPE flange plastic beams, the initial addition of talc filler significantly increases the strength of the bond at the knit-line, but after the initial addition of talc filler, a difference between $38 \%$ and $20 \%$ is not evident. For the $38 \%$ talc content HDPE web plastic and HMW HDPE flange plastic beams, the addition of talc filler has an adverse effect on the strength of the bond at the knit-line between.

For the Push-Through tests, three different beam pairs could be compared to quantify the effect of the metal deactivator, because only the flange plastic needed to be the same. Here, for the Knit-Line tests, the web and flange plastics must be the same in order to quantify the effect of the metal deactivator. Therefore, the only beams that can be directly compared for the effect of the metal deactivator are $9 \mathrm{~B}$ and $10 \mathrm{~B}$. Between these beams, the addition of the metal deactivator increased the strength at the knit-line by $4.9 \%$. 
Overall, with the exceptions of beam A and $4 \mathrm{~B}$ (outliers on the strength range), the rest of the beams steadily increase in strength at the knit-line with no major breaks in the values. This may indicate certain trends, however it is important to note that only 3 specimens of each beam type were tested and a larger sample size would support more confidence in the values.

\section{Tensile Tests}

Tensile tests were performed on multiple flange and web plastics of the aluminum-plastic composite I-beams per ASTM D638-10 [6], and the modulus of elasticity and tensile strength for each specimen was calculated according to the same standard. Two specimens of each plastic were tested. Example specimens after testing are shown in Figure 5-23 and the results are summarized in Table 5-8. Similar to how the knit-line strength results were presented, the tensile test results in Table 5-8 are listed from smallest to greatest modulus of elasticity values for easier comparisons.

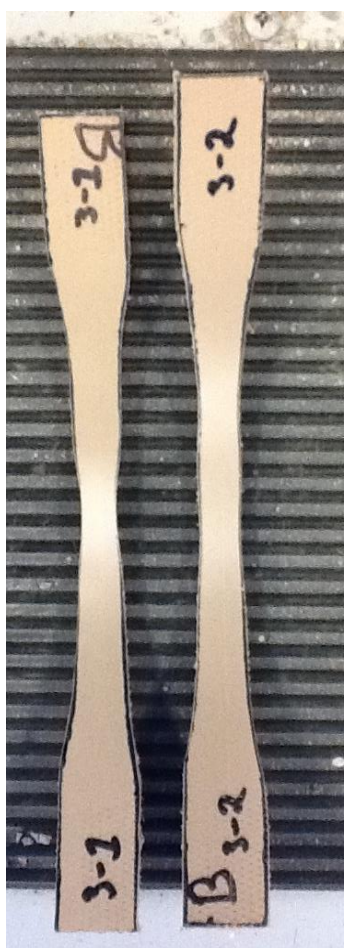

A

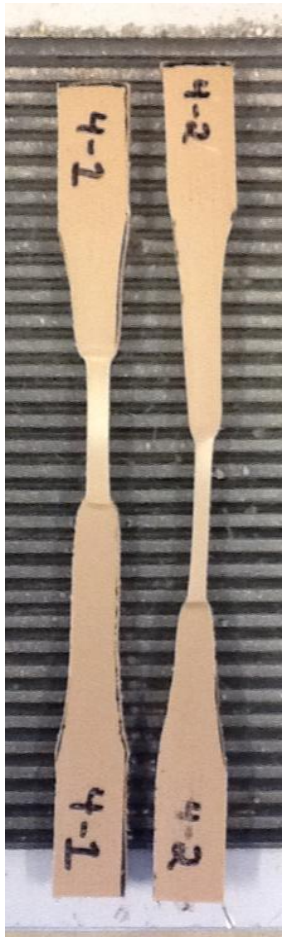

B

Figure 5-23: Example tensile test specimens after testing 
Table 5-8: Tensile test results

\begin{tabular}{|c|c|c|c|}
\hline Beam Name & Web/Flange & E (psi) & Tensile Strength (psi) \\
\hline 3B & Flange & 80200 & 1400 \\
\hline 4B & Flange & 87000 & 2400 \\
\hline 5B & Flange & 95400 & 2630 \\
\hline 28/15" & Flange & 102000 & 2150 \\
\hline 1B & Flange & 180000 & 3050 \\
\hline 8B & Flange & 186000 & 2900 \\
\hline "28/15" & Web & 221000 & 3120 \\
\hline 10B & Web & 864000 & 10500 \\
\hline 9B & Web & 881000 & 11000 \\
\hline 4B & Web & 1030000 & 10600 \\
\hline
\end{tabular}

Due to limited time and material availability, only two specimens of each plastic were tested and a larger sample set is desired for more confidence in the modulus and strength values. For the purpose of this thesis, understanding the general trend with respect to filler materials and content was desired and was gained through these tests. The general trends in modulus of elasticity and tensile strength will be addressed, but the actual values of modulus must be viewed with the limited number of specimens in mind.

Not only must the web of an I-beam resist shear forces, it must also be stiff enough to support the flanges' increased distance from the neutral axis. To resist these shear forces, the web needs to have a high modulus for stiffness considerations. Therefore, as designed, the web plastics all have a larger modulus of elasticity than the flange plastics. Also, note that the three web plastics made from HDPE have modulus values at least three times that of the " $28 / 15$ " web plastic. This is again due to the switch to the high molecular weight high-density polyethylene previously described in this chapter. The web plastics with the three highest modulus values all have $38 \%$ talc filler content. It can be seen that 4B's web has a large jump in modulus value compared to 
the plastic just below it. The only difference between $10 \mathrm{~B}, 9 \mathrm{~B}$, and $4 \mathrm{~B}$ is that $10 \mathrm{~B}$ and $9 \mathrm{~B}$ are high molecular weight, while $4 \mathrm{~B}$ is not. Tensile strengths are all extremely close between these three web plastics.

Beam 3B's flange has both a significantly lower modulus of elasticity and tensile strength than the other plastics. This beam has $25 \%$ of the bonding elastomer described in the Materials and Geometry chapter. Problems were encountered immediately with the beams that contained this elastomer, mostly with separation from the other components of the plastic formula during extrusion due to differing melting temperatures. For this reason, it was decided almost immediately after this extrusion run that this elastomer would not be mixed with the HMW HDPE for future research and development. Therefore, only one beam with the elastomer in the flange was tested, just for data comparison, and Beam 3B's modulus value was at least $7.8 \%$ less than all the other flange plastics and its tensile strength was at least $41.7 \%$ lower. Although not shown in Table 5-8, it is important to note that the values from specimen to specimen varied greatly for Beam 3B's flange plastic. This shows the inconsistencies and variability associated with this plastic's properties, which is caused by the separation that occurred during extrusion.

As previously discussed, beams $4 \mathrm{~B}$ and $5 \mathrm{~B}(\mathrm{md})$ have the same flange plastics with the exception of the metal deactivator (md) present in one. This same relationship exists for beams $1 \mathrm{~B}$ and $8 \mathrm{~B}(\mathrm{md})$. In both cases, these plastic pairs had close modulus and strength values, with the metal deactivator addition resulting in an average of a $6.5 \%$ increase in the modulus of elasticity. Beams $1 \mathrm{~B}$ and $8 \mathrm{~B}$ have $20 \%$ talc content, compared to $4 \mathrm{~B}$ and $5 \mathrm{~B}$ having $0 \%$ talc content. It is expected that higher talc content increases the stiffness of a plastic. Therefore, it is expected that an increase in talc would result in an increase in the elastic modulus. In this case, a jump from 
$0 \%$ to $20 \%$ resulted in a doubling of the elastic modulus in the flange plastics from beams $1 \mathrm{~B}$ and $8 \mathrm{~B}$ to $4 \mathrm{~B}$ and $5 \mathrm{~B}$.

\section{Duration of Load Tests}

Tertiary creep is the number one characteristic of a beam observed in a duration of load test. Tertiary creep is defined as increasing creep rate and can be seen on a deflection vs. time graph as an increase in the slope of the line. Table 4-6 is repeated here for ease of explanation.

Table 4-6: Duration of Load test specimen details

\begin{tabular}{|c|l|l|r|l|}
\hline DoL \# & \multicolumn{1}{|c|}{ Beam Identification } & \multicolumn{1}{|c|}{ Date Test Started } & Load (lbs) & \multicolumn{1}{|c|}{ Length of Test } \\
\hline 1 & 28-15 Bandburry Line (1) & 27 April, 2013 & 2464 & 27 hours \\
\hline 2 & 28-15 Bandburry Line (2) & 3 May, 2013 & 1680 & 90 days \\
\hline 3 & WP Production Line Replication & 18 September, 2013 & 1680 & 63 days \\
\hline 4 & 5B from Table 4-1 & 14 December, 2013 & 1680 & 12 days \\
\hline 5 & 1B from Table 4-1 & 8 January, 2014 & 2200 & on going \\
\hline 6 & 10B from Table 4-1 & 8 January, 2014 & 2200 & on going \\
\hline
\end{tabular}

Only Beam 2 was tested for the complete 90 days. Other influences during the research and development stages of these aluminum-plastic composite I-beams, along with other logistics, dictated when the duration of load tests were stopped. Tertiary creep never occurred in any of the beams and therefore, none of the tests were stopped because a beam demonstrated tertiary creep. Because of the differing time lengths of each of these tests, only the data gathered up to about 4000 minutes (67 hours) is shown in Figure 5-24. 


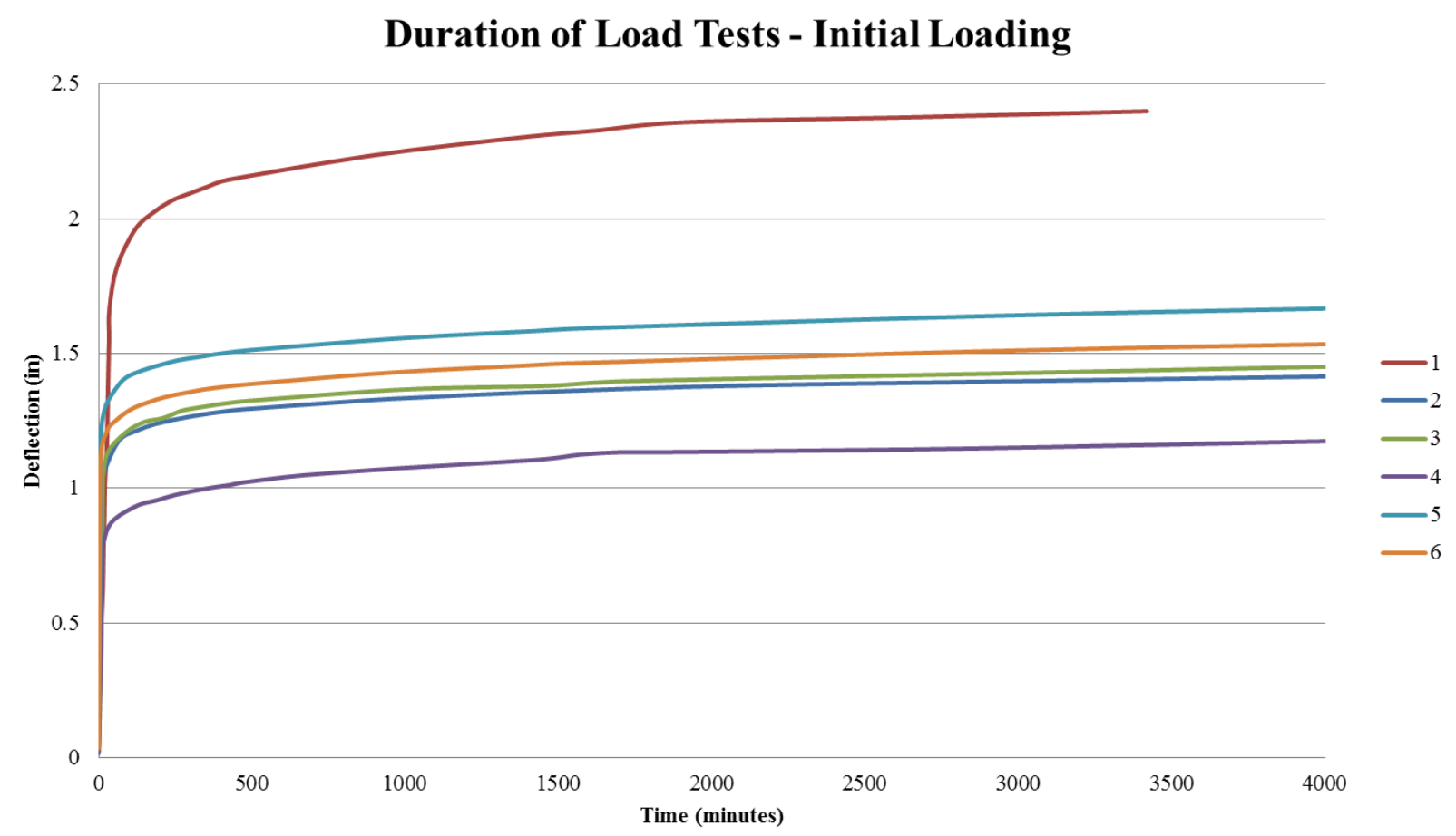

Figure 5-24: Duration of Load test results

The amount of deflection under the initial loading time (about 200 minutes), was dependent on the amount of static load placed on the beam. As expected, comparing Table 3-7 with Figure $5-24$, it is noted that the beam with the highest load has the highest initial deflection and this trend continues to the lowest load. It is interesting that the beam composed of the high molecular weight HDPE in both the flange and web (DoL \#6) has almost the same exact curve as the old "28/15" beam (DoL \#2). Due to the research and development aimed at a desired increase in stiffness (described above in the tensile test section), this result is particularly promising, because DoL \#6 is loaded with over $25 \%$ more of the static load on DoL \#2. Because none of the beams exhibited tertiary creep and no decisions were made because of these tests, other results from the Duration of Load tests are not of particular interest to this thesis and are not discussed here. 


\section{Chapter 6 : Numerical Model of Deboss Region}

A numerical model was developed using the finite element software ABAQUS to better understand the underlying physics of the shear connector in the composite I-beams. Initially, this model has been used to represent the loading and geometry of the Push-Through Test on only a quarter of a single flange of the I-beam's cross-section with a length consisting of a single deboss region. Verification of the model's accuracy will have potential future applications to allow for rapid assessment of the controlling input parameters, primarily the deboss size and shape, without having to construct a physical model. The model's geometry and/or material properties could simply be modified in ABAQUS. This would allow for confidence in predicting the Ibeams' performance under differing design protocols.

A specimen cut from Beam \#1B was tested to validate the numerical model. The internal geometry was Aluminum Profile 1 and the flange was cut open to expose this region, shown in Figure 6-1. The physical deboss region can be seen, which was modeled using three-dimensional elasticity elements.

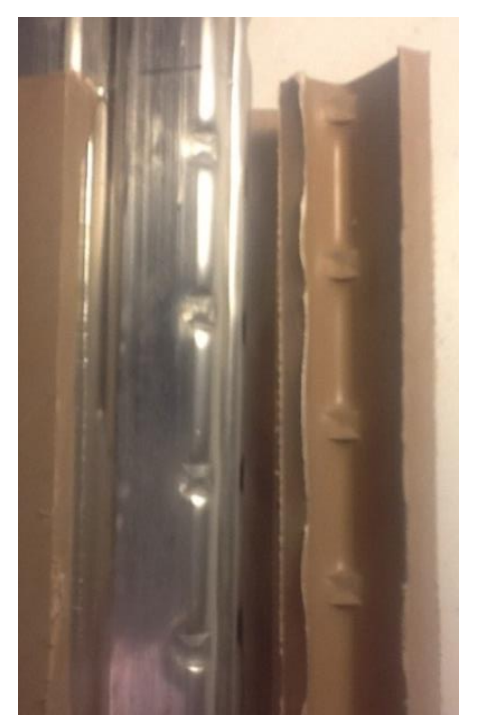

Figure 6-1: The aluminum and flange plastic deboss regions - one quarter of a single flange 


\section{Geometry}

Three solid, homogeneous regions were modeled: the aluminum, the deboss region of the flange plastic, and the remaining flange plastic. The deboss region was modeled as its own domain to allow for refinement of the mesh in this region (the critical area of study) without compromising the computational time by having to overly refine the mesh. Because the aluminum has a much higher elastic modulus than the plastic, it could have been modeled as a rigid body. This would have cut back on computational time required for ABAQUS to run the analysis. However, the simplicity of the parts' geometries resulted in the decision to model the aluminum with its actual material properties and apply a mesh instead of using the rigid body constraint. Modeling the aluminum as an elastic region will also allow for future modification of the geometry and/or material properties of this section, which is one of the main goals addressed in developing this numerical model. Figures 6-2 through 6-4 show the three regions modeled in ABAQUS and the assembled model.

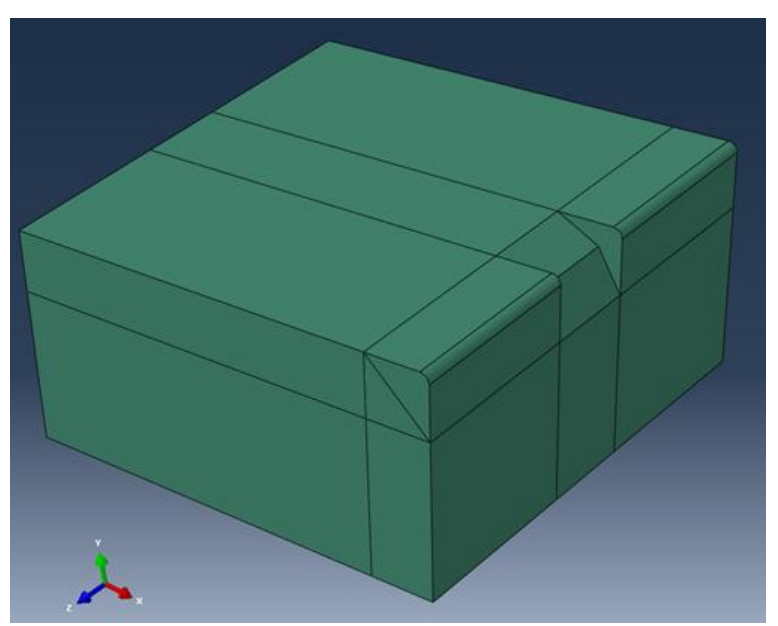

A

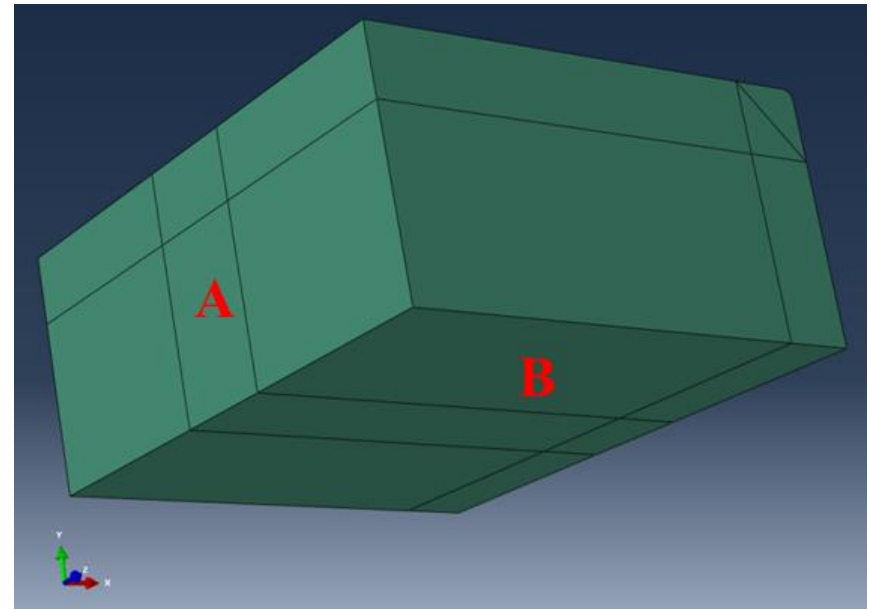

B

Figure 6-2: Aluminum region of the deboss section, with 2 different views with faces $\mathrm{A}$ and $\mathrm{B}$ referred to for boundary conditions 


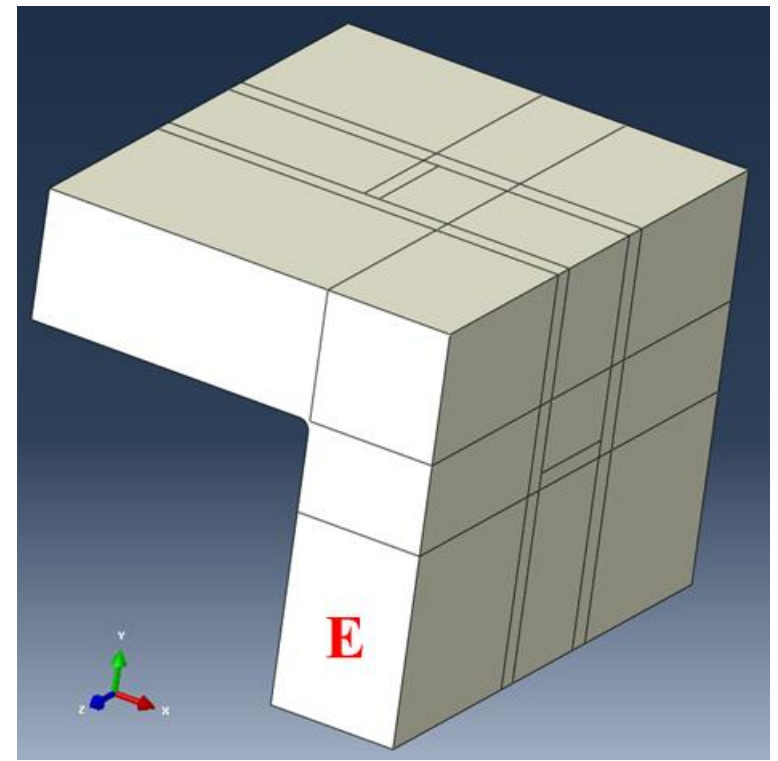

A

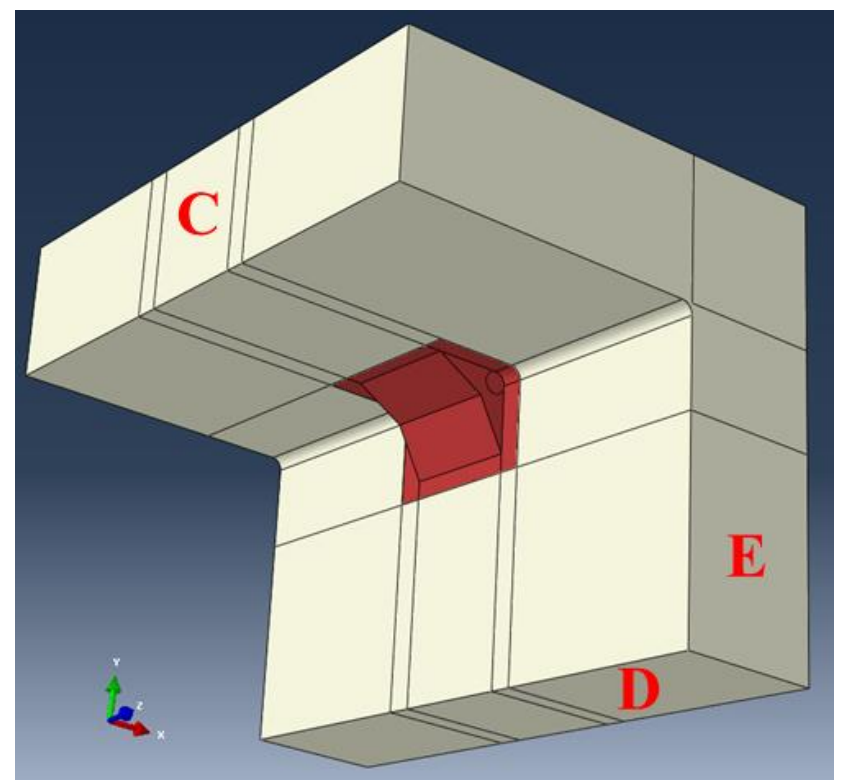

B

Figure 6-3: Flange plastic regions, 2 different views with faces C, D, and E labeled The shaded region in the center of the figure on the right is the most critical region of plastic as it contains the material that is embedded in the aluminum notch.

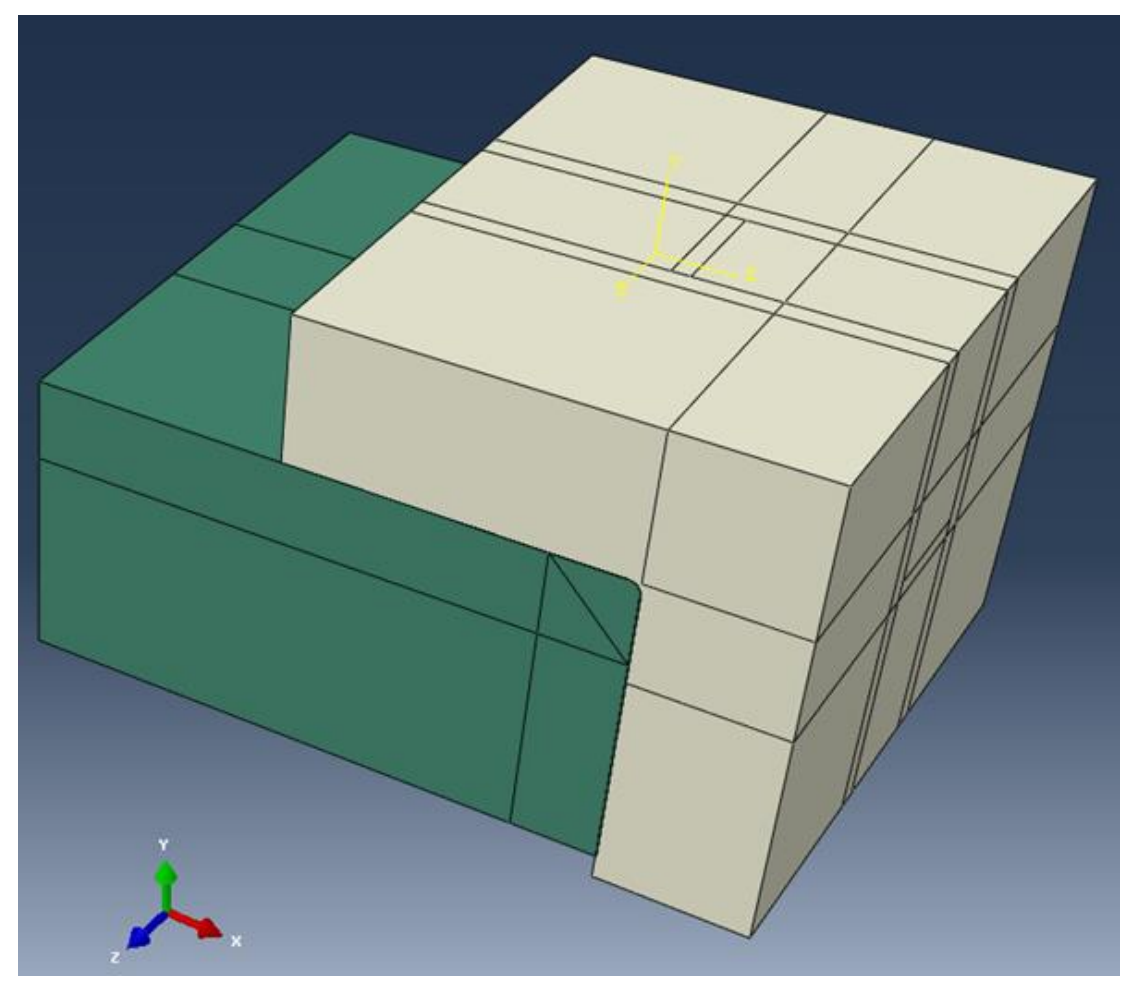

Figure 6-4: Assembled model in ABAQUS

Figures 6-1 through 6-3 show that although the modeled region is a representation of the physical deboss geometry, it is not identical. Instead, as is common in numerical models, the key 
features of the domain have been idealized for the purposes of this study. One of the main goals of this numerical model is to compare the experimental results with theoretical predictions and gain confidence for future shear connector geometry modifications. Therefore, if this model with idealized geometry can give results that are reasonably close to the experimental results, it will be considered accurate and ready for application to other configurations. Modeling the exact geometry of the areas away from the deboss region are not critical, because under the loading assumed in this study, only the deboss region is resisting the load and the material even a small distance removed from this region will not make a difference in the results.

\section{Material Properties}

Length and force are dimensionless in ABAQUS; therefore care must be taken by the user to ensure consistent units throughout all inputs. Pounds and inches were chosen for this model. Using those base units, density must be entered into ABAQUS in $\mathrm{lb} / \mathrm{in}^{3}$ divided by acceleration due to gravity in appropriate units $\left(386.2 \mathrm{in} / \mathrm{s}^{2}\right.$ in this case). Although a mandatory input for ABAQUS, the density is irrelevant because the model was only subjected to static loading and inertial effects were ignored. Both the aluminum and plastic were given a uniform density distribution and were classified as isotropic. A true stress vs. true plastic strain curve was needed for the flange plastic. Because there were two tensile tests run on the flange plastic of the beam being compared with this model, multiple analyses were ran for both curves, shown in Figures 6-5 and 6-6. ABAQUS does not allow for the material stiffness to decrease. Therefore, the idealized curves represented in these figures show what was assumed in the numerical analysis. After the maximum true stress of the exact curve, the idealized curve is increasing linearly. This increase is extremely small and therefore the line almost looks horizontal on Figures 6-5 and 6-6. Of particular interest in this model is the magnitude of loading where the deboss region begins to 
yield. Hence this behavior represents an under-prediction of total structural capacity of the deboss while providing an estimate of post-yield behavior of the shear connection.

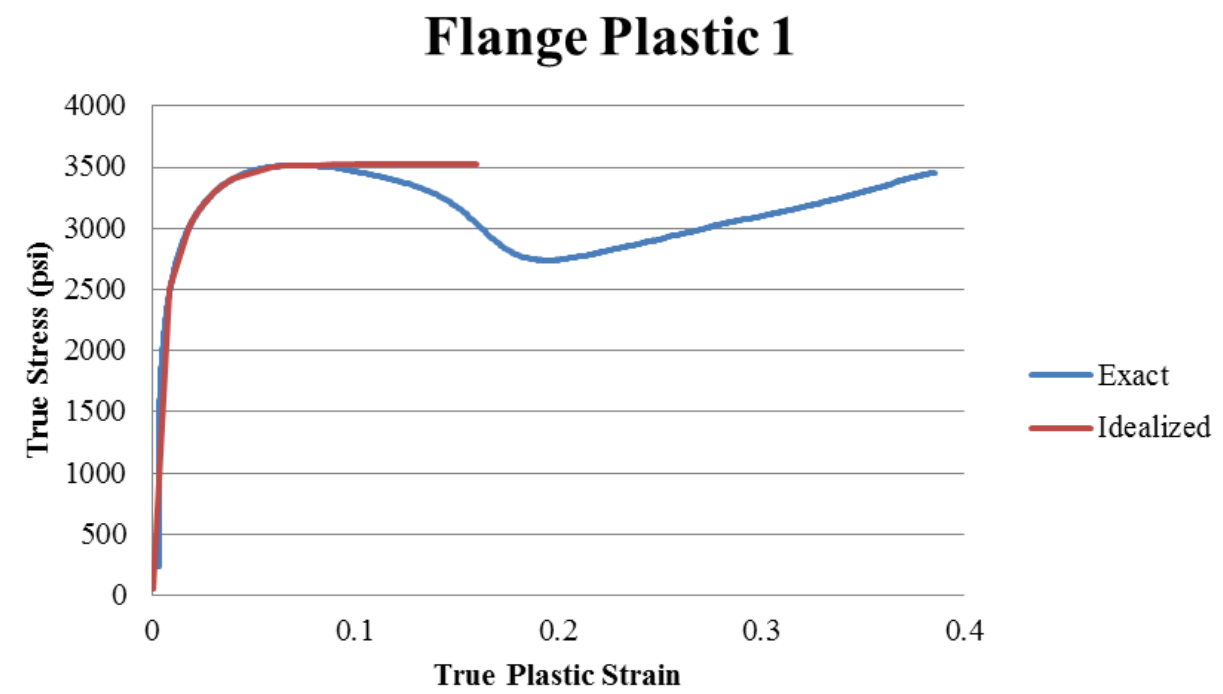

Figure 6-5: Plastic material property input curve for ABAQUS - Flange Plastic 1

Flange Plastic 2

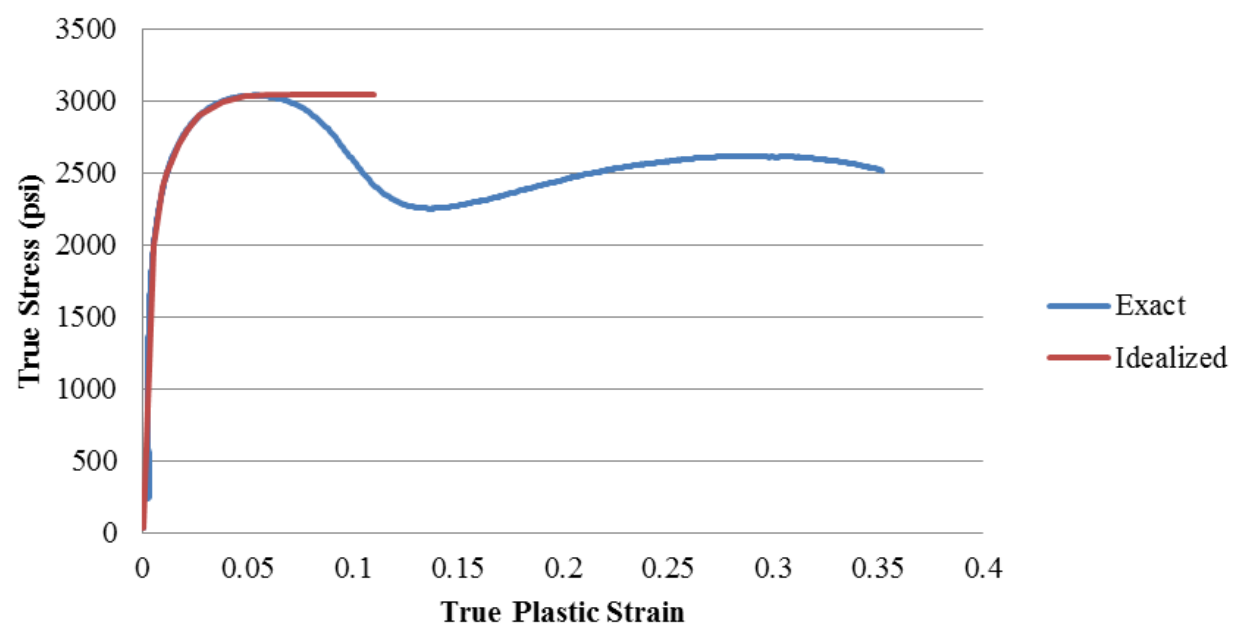

Figure 6-6: Plastic material property input curve for ABAQUS - Flange Plastic 2

Strain gauges were not used during the tensile tests to calculate Poisson's ratio and this quantity has not been measured by the manufacturer or any other entity, so exact values are not yet 
known. With information found in the literature and values estimated by the plastic distributers, it was known that a range of 0.42-0.49 was possible for Poisson's ratio of the plastics, but this value is driven by talc filler content, amount and type of additives, etc. Therefore, several different values of the Poisson's ratio were assumed for the flange plastic of Beam \#1B. Table 6-1 lists the material properties of the materials used, including both flange plastic tensile test results and the numerical model results discussed later in this chapter will specify for which material properties they correspond. Because only a quarter of one flange was modeled, the web plastic material properties were not included in the model. For the remainder of this chapter, "plastic" will refer to the flange plastic.

Table 6-1: Material Property Inputs for ABAQUS

\begin{tabular}{|l|r|r|r|}
\hline Material & \multicolumn{1}{|c|}{ Aluminum } & Flange Plastic 1 & Flange Plastic 2 \\
\hline Poisson's Ratio & $* 0.33$ & $0.42-0.49$ & $0.42-0.49$ \\
\hline Young's Modulus (psi) & $* 10,000,000$ & 199,000 & 161,000 \\
\hline Density $\left(\mathbf{l b} /\right.$ in $^{3}$ ) & $* 0.0975$ & 0.0401 & 0.0401 \\
\hline ABAQUS input Density & 0.00025245 & 0.00010383 & 0.00010383 \\
\hline *Values referenced from Aerospace Specification Metals Inc. [11]. \\
\hline
\end{tabular}

\section{Interactions between the Aluminum and Plastic}

A tie constraint was applied between the joining surfaces of the two plastic regions. A tie constraint "allows you to fuse together two regions even though the meshes created on the surfaces of the regions may be dissimilar" [24]. This essentially models all of the plastic as one continuous material, while allowing for different sized meshes at different locations, which in this case is the refined mesh at the deboss region. The interaction between the touching aluminum and plastic surfaces was defined as hard contact with normal behavior that allowed for 
separation after contact. Hard contact will not allow the materials to protrude into each other or occupy the same space at the same time.

\section{Boundary Conditions}

Faces $\mathrm{A}$ and $\mathrm{B}$ of the aluminum labeled in Figure 6-2 were assumed to be fixed. This means that all displacement components were specified to be zero. Faces $\mathrm{C}$ and $\mathrm{D}$ of the plastic labeled in Figure 6-3 were given boundary conditions that did not allow them to translate in the $\mathrm{X}$ or $\mathrm{Y}$ directions. These boundary conditions simulate symmetry about these planes. The plastic boundary conditions will closely represent the relationship between the plastic and aluminum in the physical part, while still allowing the plastic to potentially "bulge out" at the corner as observed during the experimental Push-Through tests.

\section{Meshing}

Regions were purposely defined to allow for mesh refinement at the critical zone of the plastic deboss region. Table 6-2 shows the mesh properties and these regions are shown in Figures 6-7 and 6-8. The highlighted cells are the total numbers of nodes and elements.

Table 6-2: Mesh properties for the ABAQUS model

\begin{tabular}{|c|c|c|c|c|c|}
\hline Model Region & $\begin{array}{c}\text { ABAQUS } \\
\text { Element Type }\end{array}$ & Element Shape & $\begin{array}{c}\text { Geometric } \\
\text { Order }\end{array}$ & $\begin{array}{c}\text { \# of } \\
\text { Nodes }\end{array}$ & $\begin{array}{c}\text { \# of } \\
\text { Elements }\end{array}$ \\
\hline Aluminum & $* \mathrm{C} 3 \mathrm{D} 8 \mathrm{R}$ & hexahedral & linear & 1908 & 1457 \\
\hline \multirow{3}{*}{ Plastic Deboss Region } & $* \mathrm{C} 3 \mathrm{D} 8 \mathrm{R}$ & hexahedral & linear & \multirow{3}{*}{4510} & 3631 \\
\hline & $* * \mathrm{C} 3 \mathrm{D} 6$ & wedge & linear & & 66 \\
\hline & $* * * \mathrm{C} 3 \mathrm{D} 4$ & tetrahedral & linear & & 90 \\
\hline \multirow[t]{2}{*}{ Remaining Plastic } & $* \mathrm{C} 3 \mathrm{D} 8 \mathrm{R}$ & hexahedral & linear & 1916 & 1335 \\
\hline & & & Totals & 8334 & 6579 \\
\hline \multicolumn{6}{|c|}{ *8-node linear brick, reduced integration, hourglass control } \\
\hline \multicolumn{6}{|c|}{$* * 6$-node linear triangular prism } \\
\hline \multicolumn{6}{|c|}{$* * * 4$-node linear tetrahedron } \\
\hline
\end{tabular}




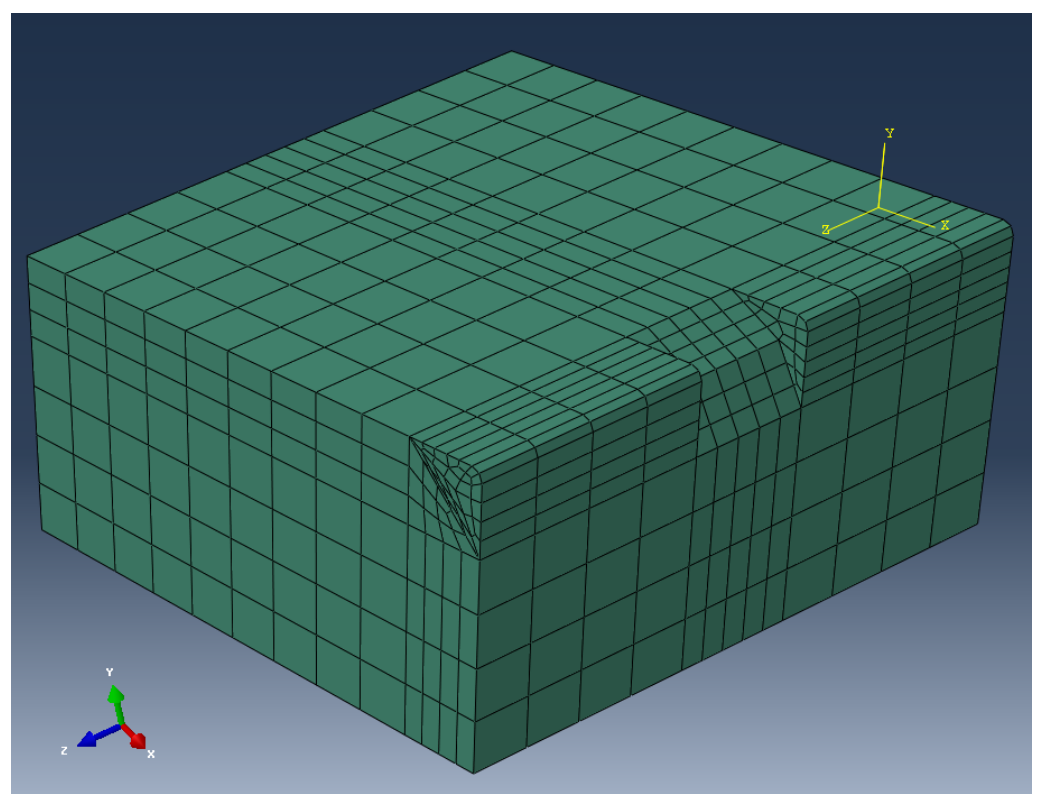

Figure 6-7: Aluminum mesh

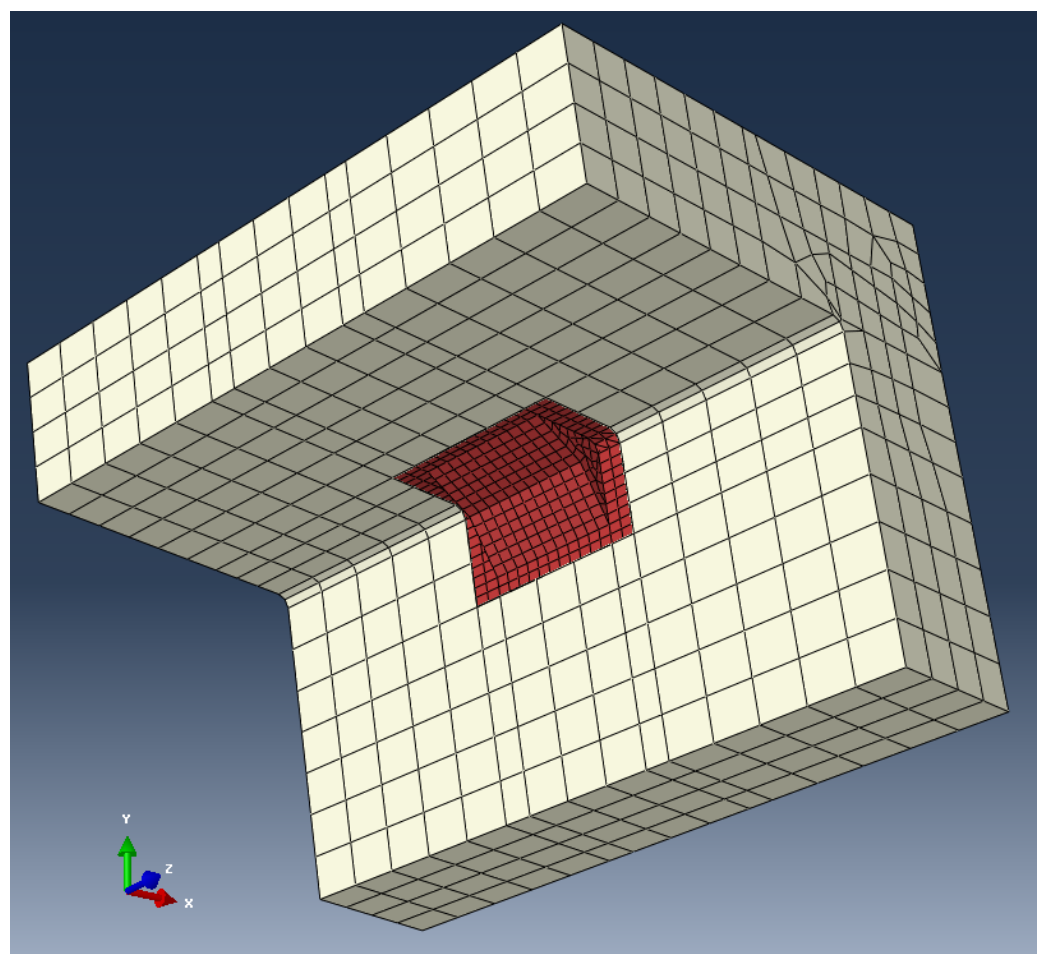

Figure 6-8: Plastic mesh, refined at the deboss region

\section{Loading}

The primary loading surface was defined on face E of the plastic part labeled in Figure 6-3. This is one important difference between the experimental tests and the numerical model. In the Push- 
Through Test, the aluminum is physically going through the displacement while the plastic region remained vertically fixed at the boundaries. From the boundary conditions and the defined loading surface, it can be seen that in the ABAQUS model the situation is reversed and the plastic is given an imposed displacement. Considering the force applied to the aluminum profile during the physical test created a reaction pressure load on the plastic surface at the bottom, this is an accurate representation of the loading.

The loading was imposed using a displacement boundary condition on face E in Figure 6-3. The analyses were terminated once the plastic reached the portion of its stress strain curve corresponding to a constant load needed to continue displacement. This is because adaptive remeshing was not used and the mesh of the distorted geometry reached a point of instability. The ABAQUS analysis was terminated once the elements deformed to a point where they were geometrically unstable and the analysis could not continue. For the purposes of comparing with the experimental results, failure was defined at this point.

\section{Quantities of Interest}

The physical measures required to perform a direct comparison with the experimental results are 1) the total reaction force on face $E$, and 2) the corresponding displacement of face $E$. The total reaction force was found by adding the reaction forces of all nodes on this face in the ABAQUS model at the point of termination. This quantity was compared to the load per deboss recorded during physical testing at the corresponding displacement. For interpretation of the results, the experimental load values must be divided by four because only a quarter of the flange crosssection, consisting of a single deboss region, was modeled in ABAQUS. This factoring was included in all comparisons between the results of the numerical model and the physical experiment. 


\section{Results and Discussion}

Figure 6-9 gives the results of the small specimen tested in the Push-Through test. The y-axis is the total load taken divided by 4 . This normalizes the load to a load per deboss region and therefore can be directly compared with the total reaction forces found in the ABAQUS model.

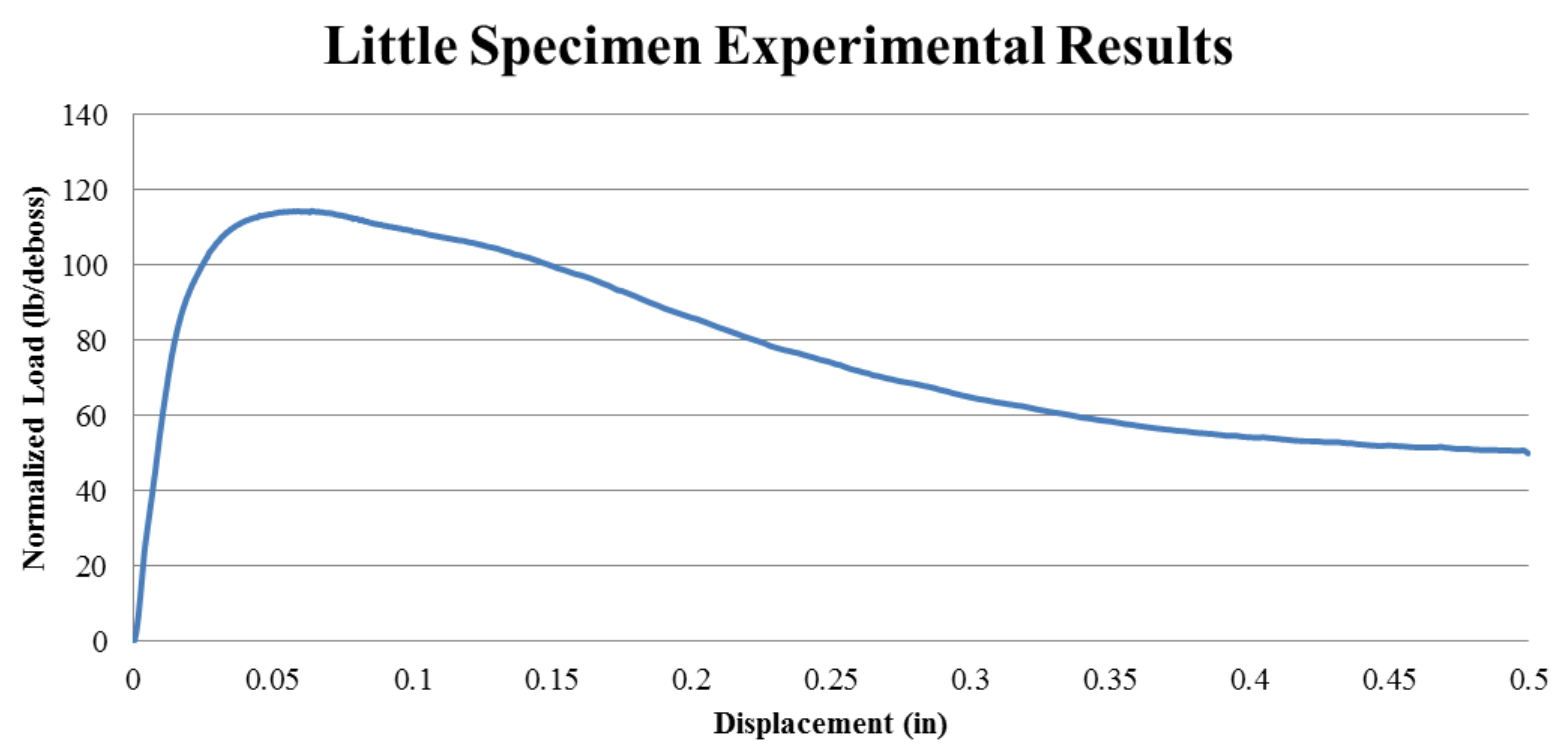

Figure 6-9: Small specimen Push-Through test experimental results

Figure 6-10 shows an example figure of the results from ABAQUS. This example is the Flange Plastic 1 with Poisson's Ratio of 0.45 and the contours are Von Mises stress. Figure 6-10 is for visual purposes only and the actual quantities of stress are not shown as they will not be discussed here. 


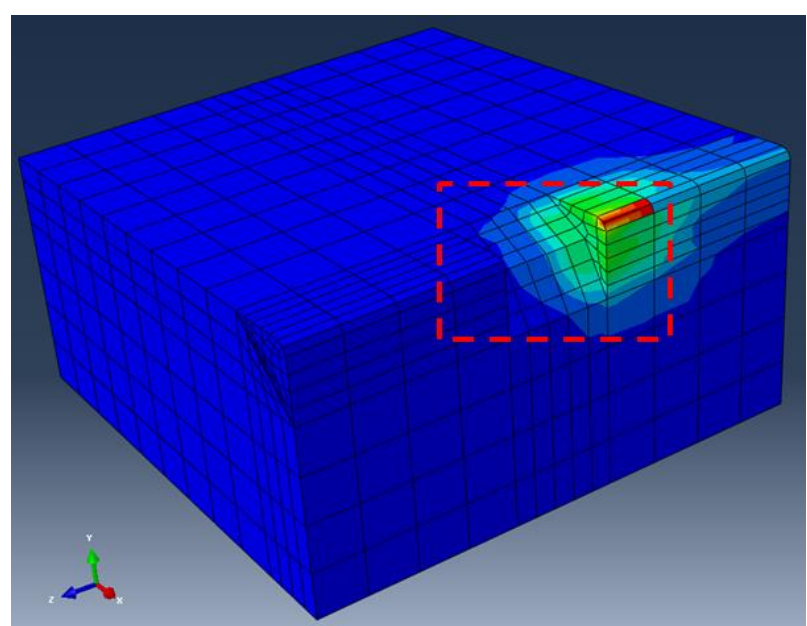

A) Aluminum

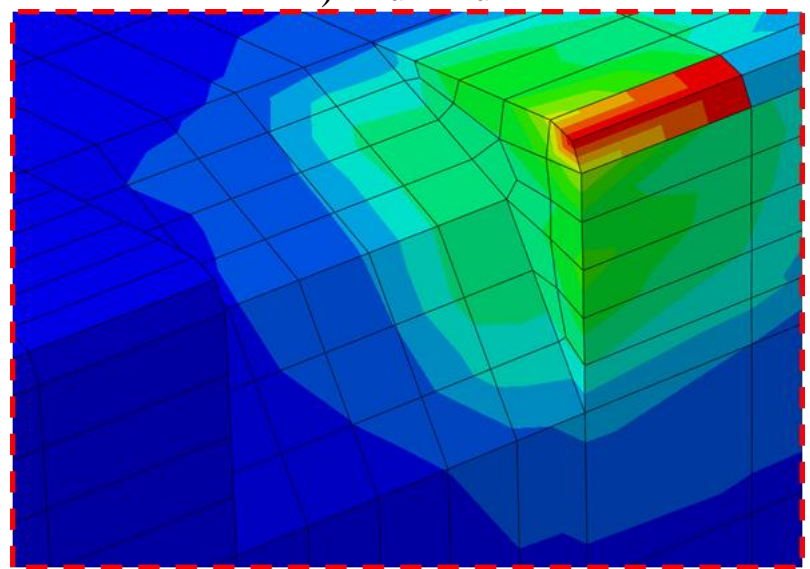

C) Aluminum zoomed deboss region

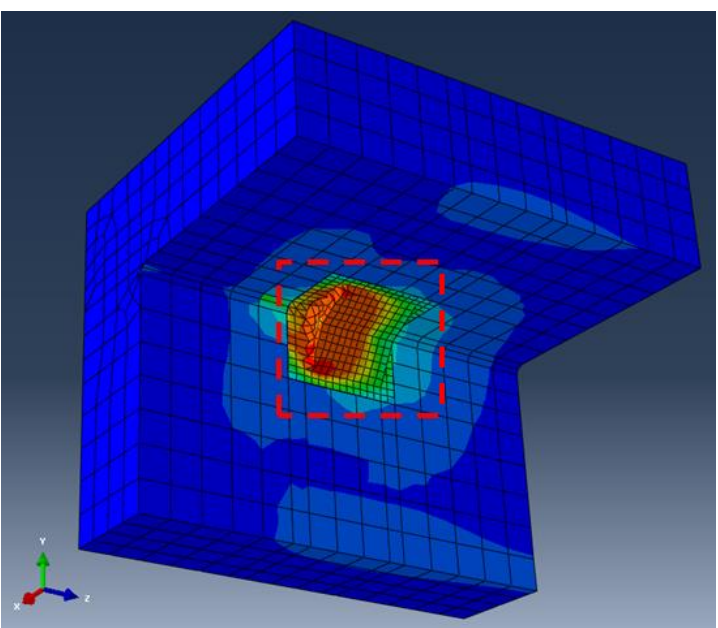

B) Plastic

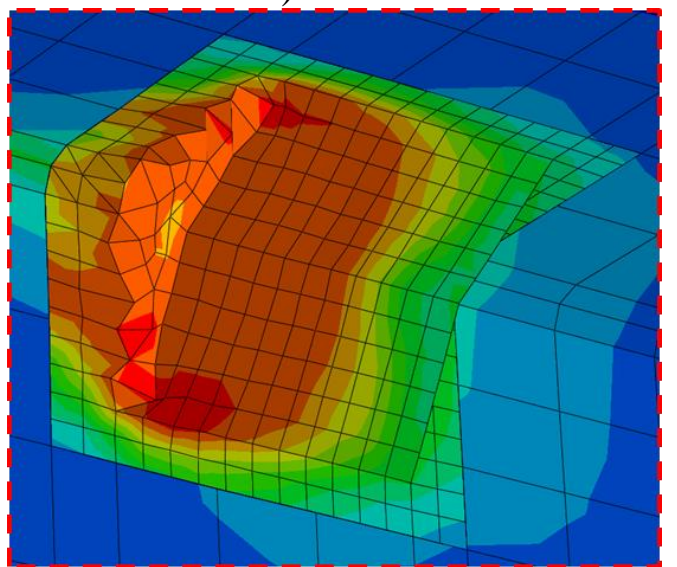

D) Plastic zoomed deboss region

Figure 6-10: Example ABAQUS Results

Table 6-3 shows the summarized results from the ABAQUS model. Excellent agreement was obtained, with several of the results within ten percent for the values of Poisson's ratio tested. The model was run for the two flange plastic curves shown above in Figures 6-5 and 6-6, and for eight different Poisson's ratio values, 0.42-0.49, resulting in 16 different runs performed in ABAQUS. The highlighted cells are for results equal to or less than $10 \%$ different from the experimental results. Overall, all analyses terminated once the plastic began to deform to a point where the individual elements protruded into one another. This corresponds to the point where the plastic reaches the non-linear portion of its stress-strain curve and would need more vigorous computational techniques in the model to be analyzed. 
Table 6-3: ABAQUS Results

\begin{tabular}{|l|c|c|c|c|c|c|c|c|}
\hline & \multicolumn{7}{|c|}{ Flange Plastic 1 } \\
\hline Poisson's Ratio & 0.42 & 0.43 & 0.44 & 0.45 & 0.46 & 0.47 & 0.48 & 0.49 \\
\hline Max Load (lb/deboss) & 81.3 & 84.7 & 82.3 & 84.3 & 81.3 & 85.5 & 86.1 & 78.9 \\
\hline At displacement (in) & 0.0134 & 0.0306 & 0.0137 & 0.0180 & 0.0194 & 0.0185 & 0.0147 & 0.0089 \\
\hline \multicolumn{1}{|c|}{ \% diff } & $9.0 \%$ & $-20.4 \%$ & $8.3 \%$ & $-4.6 \%$ & $-11.6 \%$ & $-4.9 \%$ & $9.7 \%$ & $54.8 \%$ \\
\hline & \multicolumn{7}{|c|}{ Flange Plastic 2 } \\
\hline Poisson's Ratio & 0.42 & 0.43 & 0.44 & 0.45 & 0.46 & 0.47 & 0.48 & 0.49 \\
\hline Max Load (lb/deboss) & 72.2 & 72.6 & 71.9 & 66.1 & 73.7 & 67.3 & 77.0 & 65.6 \\
\hline At displacement (in) & 0.0168 & 0.0170 & 0.0132 & 0.0084 & 0.0172 & 0.0088 & 0.0153 & 0.0071 \\
\hline \% diff & $-15.9 \%$ & $-15.4 \%$ & $-1.7 \%$ & $34.7 \%$ & $-15.0 \%$ & $32.0 \%$ & $-4.8 \%$ & $66.1 \%$ \\
\hline
\end{tabular}

There are several key results in this Table. First, Flange Plastic 1's results are much closer to the experimental values than Flange Plastic 2's results. This suggests the tensile test for flange plastic 1 better represents the flange plastic of the small specimen. Second, assuming that flange plastic 1 controls, the results for Poisson's ratio of $0.44-0.48$ for this particular plastic are consistent and all results are within $10 \%$ of experimental values for this range, with the exception of one at $11.6 \%$. The confidence in the ABAQUS model would be greater if the exact Poisson's ratio was known for each of the plastics.

Note that the results for a Poisson's ratio of 0.49 were off by more than $50 \%$ for both plastic curves. This result is due to an internal limitation of ABAQUS. When a material's ratio value approaches incompressibility (0.50), the solver in ABAQUS begins to have trouble converging. This is also shown by the low displacement values reached for both plastic curves at Poisson's ratio equal to 0.49 . These results are included here only for purposes of comparison.

Overall, the correlation of these results is very good. If the exact material properties are known for any plastic, this model could be modified for any deboss geometry and the load at which the plastic at a single deboss region would begin to yield and excessively deform could be calculated 
within $10 \%$. Although the results of an analysis past this point would be interesting, it is important to note that under realistic loading that these plastic-aluminum composite I-beams will see, the deboss regions will not reach this point of deformation. If the plastic at the deboss regions deforms enough to separate from the aluminum at the deboss regions, the beams would be considered failed from a performance perspective in actual construction. In the field, this failure would be seen by observing the bulging out on the corners of the flange. This behavior was shown in Figure 5-2 of the Results and Discussion chapter.

\section{Sources for Discrepancy}

Although good agreement was found between the theoretical predictions of deboss strength and experimental results, there are several possible sources for discrepancy between the numerical model results and experimental values. These will be summarized here.

1. The deboss region geometry was idealized in the ABAQUS model.

2. Two different true stress versus true plastic strain curves were used for the analyses, because two tensile tests were ran on the flange plastic from Beam \#1B (beam type that the small specimen was cut from). The results between the two tensile tests differed and were not averaged.

3. The experimental stress strain curves were idealized in ABAQUS. In actuality, after yielding, the plastic continues to resist load, but failure was assumed at the point that the ABAQUS analyses were terminated. Termination was due to the idealized curves.

4. Only one specimen was used for the experimental comparison. More time and resources would allow for more testing to compare with the ABAQUS model.

5. The ABAQUS model assumes that only the surface area between the plastic and the aluminum of the deboss region resists the load. In actuality, hoop stress most likely exists 
around the flanges due to residual stresses induced during extrusion. This hoop stress helped to resist the load during the physical experiments, but has not been quantified.

A more comprehensive analysis in ABAQUS involving adaptive remeshing would allow for a more robust comparison with the experimental results for what is occurring after the plastic yields and pushes out of the aluminum deboss region. This is outside the scope of this thesis, but a possibility for future research. 


\section{Chapter 7 : Conclusions}

This thesis investigated plastic-aluminum composite I-beams new to the world of composites in structural engineering. The pertinent literature was reviewed, the deboss geometries were discussed, the material properties were investigated, and several physical tests were performed to quantify different strengths and properties of the beams. Finally, a numerical model was developed in ABAQUS on one geometry of the deboss regions and results were compared with a physical experiment. Conclusions and recommendations for future work are presented for this novel composite.

Many physical experiments were performed on the plastic-aluminum composite I-beams discussed in this thesis. Although this thesis is just an initial investigation of these beams, there are several quantifiable results.

\section{Push-Through Tests}

The Push-Through test was designed specifically for these composite I-beams to quantify the strength between the aluminum and the plastic. The following bullet points summarize the results from this testing.

- The strengths between the aluminum and plastic of Aluminum Profiles 1, 2, and 3 are $299.6 \mathrm{lb} / \mathrm{in}, \quad 322.3 \mathrm{lb} / \mathrm{in}$, and $87.4 \mathrm{lb} / \mathrm{in}$, respectively. Due to manufacturing considerations, Aluminum Profile 1 is preferred and is assumed for the remainder of the beams whose results are discussed.

- A linear relationship exists between the strength between the aluminum and plastic and the length of the beam. This relationship makes it possible for all of the results of the 
Push-Through tests to be divided by the number of deboss regions tested to quantify a strength per deboss for each of the different plastics.

- The active strengths of the seven types of plastic range from $268-443 \mathrm{lb} / \mathrm{in}$. Additionally:

- Elastomer is weakest and strength increases with increased talc content and addition of the metal deactivator.

○ An increase from $0 \%$ to $20 \%$ talc content results in a $9.6 \%$ increase in strength.

- An increase from $20 \%$ to $38 \%$ talc content results in a $5.2 \%$ increase in strength.

- Adding the metal deactivator increases the strength, on average by $5.4 \%$ when nothing else in the plastic formula varies.

- When a single screw is in place, an average of $425.4 \mathrm{lb}$ is added to the strength between the aluminum and the plastic.

\section{Knit-Line Pull Tests}

The Knit-Line test was designed to quantify the strength at the boundary between the flange plastic and the web plastic. The following bullet points summarize the results from this testing.

- Specimens either failed in a complete brittle or partial brittle fashion. All of the beams with a rubbery material in the flanges (in this case either EPDM or the bonding elastomer) failed in the partial brittle fashion. During the testing, the specimens exhibiting partial brittle failure absorbed over three times as much energy as the specimens exhibiting complete brittle failure.

- Ten different web and flange plastic combinations were tested and the strengths of the knit-line ranged from 7400-10800 lb/ft. Additionally:

- Flanges composed of HMW HDPE have greater strengths than the one composed of PPTPE. 
- For all beams of HMW HDPE web plastic with $38 \%$ talc content and HMW HDPE in the flange plastic:

- An increase from $0 \%$ to $38 \%$ talc content results in a $18.9 \%$ increase in strength.

- A decrease from $38 \%$ to $20 \%$ talc content results in a $1.3 \%$ increase in strength.

- This concludes that the initial addition of talc filler significantly increases the strength at the knit-line between $38 \%$ talc content HMW HDPE web plastic and HMW HDPE flange plastic, but after the initial addition of talc filler, a difference between $38 \%$ and $20 \%$ is not evident.

- For all beams of HDPE web plastic with $38 \%$ talc content and HMW HDPE in the flange plastic:

- A decrease from $20 \%$ to $0 \%$ talc content results in a $17.7 \%$ increase in strength.

- This concludes that the addition of talc filler has an adverse effect on the strength at the knit-line between $38 \%$ talc content HDPE web plastic and HMW HDPE flange plastic.

$\circ$ Adding the metal deactivator increases the strength by $4.9 \%$ when nothing else in the plastic formula is changed.

\section{Tensile Tests}

Tensile tests quantified the modulus of elasticity and tensile strength for each of the different plastics tested. For the flange plastics, the moduli ranged from $0.08 \mathrm{e} 6$ psi to $0.19 \mathrm{e} 6 \mathrm{psi}$, with 
tensile strengths ranged from 1400-2900 psi. For the web plastics, the moduli ranged from $0.22 \mathrm{e} 6 \mathrm{psi}$ to $1.03 \mathrm{e} 6 \mathrm{psi}$, with tensile strengths ranged from 3120-10600 psi. Additionally:

- The three web plastics made from HDPE have modulus values at least three times that of the " $28 / 15$ " web plastic.

- The web plastics with the three highest modulus values all have 38\% talc filler content.

- Going from HMW HDPE to normal HDPE in the web increases the modulus of elasticity by $16.9 \%$ (from 9B web to 4B web). [10B and 9B have high molecular weight webs, while 4B does not.]

- Due to the elastomer, the flange plastic from Beam 3B had a modulus of elasticity value at least $7.8 \%$ less than all the other flange plastics and its tensile strength was at least $41.7 \%$ lower.

- The metal deactivator addition resulted in an average of a $6.5 \%$ increase in the modulus of elasticity.

- An increase in talc content from $0 \%$ to $20 \%$ in the flange plastics resulted in the modulus of elasticity doubling.

\section{Duration of Load Tests}

Duration of Load tests were performed to observe the effects on multiple beams' deflection rates under a constant static load. The following bullet points summarize the results from this testing.

- None of the beams exhibited tertiary creep.

- A beam composed of HMW HDPE in both the flange and web had almost the exact same load versus deflection curve as the " $28 / 15$ " beam, but is loaded with over $25 \%$ more static load. 


\section{Numerical Model of Deboss Region}

A numerical finite element model was developed in ABAQUS to better understand the underlying physics of the shear connector in the composite I-beams and was compared with a Push-Through test specimen. It was found that:

- the results over a range for Poisson's ratio of 0.44-0.48 are consistent

- the load per deboss region that can be resisted before the plastic begins to yield and extensively deform matched experiments to within $10 \%$.

\section{Recommendations for Future Work}

A more in-depth analysis can be investigated on the numerical model in ABAQUS. Using the already developed ABAQUS model, adaptive remeshing can be used to allow for a more robust comparison with the experimental results for what is occurring after the plastic yields and pushes out of the aluminum deboss region. By comparing the numerical model results with experimental results, confidence is gained in the accuracy of this preliminary ABAQUS analysis. With potential geometry modifications and material property alterations, additional numerical models can be further investigated, which allows rapid assessment of the controlling parameters without having to actually construct a physical model.

Because the technical infrastructure, more specifically ASTM testing standards, are currently lacking for larger scale structural plastic-aluminum composites, a sequence of physical experiments can be designed and tested so that the needed standards can come into being. This could be done by structuring a sequence of tests that meet the conditions outlined by current ASTM testing standards for competitive materials, such as those that exist for wood. Standards

that currently exist do not take into account the collective properties between a metal and a 
plastic that need to be addressed. This would give plastic-aluminum composite materials a path from initial concept to final manufacturing.

Overall, the long-term goals for future work on this project include performing more complicated numerical model analyses, formulating the scientific foundation of research to develop testing standards applicable to plastic-aluminum composites, and further exploring this innovative, new class of material technology for use as a structural material. 


\section{References}

[1] Tegracore LLC. (2013). Tegracore - premium structural materials. Retrieved December 2, 2013, from Tegracore: www.tegracore.com

[2] American Wood Council. (1997). Wood Beams. Retrieved March 30, 2014, from Safe Load Tables: http://www.awc.org/pdf/wsdd/c2b.pdf

[3] Record, S. J. (1914). The Mechanical Properties of Wood. New York: J. Wiley \& Sons, Inc.

[4] American Wood Council. (1997). Properties of Structural Lumber. Retrieved March 30, 2014, from http://www.awc.org/pdf/wsdd/C1.pdf

[5] Building Products Plus. (n.d.). Timber Structures - Preservation of Wood. Retrieved March 30, 2014, from Army Marine Treatment Recommendations:

http://www.buildingproductsplus.com/pdf/army_marine_treatment_recommendations.pdf

[6] American Society for Testing and Materials. (2010). Standard Test Method for Tensile Properties of Plastics D638-10. West Conshohocken: ASTM International.

[7] American Society for Testing and Materials. (2011). Standard Guide for Evaluating Mechanical and Physical Properties of Wood-Plastic Composite Products D7031-04. West Conshohocken: ASTM International.

[8] Droste, A., Naughton, P., Bowser, B., Rottger, J., Burr, S., Imam, O., et al. (2003). Bonded metal-plastic composite structures - the future of lightweight, cost-effective performance. SPE Automotive Composites Conference. Dow Automotive.

[9] Eksi, S., Kapti, A. O., \& Genel, K. (2013). Buckling behavior of fiber reinforced plasticmetal hybrid-composite beam. Materials and Design, 130-138.

[10] Johnson, T. (n.d.). Composites/Plastics. Retrieved January 10, 2014, from About: http://composite.about.com/od/aboutcompositesplastics/a/HistoryofComposites.htm

[11] ASM Inc. (n.d.). Aluminum 6061-T6; 6061-T651. Retrieved November 4, 2013, from Aerospace Specification Metals: http://asm.matweb.com/search/SpecificMaterial.asp?bassnum=MA6061t6

[12] Waynick, J. A. (2001). The Development and Use of Metal Deactivators in the Petroleum Industry: A Review. Energy \& Fuels, 1325-1340.

[13] Beer, F., Johnston, E., DeWolf, J., \& Mazurek, D. (2009). Mechanics of Materials 5th Edition. New York: McGraw-Hill.

[14] Wypych, G. (1999). Handbook of Fillers. Toronto: ChemTec Publishing. 
[15] Wernett, P. C. (2006). Optimizing Thermoplastic Olefin (TPO) Performance with Fine and Ultrafine Talcs. ChinaPlas.

[16] Huang, R., Xu, X., Lee, S., Zhang, Y., Kim, B.-J., \& Wu, Q. (2013). High Density Polyethylene Composites Reinforced with Hybrid Inorganic Fillers: Morphology, Mechanical and Thermal Expansion Performance. Materials, 4122-4138.

[17] Mondo Minerals. (n.d.). Talc in Plastics. Amsterdam: Mondo Minerals B.V.

[18] Schubert, H. (1975). Tensile Strength of Agglomerates. Powder Technology, 107-119.

[19] Karrad, S., Lopez Cuesta, J. M., \& Crespy, A. (1998). Influence of a fine talc on the properties of composites with high density polyethylene and polyethylene/polystyrene blends. Journal of Materials Science, 453-461.

[20] Scott, C., Ishida, H., \& Maurer, F. (1991). Characterization of polyethylene/EPDM/silicon dioxide multicomponent composites by solid-state dynamic mechanical spectroscopy. Journal of Materials Science, 5708-5716.

[21] Scott, C., Ishida, H., \& Maurer, F. (1988). Interfacial effects on the melt state behavior of polyethylene-EPDM-calcium carbonate composites. Rheologica Acta, 273-278.

[22] Vranjes, N., \& Rek, V. (2007). Effect of EPDM on Morphology, Mechanical Properties, Crystallization Behavior and Viscoelastic Properties of iPP+HDPE Blends. Macromolecular Symposia, 90-100.

[23] Kline, D., Sauer, J., \& Woodward, A. (1956). Effect of Branching on Dynamic Mechanical Properties of Polyethylene. Journal of Polymer Science, 455-462.

[24] Dassault Systemes. (2012). ABAQUS 6.12 Online Documentation. Dassault Systemes. 